\title{
Experimental Investigation of Airfoil Thermosyphons
}

\author{
A Thesis \\ presented to \\ the faculty of the School of Engineering and Applied Science \\ University of Virginia
}

\begin{abstract}
in partial fulfillment
of the requirements for the degree of

Master of Science

Mechanical and Aerospace Engineering
\end{abstract}

by

Christina Ann Pappas

May

2012 


\section{APPROVAL SHEET}

This thesis is submitted in partial fulfillment of the requirements for the degree of

Master of Science in Mechanical and Aerospace Engineering

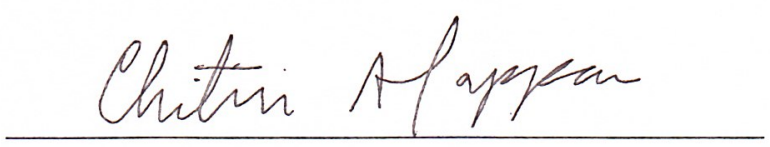

Christina A. Pappas, Author

This thesis has been read and approved by the Examining Committee:

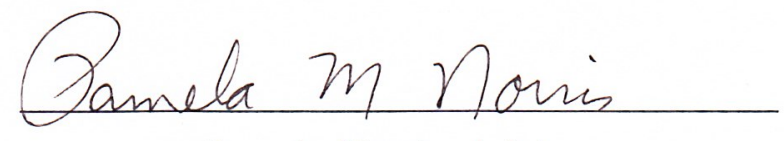

Pamela Norris, Advisor
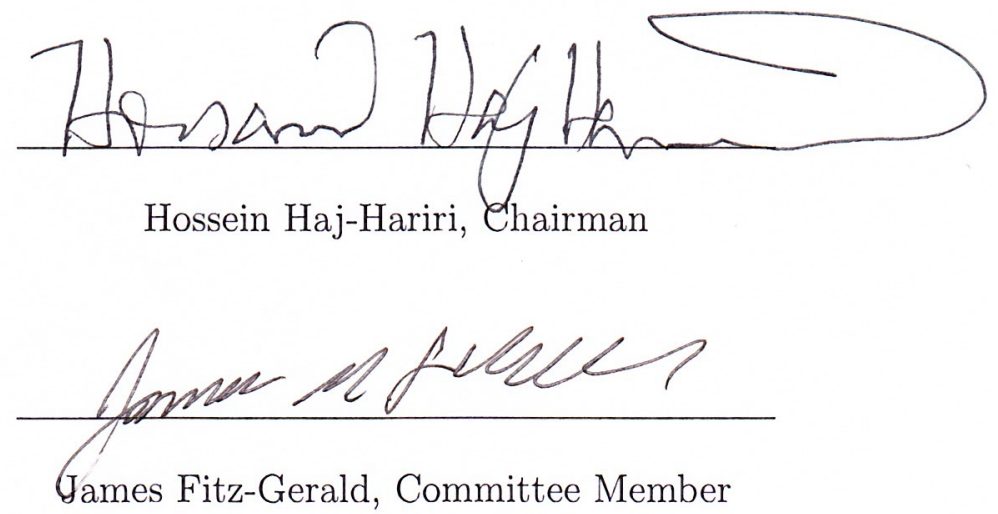

Accepted for the School of Engineering and Applied Science:

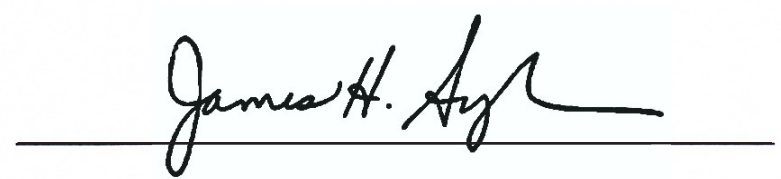

James H. Aylor, Dean

School of Engineering and Applied Science 


\begin{abstract}
Both cooling fins and closed two-phase thermosyphons are widely used in many fields for passive thermal management. Assuming a favorable gravitational field, the development of a cooling fin thermosyphon device could enhance the heat transfer capabilities of a cooling fin alone. A particular application of interest is that of an air-cooled cooling fin thermosyphon with a large condenser section. The successful development of this type of device could eventually be utilized in a broad range of air-cooled cooling fin applications.

An airfoil-shaped thermosyphon design was developed to minimize drag in a cooling airflow. The thermosyphon material is copper, and the working fluid used is deionized water. The effect of cavity shape and fill volume on performance (rate of heat transfer) was investigated. The two cavity shapes tested were cylindrical and slot-shaped, and the three fill volumes tested were $0 \%, 5 \%$, and $20 \%$ (as a percentage of the entire cavity volume). The condenser section was air-cooled in a wind tunnel at a wind speed of $100 \mathrm{mph}$ and subjected to evaporator temperatures ranging from $250^{\circ} \mathrm{F}$ to $325^{\circ} \mathrm{F}$.

The measured rate of heat transfer is highest for both the slot-shaped and cylindrical cavity thermosyphons at 5\% fill volume. The heat transfer rate for the slot-shaped cavity thermosyphon is over $100 \%$ larger at $5 \%$ fill volume than it is at $0 \%$ fill volume. This dramatic increase in performance upon the addition of a small amount of working fluid for the slot-shaped cavity thermosyphon is indicative of the positive effect that thermosyphon technology has on the performance of a cooling fin alone. For the cylindrical cavity thermosyphon, the percent increase between the $0 \%$ and $5 \%$ fill volumes is approximately 25\%. For both thermosyphons, the heat transfer rate increases with evaporator temperature for all fill volumes.
\end{abstract}




\section{Acknowledgements}

The Boeing Corporation and the U.S. Department of Defense through the NDSEG Fellowship program -

For their financial support

Dr. Pamela Norris and Dr. Donald Jordan -

For their excellent guidance and unwavering support throughout

my graduate career and for pushing me to fulfill my potential

Louis Steva, Kevin Knight, and Claude Mitchell -

For their eternal patience and skill in the machine shop

Thomas Randolph and Paul DeCecchis -

For their prior quality work done on this project and their camaraderie

Family, Friends, and my husband Nathan -

For their constant, unconditional love and encouragement 


\section{Contents}

$\begin{array}{ll}\text { Acknowledgements } & \text { i }\end{array}$

1 Introduction 1

1.1 Cooling Fins . . . . . . . . . . . . . . . . . . . 1

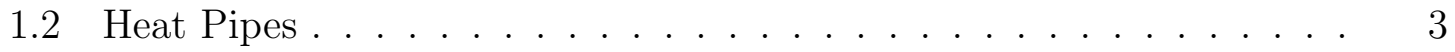

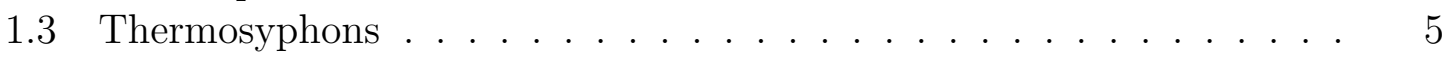

1.4 Cooling Fin Thermosyphons . . . . . . . . . . . . . . 6

1.5 Outline . . . . . . . . . . . . . . . . . . . 7

2 Background $\quad 8$

2.1 Closed Two-Phase Thermosyphons . . . . . . . . . . . . . . 9

2.1.1 Fill Volume . . . . . . . . . . . . . . . . . 999 9

2.1.2 Evaporator Length . . . . . . . . . . . . . . . . . . . 11

2.2 Cooling Fin Thermosyphons . . . . . . . . . . . . . . . . . . . . . . 12

2.3 Contribution of This Work . . . . . . . . . . . . . . . 14

3 Thermosyphon Design 16

3.1 Design Constraints . . . . . . . . . . . . . . . . . . 17

3.2 Design Modeling . . . . . . . . . . . . . . . . . . 19

3.3 Design Analysis . . . . . . . . . . . . . . . . . . . . . 20

3.4 Final Design . . . . . . . . . . . . . . . . . . . 24

3.5 Method of Fabrication . . . . . . . . . . . . . . 26

4 Experimental Setup $\quad 28$

4.1 Assembly . . . . . . . . . . . . . . . . . . . . . . . 28

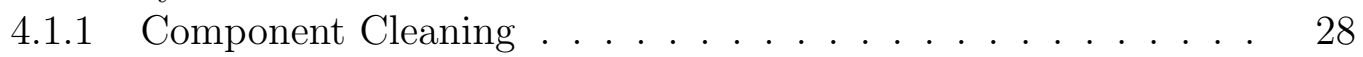

4.1.2 Thermosyphon Assembly . . . . . . . . . . . . . . . . . . 29

4.2 Safety Testing . . . . . . . . . . . . . . . . . . 30

4.3 Leak Testing . . . . . . . . . . . . . . . . . . . . . . . 31

4.4 Experimental Outline . . . . . . . . . . . . . . . . . . . . . . . . . . . . . . . . . . . . 32

4.5 Experimental Setup Details . . . . . . . . . . . . . . 33

4.5.1 Fill Volume . . . . . . . . . . . . . . . . . 33

4.5.2 Wind Tunnel . . . . . . . . . . . . . . . . 36

4.5.3 Heater Block . . . . . . . . . . . . . . . . . . . . . 37

4.5.4 Vacuum Pump Setup . . . . . . . . . . . . . . . . 39 
4.6 Data Acquisition . . . . . . . . . . . . . . . . . . . . . . . . . 40

4.6 .1 Wind Speed . . . . . . . . . . . . . . . . . . 40

4.6.2 Thermosyphon Internal Pressure . . . . . . . . . . . . . 41

4.6.3 Thermosyphon Surface Temperature . . . . . . . . . . . . 42

4.6.4 Thermosyphon Rate of Heat Transfer . . . . . . . . . . . . . . 44

4.7 Testing . . . . . . . . . . . . . . . . . . . . . 46

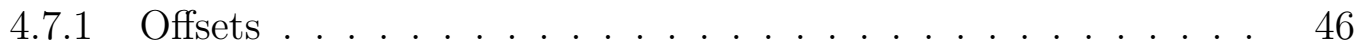

$4.7 .2 \quad$ Experiment Details . . . . . . . . . . . . . . . 47

5 Results and Discussion 49

5.1 Cylinder-Shaped Cavity Thermosyphon Results . . . . . . . . . 49

5.1 .1 Rate of Heat Transfer . . . . . . . . . . . . . . . . . . . . 49

5.1 .2 Surface Temperature . . . . . . . . . . . . . . . . . 50

5.1 .3 Internal Pressure . . . . . . . . . . . . . . . . . . . 53

5.2 Slot-Shaped Cavity Thermosyphon Results . . . . . . . . . . . . . 54

5.2 .1 Rate of Heat Transfer . . . . . . . . . . . . . . . . . . . 54

5.2 .2 Surface Temperature . . . . . . . . . . . . . . . 55

5.2 .3 Internal Pressure . . . . . . . . . . . . . . . . . . . . . 57

5.3 Discussion of Results . . . . . . . . . . . . . . . . . . . . 58

$5.3 .1 \quad 0 \%$ Fill Volume . . . . . . . . . . . . . . . . . . 58

$5.3 .25 \%$ Fill Volume . . . . . . . . . . . . . . . . . . . . . 59

$5.3 .3 \quad 20 \%$ Fill Volume . . . . . . . . . . . . . . . . . . . 60

5.3 .4 Pressures . . . . . . . . . . . . . . . . . . . 61

5.4 Future Work . . . . . . . . . . . . . . . . . . . . . . . . 65

$\begin{array}{lll}6 & \text { Conclusion } & 67\end{array}$

A Thermosyphon Drawings $\quad \mathbf{7 2}$

A.1 Cylinder Thermosyphon . . . . . . . . . . . . . . . . 72

A.2 Slot Thermosyphon . . . . . . . . . . . . . . . 72

$\begin{array}{ll}\text { B Leaking } & 79\end{array}$

B.1 End Cap Attachment Options . . . . . . . . . . . . . . . . . . 79

B.2 Leaking and Solutions . . . . . . . . . . . . . . 80

C Error Analysis

C.1 Pressure Error . . . . . . . . . . . . . . . . . . . . . . . . . . . 83

C.1.1 Voltage to Pressure Conversion . . . . . . . . . . . . . . 83

C.1.2 Pressure Error . . . . . . . . . . . . . . . . . . . . . . 85

C.2 Rate of Heat Transfer Error . . . . . . . . . . . . . . . 86

C.3 Temperature Error . . . . . . . . . . . . . . . . . . 86

D Supplier Contact and Product Information $\quad 88$

D.1 Suppliers . . . . . . . . . . . . . . . . . . . . . . . . . . . . 88

D.2 Products . . . . . . . . . . . . . . . . . . . . . 88 


\section{List of Figures}

1.1 Finned vs. Non-Filled Bodies . . . . . . . . . . . . . . . 2

1.2 Heat Pipe Classification . . . . . . . . . . . . . . . . 4

1.3 Heat Pipe Performance Limitations . . . . . . . . . . . . . . . 5

1.4 Internal View of Thermosyphon . . . . . . . . . . . . 6

3.1 Exploded Thermosyphon Assembly . . . . . . . . . . . . . . . . 18

3.2 Cylinder Thermosyphon Cross Section . . . . . . . . . . . . . 19

3.3 Slot Thermosyphon Cross Section . . . . . . . . . . . . . . 20

3.4 Summary of FEA results for Cylinder Thermosyphon . . . . . . . . 22

3.5 Summary of FEA results for Slot Thermosyphon . . . . . . . . . . 23

3.6 Top End Cap Example . . . . . . . . . . . . . . . . . . . . . . . . . . . 25

3.7 Bottom End Cap Example . . . . . . . . . . . . . . . . . . . . . . 26

4.1 Epoxy Placement . . . . . . . . . . . . . . . . . . . . . . . . . . . . . . . . 29

4.2 Steady State Experiment Illustration _ . . . . . . . . . . . . . 32

4.3 Thermosyphon Fill Setup . . . . . . . . . . . . . . . 34

4.4 Flask for Thermosyphon Discharging . . . . . . . . . . . . . 35

4.5 False Top Test Section Modification . . . . . . . . . . . . . . . 37

4.6 Heater Block Insulation Box . . . . . . . . . . . . . . . . . . . 39

4.7 Pfeiffer Vacuum Pump . . . . . . . . . . . . . . . . . . . . . . 40

4.8 Dwyer Differential Pressure Indicating Transmitter . . . . . . . . . 40

4.9 HP Power Supply . . . . . . . . . . . . . . . . . . . . . . . . . 41

4.10 Pressure Transducer Wiring Diagram . . . . . . . . . . . . . . 42

4.11 Thermocouple Placement . . . . . . . . . . . . . . . . . . . . 43

4.12 Variable voltage transformer . . . . . . . . . . . . . . 45

4.13 PMI Eagle 120 recorder . . . . . . . . . . . . . . . . 45

5.1 Cylinder Thermosyphon Rate of Heat Transfer . . . . . . . . . . 50

5.2 Cylinder Thermosyphon Surface Temperatures at $250^{\circ} \mathrm{F} \ldots \ldots$

5.3 Cylinder Thermosyphon Surface Temperatures at $275^{\circ} \mathrm{F} \ldots \ldots .$.

5.4 Cylinder Thermosyphon Surface Temperatures at $300^{\circ} \mathrm{F} \ldots \ldots$

5.5 Cylinder Thermosyphon Surface Temperatures at $315^{\circ} \mathrm{F} \ldots \ldots . . .652$

5.6 Cylinder Thermosyphon Surface Temperatures at $325^{\circ} \mathrm{F} \ldots \ldots$

5.7 Slot Thermosyphon Rate of Heat Transfer . . . . . . . . . . . 54

5.8 Slot Thermosyphon Surface Temperatures at $250^{\circ} \mathrm{F} \ldots \ldots \ldots \ldots$

5.9 Slot Thermosyphon Surface Temperatures at $275^{\circ} \mathrm{F} \ldots \ldots \ldots \ldots$ 
5.10 Slot Thermosyphon Surface Temperatures at $300^{\circ} \mathrm{F}$. . . . . . . . 56

5.11 Slot Thermosyphon Surface Temperatures at $315^{\circ} \mathrm{F}$. . . . . . . . 56

5.12 SlotThermosyphon Surface Temperatures at $325^{\circ} \mathrm{F} \ldots$. . . . . . 56

A.1 Cylinder Thermosyphon Top End Cap Drawing . . . . . . . . . . 73

A.2 Cylinder Thermosyphon Body Drawing . . . . . . . . . . . . . 74

A.3 Cylinder Thermosyphon Bottom End Cap Drawing . . . . . . . . . . 75

A.4 Slot Thermosyphon Top End Cap Drawing . . . . . . . . . . . . . 76

A.5 Slot Thermosyphon Body Drawing . . . . . . . . . . . . . . 77

A.6 Slot Thermosyphon Bottom End Cap Drawing . . . . . . . . . . . . . 78

B.1 Epoxy Test Pieces . . . . . . . . . . . . . . . . . 81 


\section{List of Tables}

2.1 Summary of Experimental Details for Previous Work . . . . . . . . 15

3.1 Dimensions of the Airfoil Cross-Section Shape . . . . . . . . . . 17

4.1 Fill Volumes for Cylinder and Slot Thermosyphons . . . . . . . . . . 36

4.2 AEROLAB Educational Wind Tunnel Specifications . . . . . . . . . . 36

4.3 Location of Thermocouples on Thermosyphon Surface . . . . . . . . . 44

4.4 Offset Rate of Heat Transfer Values . . . . . . . . . . . . . . . . . . . 47

5.1 Cylinder Thermosyphon Internal Pressures $($ psia $) \ldots . . . . . . .53$

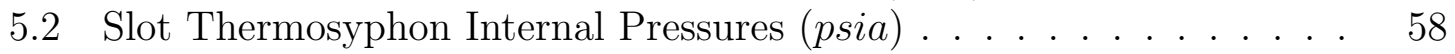

5.3 Cylinder Thermosyphon Calculated Vapor Pressure for 5\% Fill Volume 63

5.4 Cylinder Thermosyphon Calculated Vapor Pressure for 20\% Fill Volume 63

5.5 Slot Thermosyphon Calculated Vapor Pressure for 5\% Fill Volume . . 64

5.6 Slot Thermosyphon Calculated Vapor Pressure for 20\% Fill Volume . 64

B.1 Metal-Filled Epoxy Details . . . . . . . . . . . . . . . 80

C.1 Voltage Measurement Error Contributions . . . . . . . . . . . . 85

C.2 Rate of Heat Transfer Error Contributions . . . . . . . . . . . . . . . 86

C.3 Rate of Heat Transfer Error Contributions . . . . . . . . . . . . . . . 87 


\section{Chapter 1}

\section{Introduction}

\subsection{Cooling Fins}

A cooling fin serves as an extended surface on a body that is used for enhancing the rate of heat transfer from that body to its surroundings. At its simplest, the cooling fin is a classic example of combined conduction and convection energy transfer, and the way that it increases heat transfer is by increasing the effective surface area exposed to the surroundings. The cooling fin material is a primary factor in the extent to which the presence of a cooling fin leads to an increased rate of heat transfer. To maximize this improvement, the material should have as large a thermal conductivity as possible, which minimizes the temperature drop along the length of the cooling fin. Incropera notes that a cooling fin would ideally achieve maximum heat transfer improvement when there exists a uniform temperature distribution over the entire

fin [1]. Figure 1.1 shows the enhancement of surface area (and thus, enhancement of heat transfer rate) through the addition of two finned surfaces to a body in contrast to a non-finned body. 

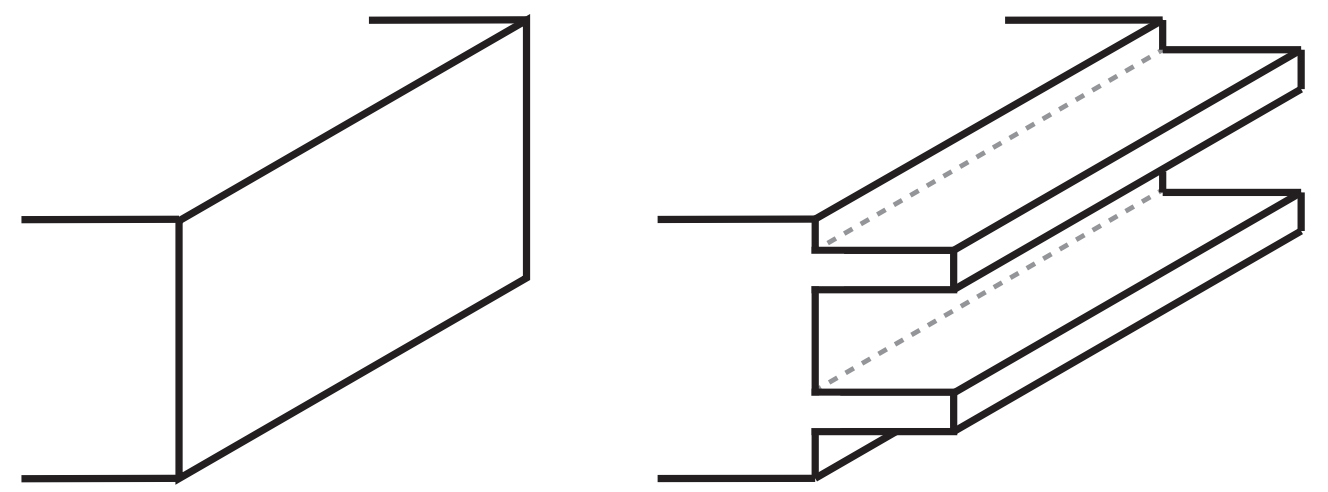

Figure 1.1: To the left is a non-finned body and to the right is the same body with two fins attached to increase surface area [1].

Up to this point it has been assumed that the addition of any cooling fin will increase a body's rate of heat transfer to its surroundings, but this is not necessarily the case. A fin may not increase the rate of heat transfer if there exists sufficient resistance to conduction from main body through the fin. The effectiveness of a fin's rate of heat transfer can be expressed as the ratio of the rate of heat transfer of the fin alone to the rate of heat transfer of the body without the fin. Incropera defines fin effectiveness as [1]:

$$
\varepsilon_{f}=\frac{q_{f}}{h A_{c, b} \theta_{b}}
$$

In Equation 1.1, $q_{f}$ is the rate of heat transfer of the fin, $h$ is the surface convection coefficient, $A_{c, b}$ is the cross-sectional area of the base of the fin, and $\theta_{b}$ is the difference between the temperature of the fin base and the temperature of the surroundings. The denominator in Equation 1.1 is equivalent to Fourier's law of conduction for the body. According to Incropera, if the fin effectiveness is less than two then the addition of the cooling fin is not worthwhile.

The efficiency of a fin, $\eta_{f}$, is defined by Incropera [1] in Equation 1.2 (where $A_{f}$ is the fin surface area). One of the ways to improve the fin efficiency is by increasing its thermal conductivity, which is proportional to the heat transfer rate of the fin, $q_{f}$. 
This can be achieved by changing the material.

$$
\eta_{f}=\frac{q_{f}}{h A_{f} \theta_{b}}
$$

Cooling fins have a wide variety of applications, including cooling heat-generating bodies themselves, like electronics components or automotive engines, and facilitating the operation of heat exchangers of all types. In real-world applications, cooling fins can be arranged in large arrays to increase surface area. They make take many different shapes. The configuration and fin shape generally depends on restrictions associated with a particular application, but the method of improving the heat transfer rate remains the same.

\section{$1.2 \quad$ Heat Pipes}

A heat pipe is a type of heat transfer device that is capable of transporting thermal energy over a distance while maintaining a relatively constant temperature over its length. This efficient device is capable of high heat transfer rates without the aid of external power input. The operation temperature and rate of heat transfer capabilities are very wide and so heat pipes may be tailored to suit many different environments [2]. Heat pipes have a wide range of applications due to their simplicity and ability to function with little outside interference. Though there are many different types of heat pipes, they all share the same basic structure, which is composed of a heat source (evaporator section), a heat sink (condenser section), and most also have a particular setup that connects the two that is neither heated nor cooled (adiabatic section). Most heat pipes are made up of a sealed vessel, a working fluid, and some kind of wicking structure that returns the working fluid from the condenser to the evaporator. The primary method of heat transfer in a heat pipe is through the energy transfer that takes place between the heated evaporator section and the working fluid (which causes the liquid to vaporize) and the subsequent condensation in the condenser section as 
the working fluid releases energy to change phase from vapor back to a liquid.

The method through which the condensed working fluid is returned to the evaporator section varies, but two common methods are through the use of a wick (a structure attached to the heat pipe walls through which the working fluid moves via capillary action) or through the use of the gravitational field to return the condensed working fluid to the evaporator. Centrifugal, electrostatic, and osmotic forces may also be utilized to return the working fluid to the evaporator section [2]. A classification tree of different types of heat pipes is displayed in Figure 1.2.

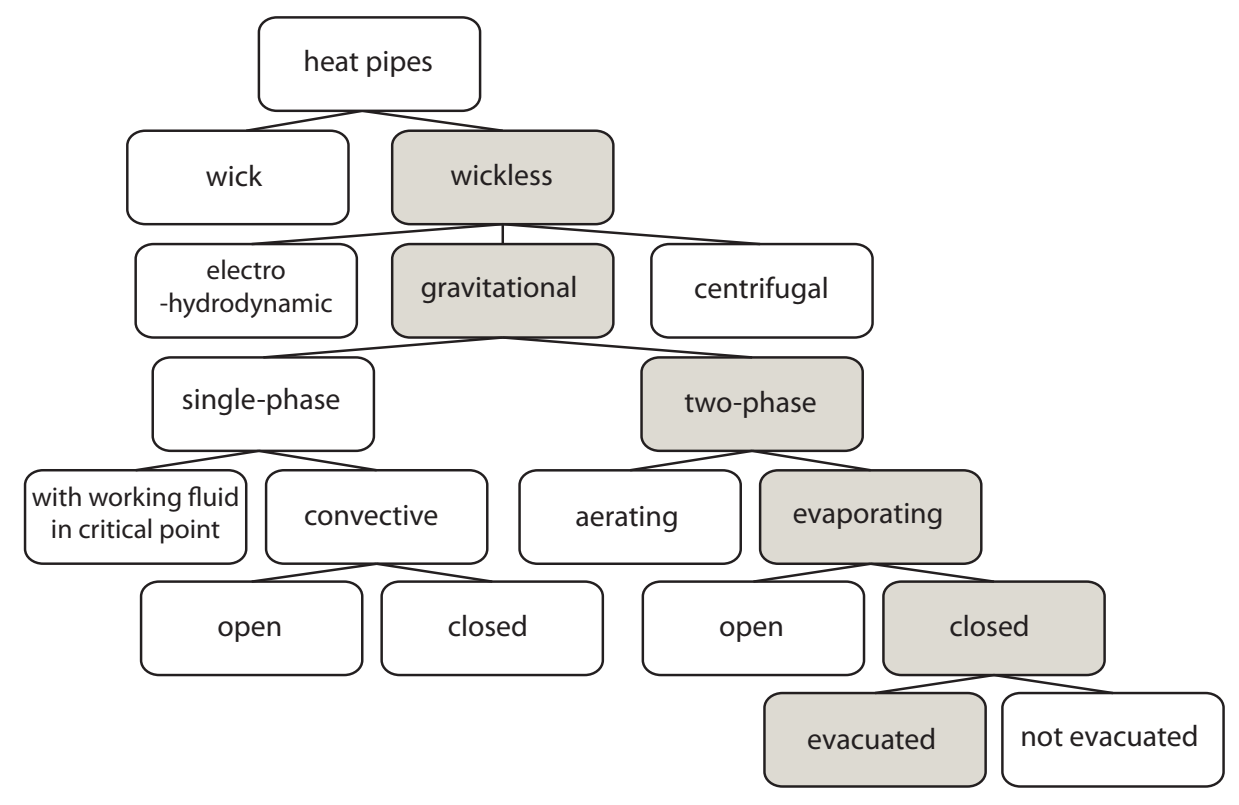

Figure 1.2: Classification tree with the closed two-phase thermosyphon categorization displayed in the gray boxes [3].

There are several performance limitations on the heat transfer capabilities of a heat pipe that arise as a direct result of physical phenomena. These performance limitations include: the vapor pressure limit, the sonic limit, the capillary limit, the entrainment limit, the condenser limit, and the boiling limit. The vapor pressure limit occurs when viscous forces are dominant in the flow of the vaporized working fluid and is encountered when the temperature is lower than the normal operating temperature of the heat pipe. The sonic limit typically occurs during startup and is reached as the vaporized working fluid accelerates along the length of the heat pipe. 
The capillary limit is reached when the capillary pressure in the wick is not large enough to force the condensed working fluid to move back to the evaporator. The entrainment limit has been reached when the condensed working fluid is pulled into the vapor flow to the point where no condensate is returned to the evaporator section [2]. The condenser heat transfer limit is essentially the maximum heat transfer rate achievable by a particular heat pipe during steady state operation [11]. The boiling limit occurs when the working fluid located inside the wick boils, thus drying out the wick in the evaporator section. The most restrictive performance limit becomes the cap on a heat pipe's heat transfer performance [2]. Figure 1.3 illustrates the operating temperature ranges where the various performance limits take effect [11].

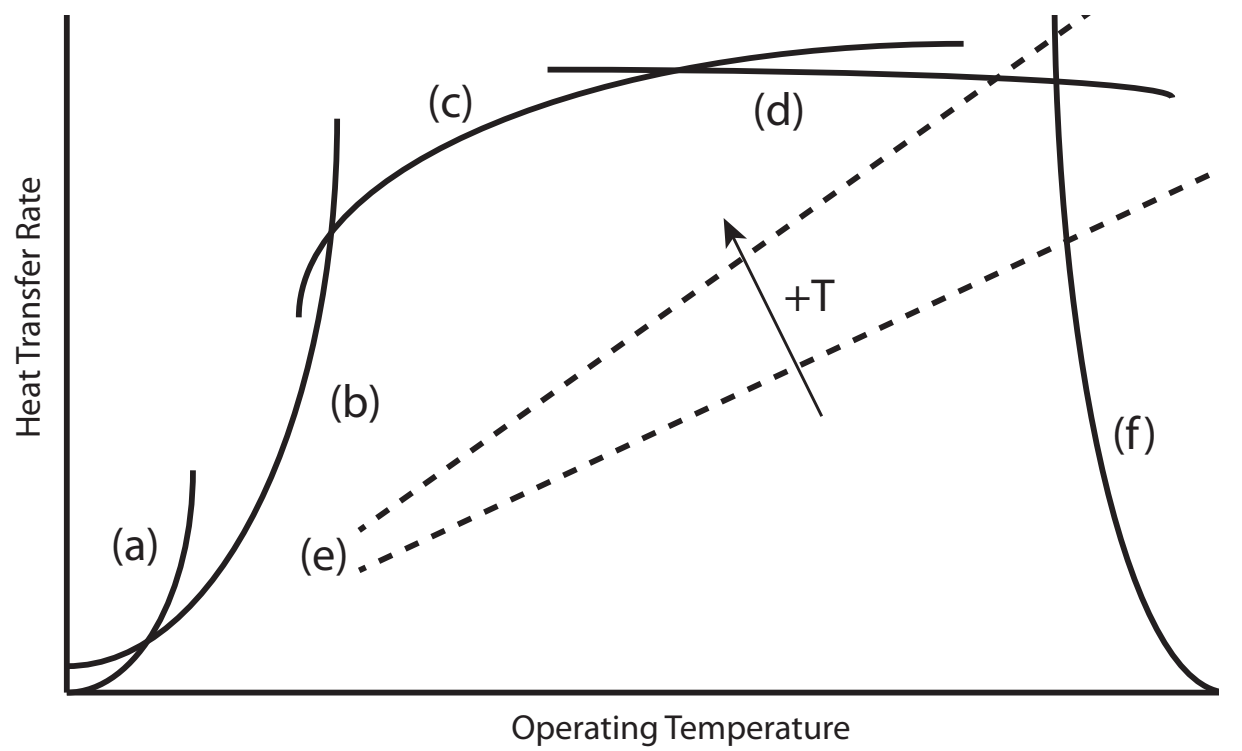

FiguRE 1.3: The performance limitations are plotted where the condenser limit is shown changing with increasing temperature, and the limits are labeled as: (a) viscous (b) sonic (c) capillary (d) entrainment (e) condenser (f) boiling.

\subsection{Thermosyphons}

For some heat transfer applications, a heat pipe must be very simple (requiring little to no maintenance) and compact. The type of heat pipe that readily fits these criteria is a closed two-phase thermosyphon, which is a wickless heat pipe that utilizes the gravitational field to return the condensed working fluid to the evapora- 
tor section [2]. Aside from the favorable orientation requirement, closed two-phase thermosyphons are extremely simple and require no external assistance to perform their function as heat transfer devices. Figure 1.4 displays the internal workings of a two-phase closed thermosyphon.

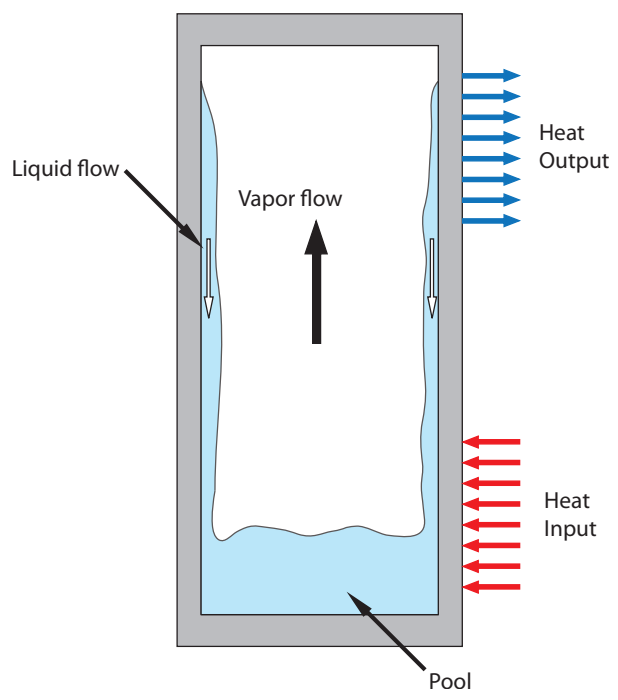

Figure 1.4: This cutaway view of a closed two-phase thermosyphon shows the evaporator section (where heat is applied), the condenser section (where heat is removed), and the adiabatic section. The cycle of vapor flow upward and condensate down along the walls to the pool in the evaporator section is also illustrated.

\subsection{Cooling Fin Thermosyphons}

A potential way to improve the heat transfer rate of a cooling fin would be to transform it into a closed two-phase thermosyphon. The thermal conductivity for a standard cooling fin is determined by what material it is made of. The effective thermal conductivity of a heat pipe made of copper can be 90 times greater than the thermal conductivity of a plain copper rod of the same size [2]. This implies that a properly functioning heat pipe would enhance the thermal performance of a cooling fin. In addition, the heat transfer capabilities of a closed two-phase thermosyphon could also enhance the heat transfer of a cooling fin as long as it is always favorably oriented in the gravitational field.

The plausibility and effectiveness of a cooling fin thermosyphon has been in- 
vestigated by Randolph [11] and DeCecchis [12]. In their preliminary experiments with cylindrical thermosyphons, both Randolph and DeCecchis found that the thermosyphons (containing various amounts of working fluid) exhibited much higher rates of heat transfer than an empty shell when in the presence of cooling air flow. The cylindrical shape of the outer surface of Randolph's first generation of thermosyphons causes early boundary layer separation, which leads to an increase in drag on the body, and therefore they are not particularly suited to applications where the cooling fins are cooled by air flow. Therefore, as a next step, Randolph fabricated airfoil-shaped thermosyphons but found that they were not structurally resilient at the high internal pressures that were encountered during operation.

The scope of this work is twofold where the first goal is to develop and fabricate an airfoil-shaped cooling fin thermosyphon that can withstand internal pressures of up to 100 psig. After fabricating a robust thermosyphon, the second goal is to conduct experiments to determine its rate of heat transfer. Within these experiments, two variables are varied in order to determine their effect on heat transfer rate: fill volume and evaporator temperature.

\subsection{Outline}

Chapter 2 outlines relevant work done in the field of closed two-phase thermosyphons and also explains Randolph and DeCecchis's work in further detail. The development of the design of the airfoil cooling fin thermosyphons is outlined in Chapter 3, and Chapter 4 discusses the experimental setup and methods in detail for the testing of those thermosyphons. A summary of the experimental results and a discussion of conclusions drawn from the data are provided in Chapter 5. Future recommendations for the project are also discussed in this chapter. Lastly, Chapter 6 summarizes the overall project, including the experimental setup, data, and conclusions. 


\section{Chapter 2}

\section{Background}

In Chapter 1, the reasoning behind the selection of a closed two-phase thermosyphon for the proposed cooling fin thermosyphon heat exchanger was discussed. A literature review of relevant experimental work with closed two-phase thermosyphons was conducted with this particular type of thermosyphon in mind, the results of which are summarized in this chapter. Additionally, the choice of thermosyphon material and working fluid was predetermined as both Randolph and DeCecchis used copper-water thermosyphons for testing, and the work discussed in this thesis is a continuation of their experiments. This choice of thermosyphon material and working fluid is very prevalent in the literature, and so most of the work summarized in this chapter focuses on copper-water thermosyphons. The effect of fill volume and evaporator length on thermosyphon rate of heat transfer is of particular interest and is the primary focus of this literature review. Many of the studies discussed in this chapter investigate factors relating to heat transfer rate that are outside of the scope of this work and are mentioned briefly when relevant. In addition to a broad literature review, both the experiments conducted by Randolph and DeCecchis that directly precede this work and their influence on this project are discussed at the end of this chapter. A summary of the results is provided in Table 2.1.

The definition of fill volume, or fill ratio, is not consistent through the studies 
outlined in this chapter. Most define the fill ratio as the ratio of the volume of working fluid to the volume of the evaporator section while some others define it as the ratio of working fluid volume to the total thermosyphon volume. This is an important definition to remember as it affects the interpretation of the dependence of output heat transfer rate on fill volume. This thesis uses the definition of working fluid fill ratio expressed as a percentage of total volume to maintain uniformity with previous work conducted by Randolph and DeCecchis. Table 4.1 converts between the two definitions to provide a basis for comparison with the literature results using the alternate fill ratio definition.

\subsection{Closed Two-Phase Thermosyphons}

\subsubsection{Fill Volume}

The studies discussed in this section investigate the role of fill volume, a measure of the quantity of working fluid in a heat pipe, in thermosyphon performance. Fill volume is typically defined in one of two ways: as a percentage of the total cavity volume or as a percentage of the evaporator section volume. These studies also investigate the influence of inclination angle, a measure of the orientation of the thermosyphon, on performance, but those results are not presented here as the topic is outside of the scope of this work.

Negishi and Sawada [4] conducted experiments on a cylindrical thermosyphon made of copper with water as the working fluid and investigated the effect of fill volume (and inclination angle, which is not discussed here) on rate of heat transfer. The evaporator and condenser sections were both approximately $45 \%$ of the length of the thermosyphon. They found that the rate of heat transfer increases as the fill ratio increases from 0.05 to unity (as a percentage of the evaporator volume) when the thermosyphon was vertically oriented. The rate of heat transfer was not investigated for fill ratios larger than unity. Noie et al. [5] conducted similar experiments with 
a copper-water thermosyphon to test the effect of fill volume and inclination angle on rate of heat transfer. The evaporator section was approximately $40 \%$ of the total length of the thermosyphon. The three fill ratios tested were $15 \%, 22 \%$, and $30 \%$ (expressed as a percentage of the evaporator volume). In the vertical position, the thermosyphon's rate of heat transfer out from the condenser increases as the fill ratio increases, though not significantly. Wang and Ma [6] were also interested in the influence of fill volume and inclination angle on thermal performance of a thermosyphon, but their experiments used a steel thermosyphon with water as the working fluid. They define fill ratio as the ratio of working fluid volume to total thermosyphon volume, and the three fill ratios tested were $10 \%, 23 \%$, and $33 \%$. The total thermosyphon length was 1.8 meters, though the length of the evaporator section was not specified. The heat transfer does not appear to be affected by fill volume when the fill ratio is less than $10 \%$. As the fill ratio increases, the mean condensation coefficient decreases when the thermosyphon was positioned vertically.

Park, Kang, and Kim [7] fabricated closed two phase thermosyphons with both smooth and grooved inner surfaces. They investigated the effect of the fill ratio on heat transfer of copper thermosyphons with FC-72 as the working fluid. The length of the evaporator section was approximately $18 \%$ of the total length of the thermosyphon. The fill charge ratios tested ranged from $10 \%$ to $70 \%$ and are defined as a percentage of the evaporator volume. For fill ratios less than $20 \%$, the limitations on heat transfer were found to be due to the phenomenon of dry out. When the fill ratio is larger (around 50\%), the interaction between the vapor and condensate limits the heat transfer. For the smooth surfaced thermosyphon, the authors found that the fill ratio has little effect on the heat transfer coefficient of the evaporator.

Similarly to Park, Kang, and Kim, who used FC-72 as their working fluid, Jouhara et al. [8] used several different working fluids in their closed two-phase thermosyphons, including water, FC-84, FC-77, and FC-3283. Only the results for the copper-water thermosyphon are mentioned here. The evaporator section represented $20 \%$ of the 
total thermosyphon length, and the amount of working fluid was kept constant at approximately $31 \%$ of the total thermosyphon volume. This fill volume slightly overfills the evaporator section. The surface temperature was measured over the length of the thermosyphon and a dip in the temperature was found along the condenser section (as compared to the evaporator and adiabatic sections) during operation. Also, it was found that the effective thermal resistance decreases as the input heat transfer rate is increased.

One of the primary conclusions that may be drawn from these studies is that using very small fill volumes risks dry out of the evaporator section. Also, all studies found that the rate of heat transfer increases as fill volume increases up to a certain point, which varies based on the study examined. Only one study examined a fill volume that exceeds the volume of the evaporator section so it is not possible to draw any conclusions based on overfilling the evaporator.

\subsubsection{Evaporator Length}

In addition to investigating the effect of fill volume on thermosyphon performance, Noie [9] also tested the effect of both the evaporator length and input rate of heat transfer for a cylindrical copper thermosyphon with water as the working fluid. The

fill ratios tested were $30 \%, 60 \%$, and $90 \%$ and the evaporator sections tested (as a percentage of the entire length of the thermosyphon) were approximately 19\%, 25\%, and $30 \%$. He found that the maximum rate of heat transfer was not encountered at one particular fill volume. When the evaporator length is smallest, the largest fill volume yields the highest heat transfer rate. When the evaporator length is longest, a fill ratio of $60 \%$ yields the highest heat transfer rate. Lee and Mital [10] also studied the effect of evaporator length and fill ratio, among other factors, on the maximum heat transfer capacity for a closed two-phase copper thermosyphon. They tested different working fluids, but only the results with the copper-water setup are discussed here. In contrast to most studies, they define the fill ratio as a percentage of the total 
thermosyphon volume. It is also important to note that the thermosyphon tested does not have an adiabatic section. They found that the maximum heat flux and heat transfer coefficient increases with amount of working fluid until a certain fill volume, whereupon it becomes independent of fill volume. The fill ratios investigated ranged from approximately $1 \%$ to $30 \%$. The evaporator lengths tested were approximately $44 \%, 55 \%$, and $67 \%$ of the total thermosyphon length so the working fluid only ever approaches one-half to two-thirds the volume of the evaporator section. They also found that the maximum heat transfer coefficient increases when the evaporator length is decreased (thus increasing the condenser length) for the evaporator lengths tested and that the heat transfer coefficient increases as the mean operating pressure increases.

The general conclusion for Noie's study [9] is that a smaller evaporator section requires a large fill volume (as a percentage of the evaporator) to maximize heat transfer. Lee and Mital [10] found that decreasing the evaporator length yields an increase in the maximum heat transfer coefficient.

\subsection{Cooling Fin Thermosyphons}

Research aimed at developing a cooling fin thermosyphon has been conducted at the University of Virginia since 2008. Randolph [11] began the work on the project with the intent of proving that a cylindrical thermosyphon of a size comparable to a typical air-cooled cooling fin would have a high enough heat transfer rate to justify its incorporation into a cooling fin setup to enhance heat transfer. Thus the first step taken to create properly functioning cooling fin thermosyphons was to demonstrate this proof of concept, and Randolph was able to successfully show the feasibility of this idea in his work.

Randolph [11] fabricated four cylindrical thermosyphons out of copper. The four inner diameters were $0.75,1.06,1.53$, and 2.01 inches. English units are used through- 
out this thesis for ease of comparison with prior work completed by Randolph. Each had the same total length of 13 inches. The evaporator, adiabatic, and condenser sections were the same length over all thermosyphons and were 2 inches, 0.5 inches, and 10.5 inches, respectively. Water was used as the working fluid, and the fill volume was kept constant through the experiments. In contrast to the work discussed previously, each of the four thermosyphons' evaporators were significantly overfilled, with the smallest thermosyphon having a fill ratio of approximately $416 \%$ (as a percentage of the evaporator volume) and the largest thermosyphon having a fill ratio of approximately 173\%. Another primary difference between Randolph's experiments and those mentioned earlier is the cooling method. The condenser sections of Randolph's thermosyphons were air-cooled as opposed to cooled using a water jacket. He tested the thermosyphon rate of heat transfer at several evaporator temperatures and found that the output heat transfer rate increases with inner diameter and input heat transfer rate. Randolph also had two generations of airfoil-shaped thermosyphons (having cavities with airfoil-shaped cross-sections) fabricated but was unable to test their rate of heat transfer performance due to structural failure in both cases.

The next step taken on the project was an investigation of the effect of fill volume on output heat transfer rate. This was not addressed at all by Randolph and, in fact, all of his thermosyphons were very overfilled in terms of evaporator volume. These fill volume experiments were conducted by DeCecchis [12] using the smaller two of Randolph's four cylindrical thermosyphons (with inner diameters of 0.75 and 1.06 inches). Water was also used as the working fluid, and the fill volumes tested ranged from $10 \%$ to $90 \%$ in increments of $10 \%$ (as a percentage of the total thermosyphon volume). Two different evaporator lengths, 0.5 and 1.75 inches, were also tested. For comparison's sake, the $10 \%$ fill volume corresponds to approximately $260 \%$ of the smaller evaporator and approximately $75 \%$ of the larger evaporator for the smallest thermosyphon tested (inner diameter of 0.75 inches). He confirmed Randolph's result that increasing inner diameter increases the thermosyphon's output heat transfer 
rate. The primary conclusion drawn from changing the fill volume was that the thermosyphon's performance is largely independent of fill volume as long as dry out does not occur. Dry out was found to occur with the smallest inner diameter and evaporator tested at the highest input heat transfer rate tested at $25 \%$ fill ratio. DeCecchis also found that the length of the evaporator does not significantly affect rate of heat transfer to the air stream.

\subsection{Contribution of This Work}

The vast majority of closed two phase thermosyphons in the literature have both a cylindrical outer surface and a cylindrical inner surface (cavity). This is not conducive to optimal heat transfer in airflow as the shape of a cylinder leads to early separation of the boundary layer. There has been investigation of the heat transfer capabilities of different-shaped bodies in airflow [13], but there has not been any effort to combine a more streamlined body, e.g. an airfoil, with thermosyphon technology. This is the next step in achieving a cooling fin thermosyphon. Randolph and DeCecchis have laid the ground work for the particular experimental conditions for this thermosyphon (small evaporator section and large, air-cooled condenser section) and so the focus of this work is to develop a functioning airfoil-shaped thermosyphon. In addition to a new body shape, two different cavity shapes are also tested. Because of the mixed results in the literature for optimal heat transfer rate as a function of fill volume, an investigation of the influence of fill ratio is also conducted. 


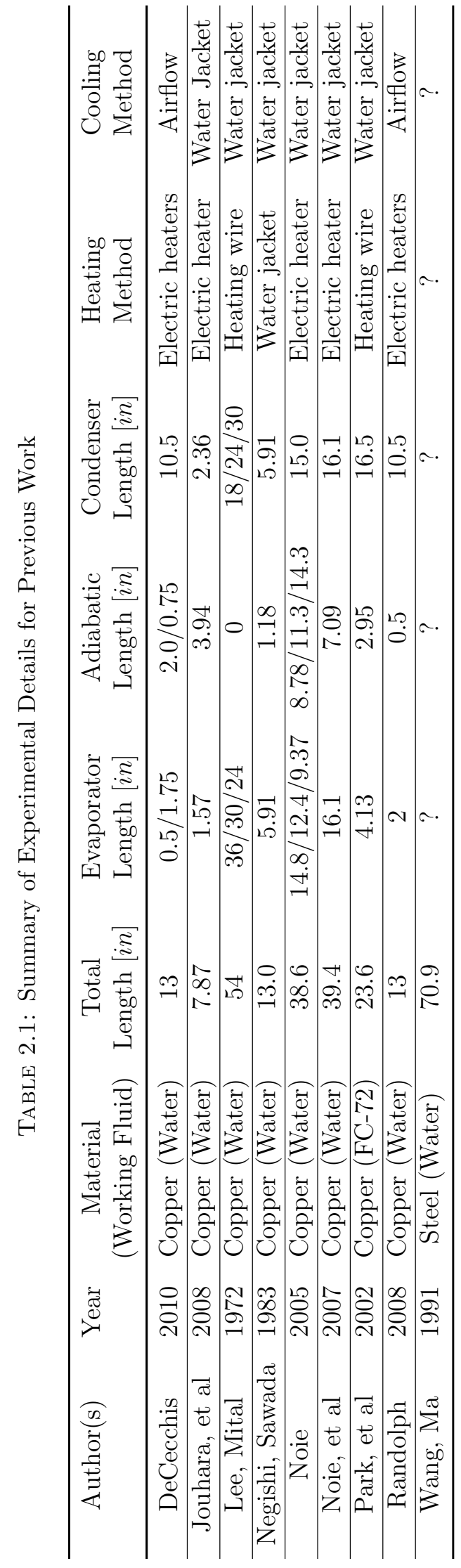




\section{Chapter 3}

\section{Thermosyphon Design}

As discussed in Chapter 1, the ultimate purpose of this work is to develop a functioning thermosyphon that can be used as a cooling fin. This chapter discusses the design methodology for the two thermosyphons used to test performance, i.e. rate of heat transfer, of a cooling fin thermosyphon. Prior to this work, Randolph designed, constructed, and tested four different cylindrical thermosyphons with cylindrical cavities [11]. In the process of testing the cylindrical thermosyphons' rates of heat transfer, he found that they experienced very high internal pressures (up to 100 psig) during operation. DeCecchis performed similar experiments using Randolph's cylindrical thermosyphons and witnessed similar internal pressures [12]. After demonstrating proof of concept with cylindrical thermosyphons it was necessary for the thermosyphon design to transition from cylinders to airfoils.

After concluding testing with the cylindrical thermosyphons, Randolph then attempted to fabricate two generations of airfoil-shaped thermosyphons with airfoilshaped cavities. Both were constructed by forming sheets of copper into an airfoil shape and welding end caps to both ends of the airfoil body. The welds failed and the walls were visibly bowed outward when the thermosyphons were hydrostatic pressure tested at very low pressures. It was hypothesized that the severe wall displacements led to the failure of the welds and that this overall structural failure was a result of the 
cavity shape (and wall thickness) and the method of fabrication. Therefore, in order to successfully conduct experiments on airfoil-shaped thermosyphons, the first goal of this work is to design and construct a thermosyphon that can withstand a hydrostatic pressure test up to 100 psig. This goal is based on the internal pressures achieved by Randolph's cylindrical thermosyphons under similar experimental conditions. In particular, the new airfoil thermosyphon design should satisfy two requirements while pressurized: the seams should not fail and the walls should not be displaced.

\subsection{Design Constraints}

The primary design constraint for the proposed cooling fin thermosyphon was that it must have an airfoil-shaped cross-section of particular dimensions. Table 3.1 displays the dimensions of the airfoil-shaped cross-section, which has the same shape as that of a NACA0010 airfoil.

TABle 3.1: Dimensions of the Airfoil Cross-Section Shape

\begin{tabular}{lc}
\hline Characteristic & Value \\
\hline Camber & none (symmetrical) \\
\hline Maximum Thickness & 0.25 inches \\
\hline Chord Length & 2.5 inches \\
\hline
\end{tabular}

The thermosyphon assembly has three components that were fabricated separately and will henceforth be referred to as the top end cap, the main body or shell, and the bottom end cap. Figure 3.1 illustrates these designations.

The design approach for this cooling fin thermosyphon was very conservative to account for the possibility that high internal pressures may be encountered during operation. As mentioned at the beginning of this chapter, prior experiments with cylindrical thermosyphons indicate that this concern was a valid one. The following conclusions can be drawn based on Randolph's experience with airfoil-shaped thermosyphon designs: the vessel walls must not be too thin, the cavity cross-section 


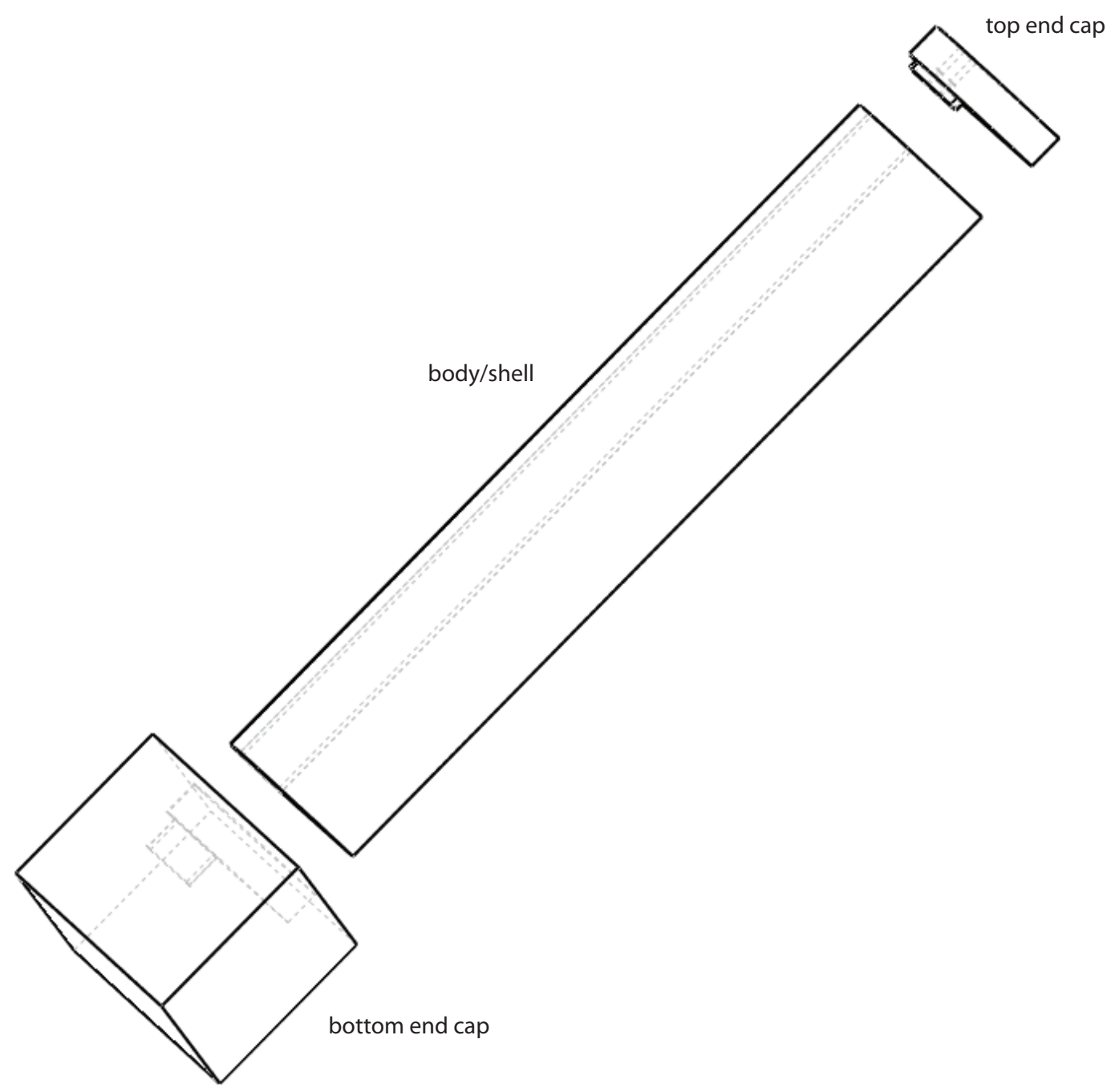

Figure 3.1: An exploded view of the top end cap, bottom end cap, and main body of the thermosyphon assembly.

must be structurally sound, and the method of fabrication for the main body must be changed. Also, the method of end cap attachment is vital to a successful design.

While investigating cavity shapes and sizes, it was necessary to keep in mind that there is a trade-off between structural stability and rate of heat transfer. Thinner shell walls and a larger cavity increase rate of heat transfer but also lead to potential structural failures, as was experienced by Randolph. However, a small cavity with thicker shell walls sacrifices rate of heat transfer for the sake of structural integrity. Therefore, the ideal cavity design would maximize thermosyphon rate of heat transfer without leading to structural failure. It was hypothesized that using a slot-shaped 
cross-section for the cavity may avoid stress concentrations and minimize deformation when the vessel is pressurized while maximizing rate of heat transfer.

\subsection{Design Modeling}

The solid modeling software SolidWorks was used to create a virtual thermosyphon shell (that is, the thermosyphon body with no end caps) and to analyze various cavity sizes and shapes. It was decided that two thermosyphons would be fabricated - one more conservative (sacrificing performance) and one less conservative (potentially sacrificing structural integrity). The reason for this was to ensure that at least one design could be tested experimentally in case of structural failure of the other. The more conservative cavity design is simply a cylinder and the less conservative cavity design, as mentioned in Section 3.1, is a slot. For simplicity, the thermosyphon with the cylindrical cavity will be referred to as the cylinder thermosyphon and the thermosyphon with the slot-shaped cavity will be referred to as the slot thermosyphon.

Two dimensions of the cross-section of the cylinder thermosyphon were varied during design analysis. The first is the distance from the center of the circle to the leading edge of the airfoil cross-section, called the LHS (left hand side) dimension. The second is the diameter of the circle, called the $D$ (diameter) dimension. These two dimensions are labeled on a cross-section of the cylinder thermosyphon in Figure 3.2 .

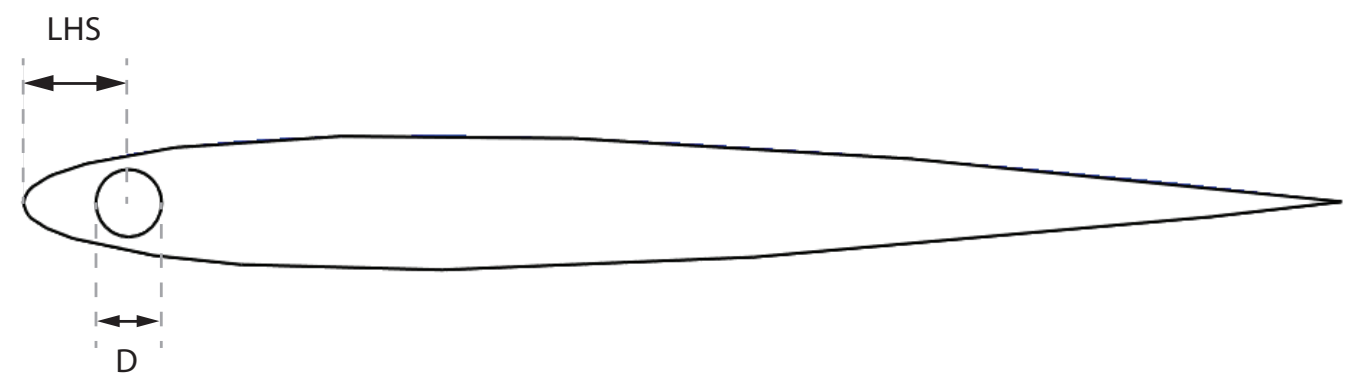

Figure 3.2: The $L H S$ and the $D$ dimensions that are varied for design analysis for the cylindrical cavity thermosyphon. 
For the slot thermosyphon, three dimensions were varied during analysis. The first is the distance from the leading edge of the airfoil cross-section to the center of the semi-circle end of the slot, called the LHS dimension. The second is the width of the slot, called the $D$ dimension. The third, called the RHS dimension, is the distance from the trailing edge of the airfoil cross-section to the center of the other semi-circle end of the slot. These three dimensions are labeled on a cross-section of the slot thermosyphon in Figure 3.3.

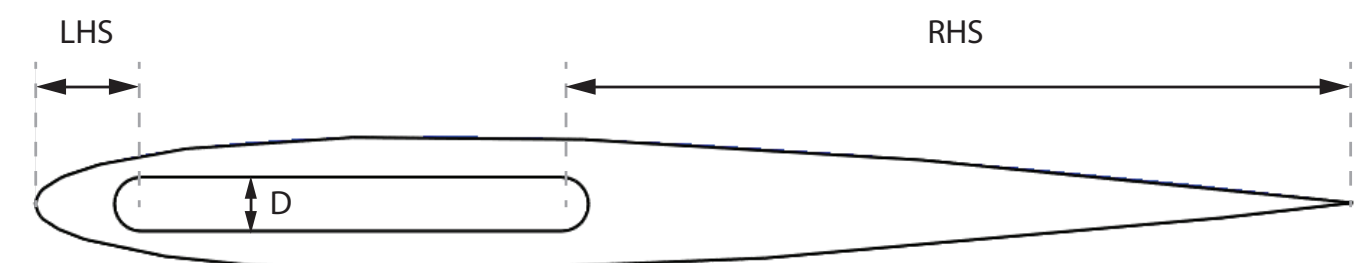

Figure 3.3: The $L H S, R H S$, and the $D$ dimensions that are varied for design analysis for the slot-shaped cavity thermosyphon.

\subsection{Design Analysis}

The primary metric by which the success of the different cavity designs was measured was the ability of the design to resist wall deformation when the cavity was pressurized. The pressurization of the cavity was simulated using the finite element analysis package in SolidWorks called COSMOS (which has since been fully integrated into the SolidWorks software). The primary quantity measured in each simulation was the resultant displacement of a given point on the surface of the shell. This resultant displacement is referred to as the URES in COSMOS. The maximum URES over the entire surface of the shell was recorded after the simulation was completed. Also, a visualization of the $U R E S$ at each point over the surface was plotted to achieve an idea of how the shape of the cavity affected the wall displacements.

To run the simulation, the ends of the shell were fixed to simulate the attachment of the end caps, which restrain the ends from deforming. Then an outward-facing 
pressure of 100 psig was designated on the cavity surface to simulate experimental conditions. After these two constraints were applied to the particular design being examined, the thermosyphon shell was meshed using the default mesh settings and the simulation was run. The maximum $U R E S$ was recorded and a plot of the displacements over the surface of the shell was created and saved. Due to the extensive number of simulations run for each thermosyphon, the results from the "worst case scenario" combinations of dimensions are given here.

In Figure 3.4 the displacement surface plots and the maximum displacements (in inches) are given for the final cylinder cavity design dimensions (discussed in Section 3.4) and two worst case scenarios: the first is when the $D$ dimension is as large as possible (as permitted by the airfoil cross-section shape and the limits of meshing) while the LHS dimension is the same as in the final design and the second is when the $L H S$ dimension is as small as possible while the $D$ dimension is the same as in the final design. The displacement plots for the different designs of the cylinder cavity do not indicate much wall displacement, which is due to the structurally conservative nature of the cylindrical cavity.

The maximum displacements and wall displacement surface plots for selected cavity designs for the slot thermosyphon are displayed in Figure 3.5. The results for the final design dimensions (discussed in Section 3.4) are provided at the top of the figure and three worst-case scenario designs are given beneath it. The first worst-case scenario is where the $D$ dimension is as large as possible with the $L H S$ and $R H S$ dimensions are the same as in the final design. The second worst-case scenario is where the LHS dimension is as small as possible, and the third worst-case scenario is where the RHS dimension is as small as possible. The displacement surface plots indicate that the worst-case scenarios are indeed worst-case as they yield larger displacements than the more conservative design that was ultimately used for testing.

Comparing the final designs of the cylinder and slot thermosyphons, it is clear that when the slot thermosyphon experiences an internal pressure of 100 psig the 


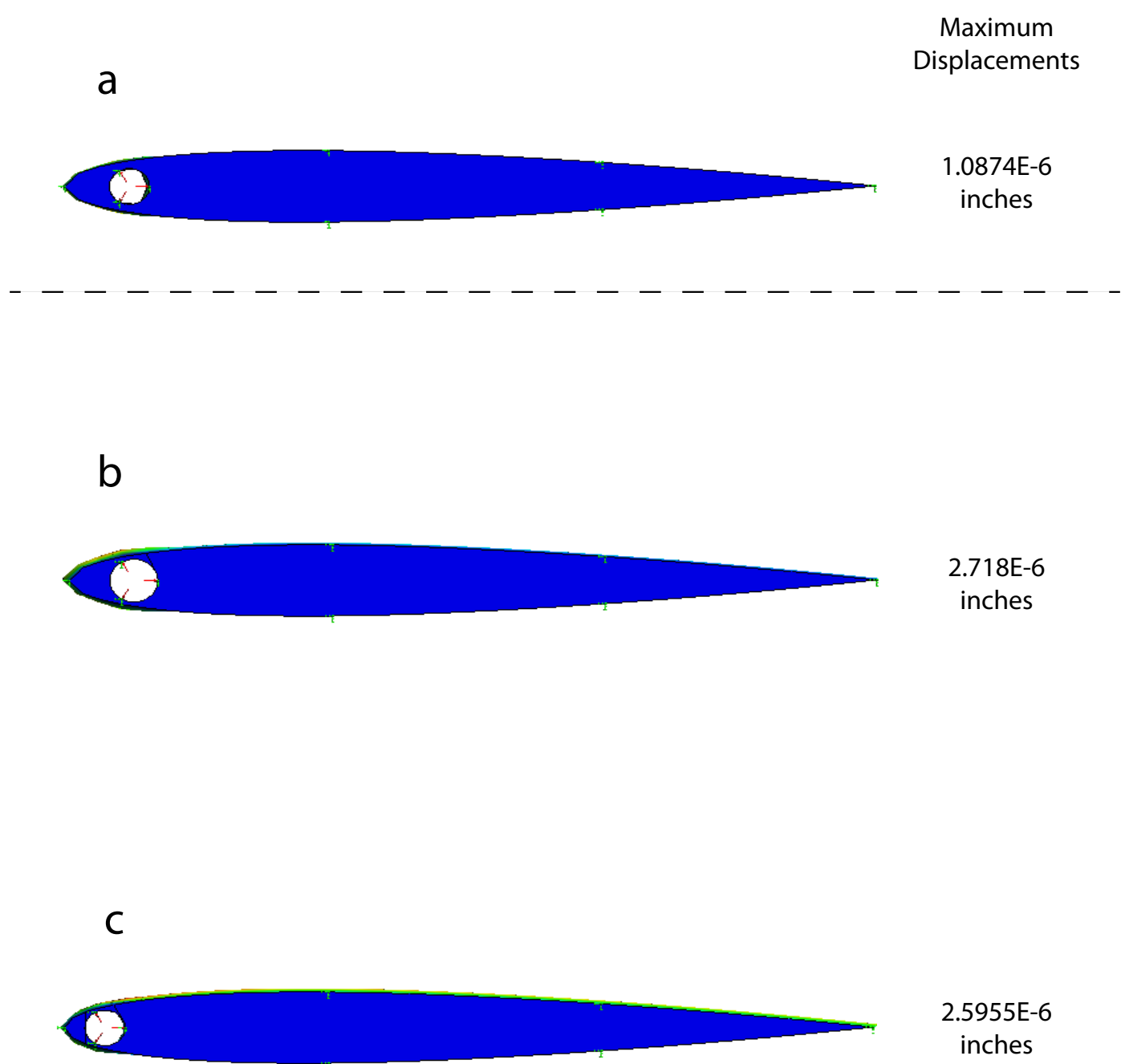

FiguRE 3.4: Resultant displacement surface plots are mapped onto the cross-section of the cylinder thermosyphon for (a) the final design $D$ and $L H S$ dimensions and two worst case scenarios: $(b)$ the largest $D$ dimension and $(c)$ the smallest $L H S$ dimension. The maximum resultant displacement for each design is displayed to the right of each airfoil.

wall displacements are 100 times larger than those for the cylinder thermosyphon.

This reaffirms the assumption that the cylinder cavity is a more conservative struc- 


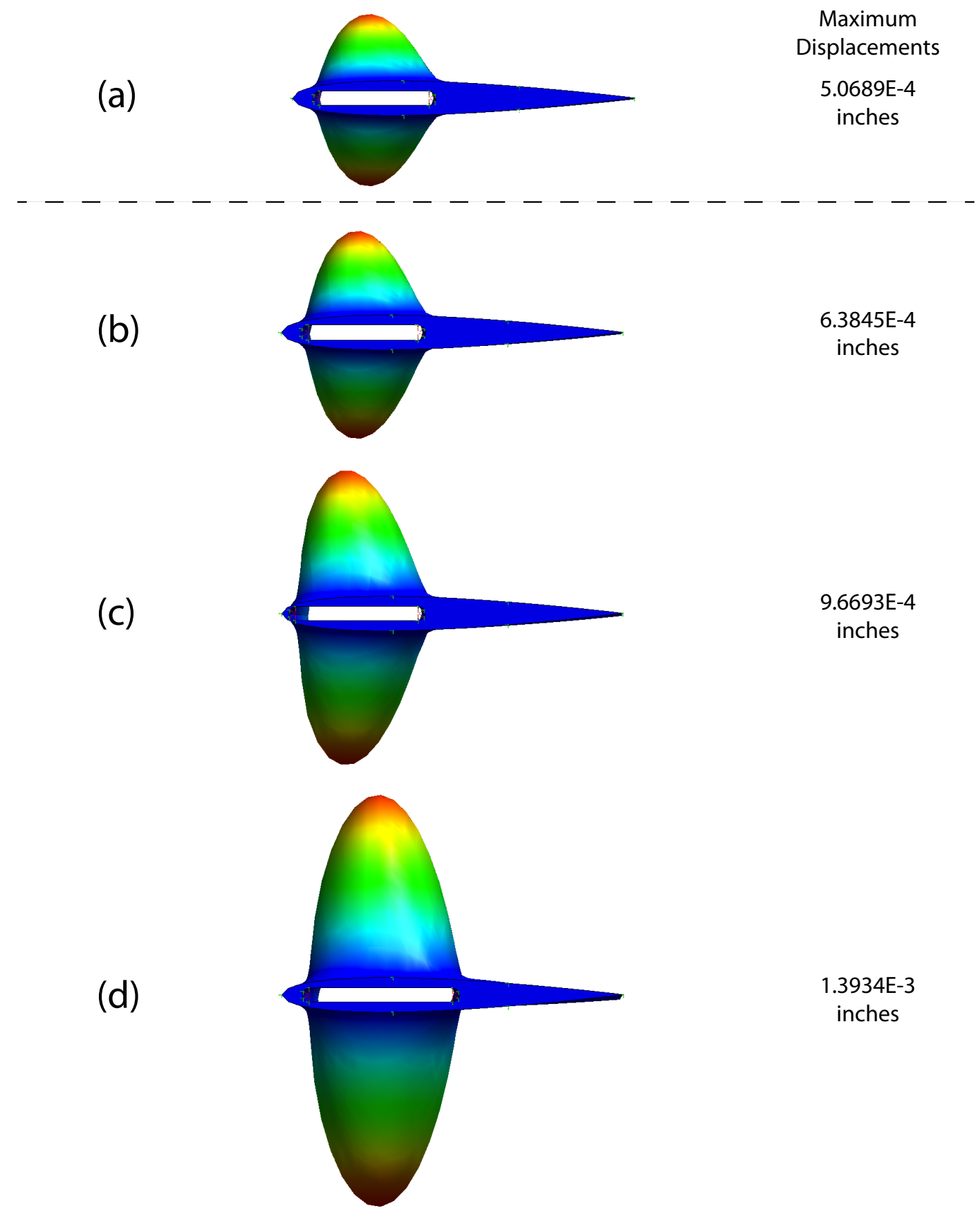

FiguRE 3.5: Resultant displacement surface plots are mapped onto the cross-section of the slot thermosyphon for (a) the final design $D, L H S$, and $R H S$ dimensions and three worst case scenarios: (b) the largest $D$ dimension, $(c)$ the smallest $L H S$ dimension, and $(d)$ the smallest $R H S$ dimension. The maximum resultant displacement for each design is displayed to the right of each airfoil.

tural design for the airfoil-shaped thermosyphons. In conducting these analyses, the baseline for an acceptable amount of wall deformation was established using results 
from similar FEA analyses carried out by Randolph [11] on his airfoil designs. The maximum wall displacements for his four airfoils ranged from $10^{-1}$ to $10^{-3}$ inches when placed under internal pressures of only 20 psig. In light of this, finding maximum displacements on the order of $10^{-3}$ or smaller with internal cavity pressures of 100 psig was promising in terms of the success of the design.

\subsection{Final Design}

The final designs for the cavities of the cylinder and slot thermosyphons were chosen based on the optimal combination of cavity dimensions found in the finite element analysis described in Section 3.3. As discussed in Section 3.1, the optimal combination of cavity dimensions was a balance between maximizing rate of heat transfer and minimizing wall deformation. After determining the appropriate cavity dimensions, the top and bottom end caps were designed. The design methodology for the end caps was the same for both the cylinder and slot thermosyphons.

The top end cap is airfoil-shaped to match the body shape. Two holes were machined through this end cap to allow for the addition of tubing to the end cap after its attachment to the shell. These tubes are used to connect the thermosyphon to the fluid reservoir and the pressure transducer, as discussed in Section 4.1.2. For the slot thermosyphon, the cavity size is large enough to allow both holes to have full and unobstructed access to the cavity itself. An illustration of the top end cap for the slot thermosyphon is given in Figure 3.6. For the cylinder thermosyphon, however, the small size of the circular cross-section necessitated the creation of a small cavity in the top end cap to allow both holes access to the small cylindrical cavity. 


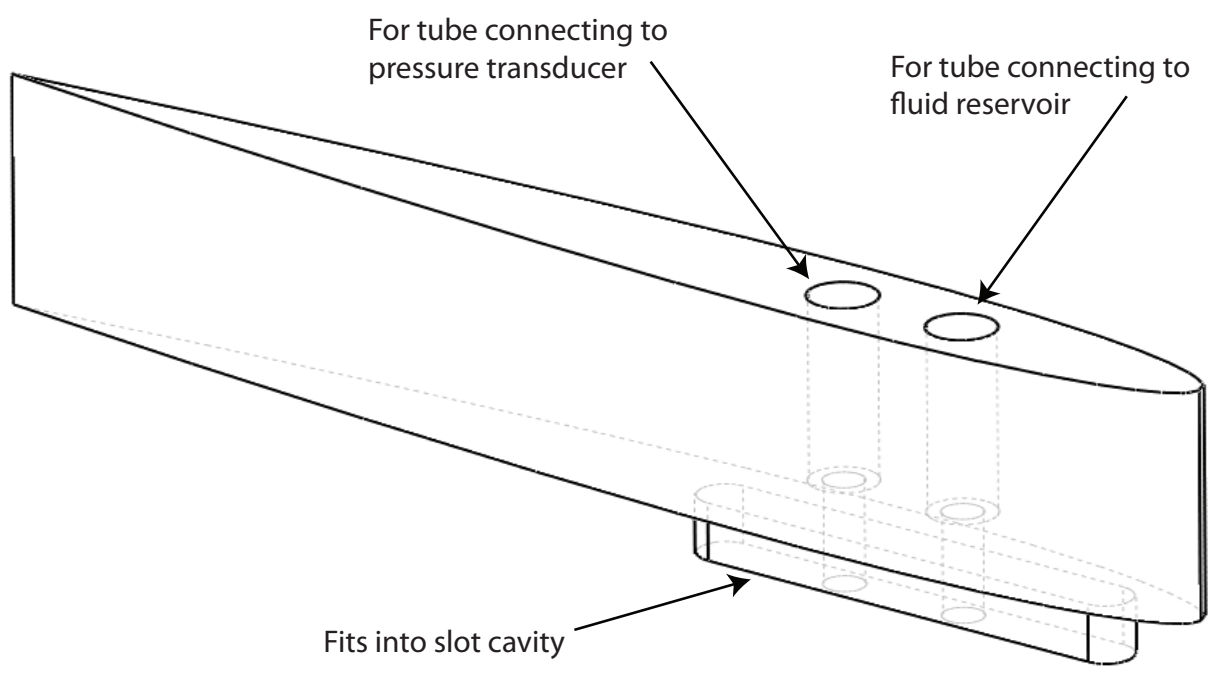

Figure 3.6: The top end cap for the slot thermosyphon has two holes for tubing and a slot-shaped tab that fits into the slot cavity in the airfoil body.

The bottom end cap is simply a block designed to act as both the end cap and the means by which the thermosyphon is heated. The block has two holes drilled through the sides where cartridge heaters are positioned to deliver energy to the evaporator section of the thermosyphon. An airfoil-shaped cavity is cut into the bottom end cap that the shell fits down into. In addition to this, a chamber of the same shape and size as the cross-section of the cavity was drilled beyond the airfoil-shaped cavity in the bottom end cap. When the thermosyphon body is attached to the bottom end cap, an evaporator section one inch in depth is created. An illustration of the bottom end cap (heater block) for the slot thermosyphon is given in Figure 3.7. 


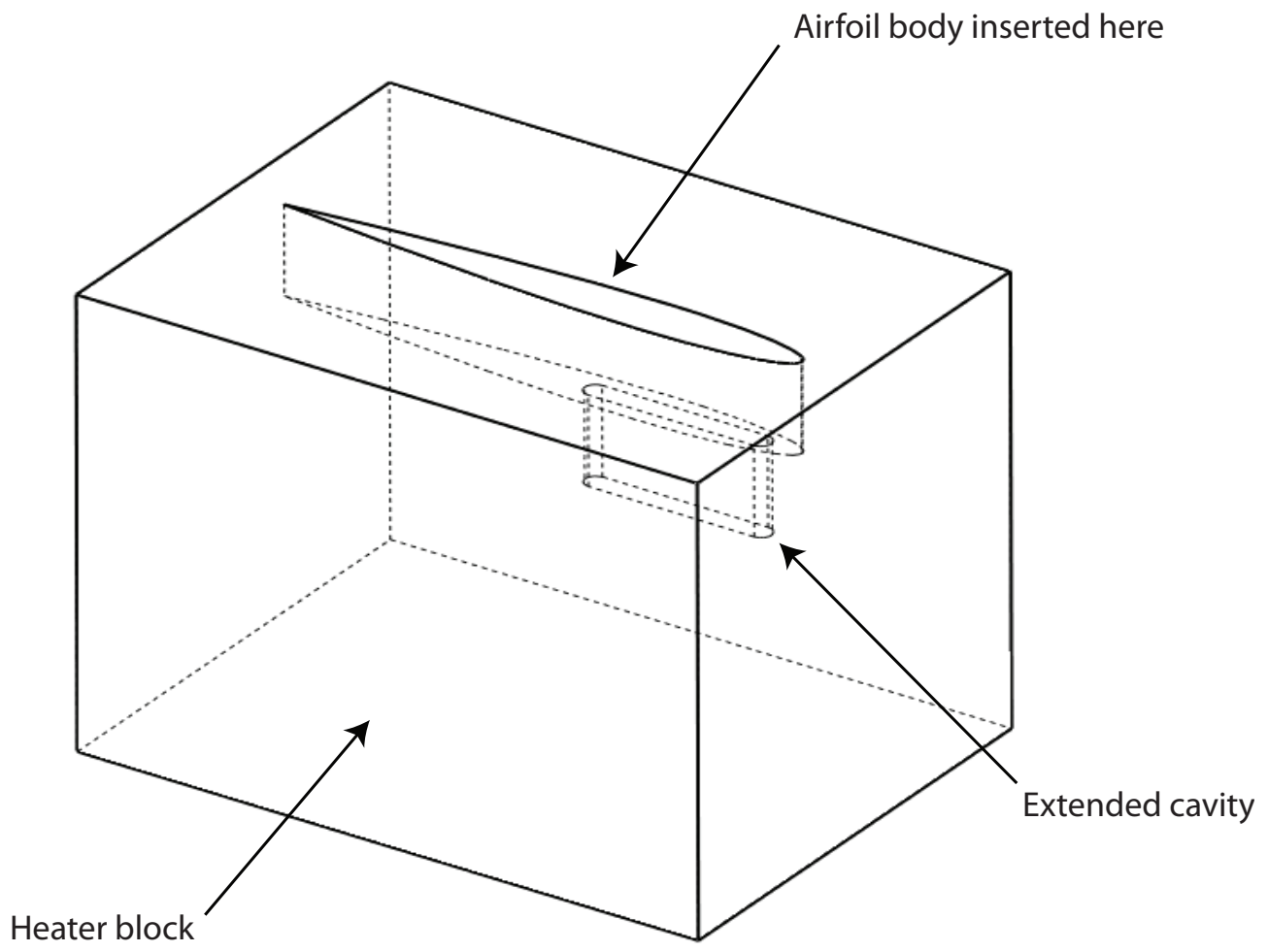

Figure 3.7: The bottom end cap for the slot thermosyphon has a chamber for the airfoil body to fit into and an extended cavity that lengths the evaporator section.

The drawings for the top and bottom end caps and the thermosyphon body, created from these designs, for the cylindrical cavity thermosyphon are provided in Appendix A.1 and those for the slot-shaped cavity thermosyphon are provided in Appendix A.2.

\subsection{Method of Fabrication}

The structural failure of the previous generation of airfoil-shaped thermosyphons was hypothesized to be partially due to the fabrication methods used. As mentioned earlier in this chapter, in prior designs the airfoil shape was created by forming copper sheeting and welding at the trailing edge to create a seam. The end caps were also attached using welding. Another method of construction was chosen in order to increase the chances of the current airfoil-shaped thermosyphons succeeding struc- 
turally. The top end cap, bottom end cap, and body of each thermosyphon were fabricated out of solid pieces of ultra-conductive copper (alloy 101). The end caps were attached to the thermosyphon body using epoxy, as outlined in Section 4.1.2 in Chapter 4 . The airfoil body shape and its cavity were created using a method called wire electrical discharge machining (EDM) by a company in Richmond, VA called Precision, Tool, and Die. The end caps were fabricating using standard CNC machining techniques by this same company. The contact information for this company is provided in Appendix D. 


\section{Chapter 4}

\section{Experimental Setup}

This chapter outlines the setup of the experiment designed to test the rate of heat transfer, or the performance, of the slot and cylinder thermosyphons. The assembly and safety testing of the thermosyphons themselves is discussed first, and then the details of the experimental setup are outlined. In addition to this, the equipment used to monitor and measure the thermosyphon internal pressure, the surface temperature, the rate of heat transfer, and other physical quantities is illustrated. Finally, the features of the experiment and the experimental method used to measure thermosyphon rate of heat transfer are outlined in detail.

\subsection{Assembly}

\subsubsection{Component Cleaning}

After fabrication, the thermosyphon components were exposed to the air and ungloved handling for some time prior to being assembled. As a result, the surface of all the components had oxidized and accumulated a film of particulate matter. In order to keep the cavity walls as pristine as possible it was necessary to clean each of the pieces prior to assembly. The thermosyphon components (both the slot and cylinder

bodies and top and bottom end caps) were cleaned using a solution recommended by 
Faghri [2] for deoxidizing heat pipes, the formula for which is: sodium dichromate (6 $o z / g a l)$, sulfuric acid (7 percent by volume), and deionized water. Each piece was placed in a bath of this solution for approximately 10 minutes. Afterward, they were placed in a bath of deionized water and then thoroughly rinsed with deionized water several times. After drying, the pieces were handled with gloves only and stored in boxes until assembled shortly thereafter.

\subsubsection{Thermosyphon Assembly}

The following description of the assembly of the thermosyphon pieces applies to both the cylinder and slot thermosyphon. The end caps were attached to the body using a metal-filled repair epoxy. The choice of epoxy and details related to its selection are discussed in Appendix B. After mixing the epoxy's resin and hardener components, the epoxy was piped along the bottom end face of the body and approximately a half-inch up the sides. The epoxy placement is illustrated in Figure 4.1. This was done to ensure maximum surface contact between the body, the epoxy, and the bottom end cap.

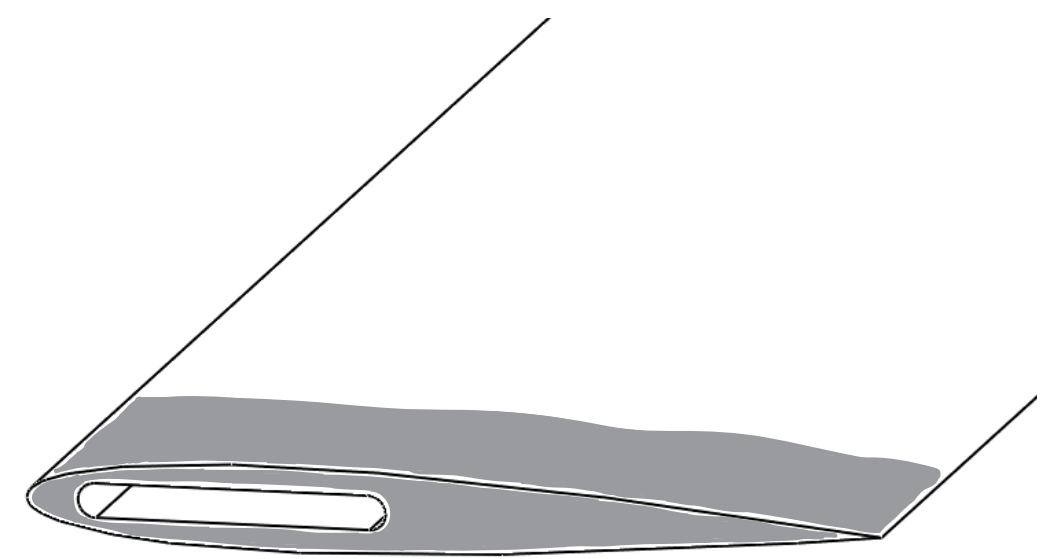

Figure 4.1: The thermosyphon body was coated with epoxy prior to placement in the bottom end cap. Care was taken to keep the epoxy from being pushed into the cavity itself as the body was placed in the end cap.

After the body was inserted into the bottom end cap, a bead of epoxy was piped 
onto the seam between the two pieces of copper. Then this bead was smoothed onto both surfaces to ensure a thorough seal as the epoxy cured. The body and bottom end cap assembly was left to cure overnight, and then the next day the top end cap was attached.

While these pieces were curing, the two stainless steel tubes that connect the thermosyphon to the fluid reservoir and the pressure transducer were attached to the top end cap using the same epoxy and the same application method. After both sets of pieces were cured, the top end cap was attached to the body to create the full thermosyphon assembly. An additional step was taken after the epoxy cured to protect against leaks and also to lend some support to the somewhat delicate and easily bent tubing. This step involved entombing almost the entirety of the top end cap seam and tubing in 5 Minute Epoxy made by Devcon. Because the temperature rating was unknown, this epoxy was only used around the top end cap where the temperatures are not nearly as high as around the bottom end cap seam.

\subsection{Safety Testing}

It was not considered strictly necessary to hydrostatic pressure test the cylinder thermosyphon because of the nature of its construction and the strength associated with the shape of the cylindrical cavity. Catastrophic failure due to pressurization was not anticipated and so the integrity of the cylinder thermosyphon was effectively tested during the process of leak testing where it was pressurized up to $100 \mathrm{psig}$.

The slot thermosyphon, however, seemed much more likely to deform when pressurized due to the cavity shape and decreased wall thickness as compared to the cylinder thermosyphon, as evidenced by the FEA analysis conducted. Therefore, after its construction the slot thermosyphon was hydrostatic pressure tested to ensure that it would remain structurally sound at high internal pressures. This testing was done by filling the thermosyphon almost completely with deionized water. The valve 
that attaches to the vacuum pump was attached to an air compressor, and then the pressure was increased in increments of $10 \mathrm{psig}$. The details for the vacuum pump used in these experiments are provided in Section 4.5.4. The particular air compressor used for this (and for leak testing) was a Porter Cable 150 psi pancake compressor. At each pressure increment, the thermosyphon was visually inspected for leaking or wall deformation. This thermosyphon was tested up to $120 \mathrm{psig}$ with no visible sign of structural failure.

\subsection{Leak Testing}

After safety testing the thermosyphons, as discussed in Section 4.2, the baseline performance (with no working fluid in the cavity) experiments were performed. After the first experiment with the cylinder thermosyphon was concluded and upon cooling, it was discovered that the epoxy had failed. The thermosyphon cavity leaked heavily, possibly due to delamination, and would not hold a vacuum. As a result, some additional sealant precautions were taken at the bottom end cap seam, which is where the epoxy failure had occurred. First, to find the location of the leaks, the valve leading to the vacuum pump was connected to the air compressor. The valve was opened, and the bottom end cap seam was sprayed with soapy water. Any leaks were immediately identified as there was visible bubbling at the location of the leaks. After the leaks were patched with the metal-filled repair epoxy the entire area was sprayed with a high vacuum leak sealant made by Vacseal, often several times, over a period of a few days. This spray sealant was found to be effective at sealing smaller leaks while the metal-filled repair epoxy was effective at sealing larger leaks. Further discussion of leak sealing is given in Appendix B. 


\subsection{Experimental Outline}

The primary quantity of interest in these experiments is the thermosyphon's rate of heat transfer at different fill volumes and different evaporator temperatures. To simulate the scenario of a cooling fin thermosyphon in an air stream, it is logical to use actual air flow as the means by which the thermosyphon is cooled. This is easily accomplished in the test section of a wind tunnel. The condenser section of the thermosyphon is positioned in the test section itself while the adiabatic and evaporator sections are located outside of it. Due to the nature of these simulated conditions, it would be difficult, if not impossible, to measure the rate of heat transfer from the surface of the condenser section to the air stream. When the experiment is at steady state, the rate of heat transfer into the thermosyphon is equivalent to the rate of heat transfer out of it. It is feasible to measure the rate of heat transfer into the thermosyphon via electrical cartridge heaters, the details of which are discussed in Section 4.6.4. The method used to measure the rate of heat transfer is possible due to the steady state nature of the experiment. A conceptual illustration of this steady state experiment is shown in Figure 4.2 .

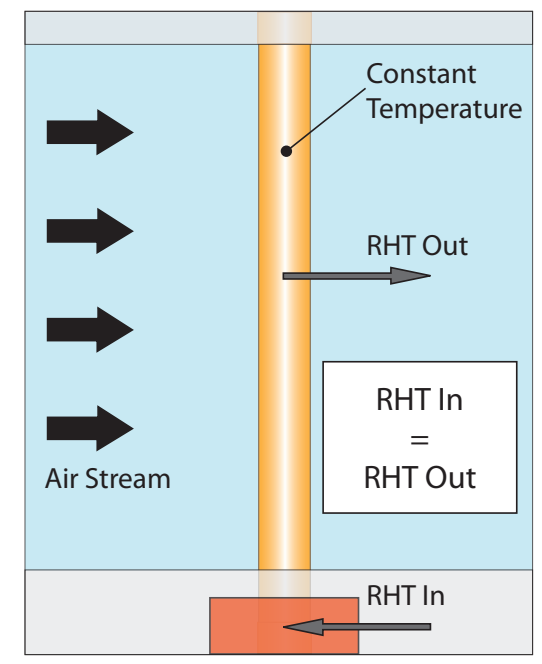

Figure 4.2: The thermosyphon's (represented in orange) condenser section is situated in the air stream in the wind tunnel test section. At steady state, the rate of heat transfer into the thermosyphon (RHT In, represented in red-orange) is equivalent to the rate of heat transfer to the air stream (RHT Out). 
The thermosyphon surface temperature is also measured as it is an indicator of whether or not the thermosyphon is truly acting as a thermosyphon. In the case of true thermosyphon action, the entire surface is isothermal. The details of the surface temperature measurements are provided in Section 4.6.3.

\subsection{Experimental Setup Details}

\subsubsection{Fill Volume}

\section{Fluid Reservoir}

Due to the small cavity size associated with the cylinder and slot thermosyphons, the amount of fluid necessary for the chosen fill volumes, is also very small. This necessitates a different fluid reservoir setup than what was used in DeCecchis' experimental setup [12] as it was difficult to find rigid, clear tubing with a small enough diameter to make reading measurements straightforward. In light of this, a $10 \mathrm{~mL}$ burette, purchased from Cole Parmer, was used as the fluid reservoir. The resolution of the burette is $0.05 \mathrm{~mL}$.

\section{Fill Setup}

The diagram in Figure 4.3 illustrates the arrangement of tubing, valves, etc. used to evacuate and fill each thermosyphon. This setup is convenient for changing the fill volume without having to replace tubing. Randolph and DeCecchis both cold-welded the fill tube after evacuation and filling, which did not allow for easy fill volume changes. Another advantage of this arrangement is that it stays in place throughout testing so that the thermosyphon may be evacuated and filled at any time while positioned in the wind tunnel test section. 


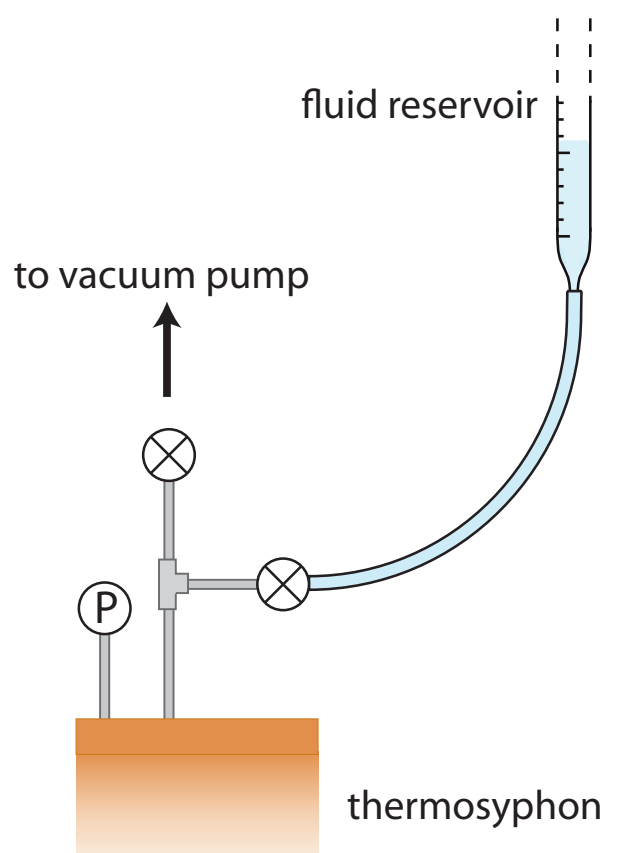

FiguRE 4.3: The top portion of the thermosyphon is shown in orange with two tubes set into the top end cap: one leading to the pressure transducer and the other leading to the tee that connects to the fluid reservoir and the vacuum pump.

As discussed in Section 4.1.2, two stainless steel tubes attach to the top end cap of the thermosyphon. One of the tubes has a Swagelok stainless steel fitting that attaches to a pressure transducer (the details of which are discussed in Section 4.6.2). The second tube is dual purpose; it connects to a tee that leads to the fluid reservoir and to the vacuum pump (or the air compressor, in the case of leak testing). Each of these connections is controlled with a separate valve. The valve that controls the flow from the fluid reservoir is a Swagelok-compatible needle valve. Clear, flexible tubing connects this needle valve to the fluid reservoir itself and is secured at each end using plumber's sealant to prevent leaking. Prior to attachment to the needle valve, the burette was filled with deionized water and bled down to the valve to ensure that no air bubbles would be present when the thermosyphon was filled. The valve that controls the flow from the vacuum pump (or air compressor) is a Swagelokcompatible ball valve. There is a flask connected in series between the thermosyphon and the vacuum pump, which is displayed in Figure 4.4. This flask is used to catch 
the water that is pulled out of the thermosyphon during the discharging process to keep the water from being sucked into the vacuum pump itself. The reason for fully discharging the thermosyphon between experiments is due to the leaking problems associated with the epoxy and is discussed in Appendix B.

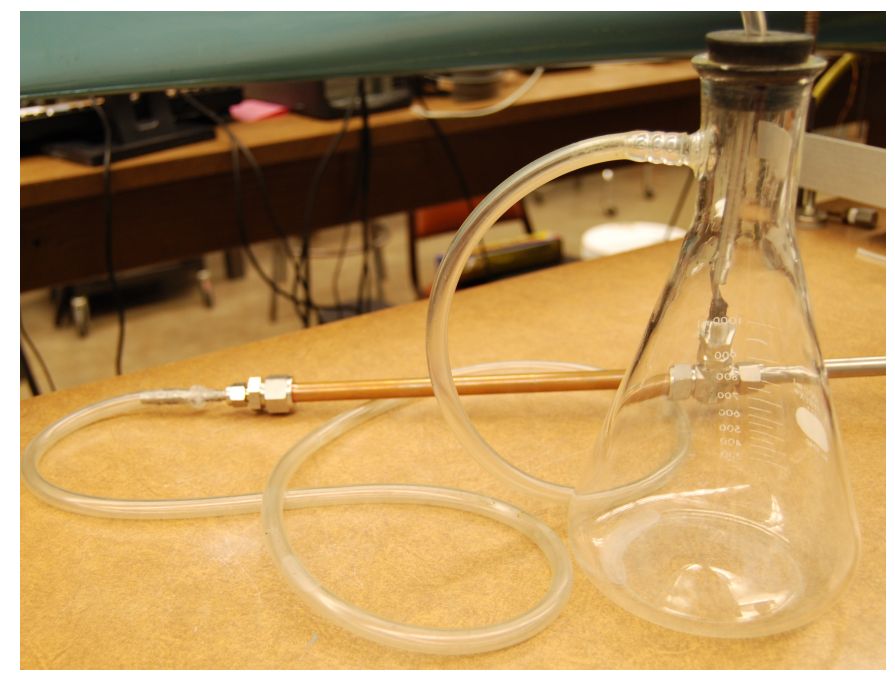

Figure 4.4: The flask is placed in series in the connection from the valve leading off the tee joint to the vacuum pump. The tubing fed through the rubber stopper leads to the valve and the tubing placed over the tabulation leads to the vacuum pump.

\section{Chosen Fill Volumes}

As a direct result from DeCecchis's findings [12] about the relationship between fill volume and thermosyphon performance, it was decided that three fill volumes should be tested, which includes a control fill volume of $0 \%$. Along with the control, two fill volumes were chosen: the first fill volume is smaller than the volume of the evaporator section (the evaporator section is $8.33 \%$ of the total cavity volume for the cylinder and slot thermosyphons) and the second fill volume is larger than the volume of the evaporator section. Table 4.1 displays these chosen fill volumes and also provides these volumes as a percentage of the evaporator section in one column and as a percentage of the total cavity volume in another column. The error associated with the fill volumes originates from the resolution of the burette used to measure out the working fluid. 
TABLE 4.1: Fill Volumes for Cylinder and Slot Thermosyphons

\begin{tabular}{cccc}
\hline $\begin{array}{c}\text { Cylinder Volume } \\
{[ \pm 0.05 m L]}\end{array}$ & $\begin{array}{c}\text { Slot Volume } \\
{[ \pm 0.05 m L]}\end{array}$ & $\begin{array}{c}\text { \% of Evaporator } \\
{[\%]}\end{array}$ & $\begin{array}{c}\text { \% of Total Cavity } \\
{[\%]}\end{array}$ \\
\hline 0 & 0 & 0 & 0 \\
\hline 0.12 & 0.86 & 60 & 5 \\
\hline 0.48 & 3.45 & 240 & 20 \\
\hline
\end{tabular}

\subsubsection{Wind Tunnel}

\section{Wind Tunnel Specifications}

The wind tunnel used for all experiments in this thesis is an AEROLAB Educational Wind Tunnel, which is located in the Aero Lab in the Mechanical and Aerospace Engineering Department building at the University of Virginia. This is the same wind tunnel that DeCecchis used for his experiments. The specifications for this wind tunnel are provided in Table 4.2. The wind speed was controlled using the wind tunnel's controller, a Siemens MIDIMASTER Eco controller.

TABLE 4.2: AEROLAB Educational Wind Tunnel Specifications

\begin{tabular}{cc}
\hline Characteristic & Specification \\
\hline Test Section Dimeinsions & 12 in by 12 in by 24 in \\
\hline Maximum Air Speed & $145 \mathrm{mph}$ \\
\hline Air Temperature & Room Temperature $(\approx 75 \mathrm{~F})$ \\
\hline Motor Power & $15 \mathrm{HP}, 110 \mathrm{VAC}$ \\
\hline Fan Size & 24 in \\
\hline Fan RPM & $2460 \mathrm{rpm}$ \\
\hline Contraction Ratio & 9.5 \\
\hline
\end{tabular}




\section{Test Section Modifications}

The test section for this wind tunnel is taller than the thermosyphon body so that if the thermosyphon was simply positioned in the test section, the end caps and tubing would be positioned in the flow. In order to avoid this problem, a false top was constructed and installed by DeCecchis for his experiments [12]. The thermosyphons constructed for the experiments discussed in this thesis are the same length as those used by DeCecchis so his false top was also utilized for these experiments. An image of this addition to the test section is shown in Figure 4.5. The use of this false top also allows for the creation of a small adiabatic section located just below the bottom of the test section.

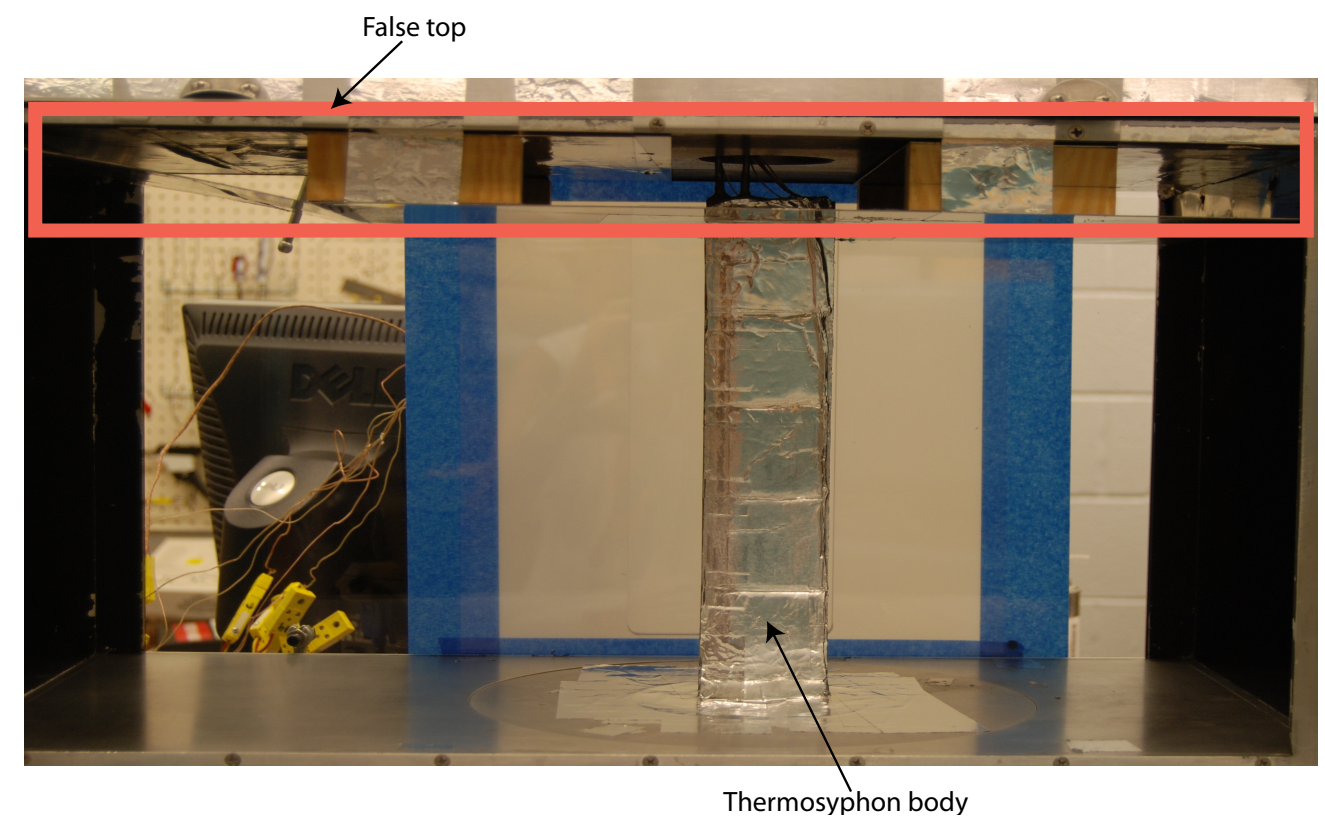

Figure 4.5: A side view of the test section is shown here. The false top is shown positioned and taped against the top face of the test section. The thermosyphon body is also shown positioned in the test section with the top end cap and tubing located inside the false top. The tubing required for the evacuation and fill setup is arranged on top of the test section.

\subsubsection{Heater Block}

The evaporator section of the thermosyphon, which is encased in the bottom end cap, is heated using two $200 \mathrm{~W}$ OMEGA electrical resistance cartridge heaters. They 
are $0.5 \mathrm{in}$ in diameter and $3 \mathrm{in}$ in length. The heaters are inserted into the holes drilled in the heater block and wired in parallel. In order to increase the amount of thermal contact between the heaters and the heater block, each of the cartridge heaters is coated with a very thin layer of OMEGATHERM 201 high temperature high thermal conductivity paste, made by OMEGA, prior to insertion. A thermocouple, the same type as those placed on the thermosyphon surface, is positioned on the side of the heater block to act as feedback for controlling the evaporator temperature. The characteristics of these thermocouples are discussed in Section 4.6.3.

To minimize heat transfer from the heater block to the surroundings during operation, it is enclosed in an insulating structure comprised of an inner and outer chamber created from layers of fiberglass board insulation coupled with air gaps stuffed with additional insulation. The bottom of the structure is created with three layers of fiberglass board placed on top of each other and taped together. The inner chamber walls are created with three layers of fiberglass board sandwiched together on each side. The heater block itself is set on small pieces of board in order to create an air gap between the bottom of the insulating structure and the block itself. An air gap is left between the block and the layers of board comprising the inner chamber walls because non-convecting stagnant air is an excellent insulator. The outer chamber walls are similarly constructed with three layers of board sandwiched together. The existing gap between the inner and outer chamber walls is stuffed with pieces of oneinch thick ultra-high temperature ceramic insulation sheeting from McMaster-Carr to minimize the possibility of any air circulation. The chamber walls are taped using the same tape that is used on the thermosyphon surface. The insulation structure is topped with two pieces of board that were cut to fit around the airfoil shape of the thermosyphon body. These two pieces were taped to the sides of the chambers to create an entirely closed insulating box. An image illustrating the configuration of this insulating box, with the top pieces removed, is displayed in Figure 4.6. 


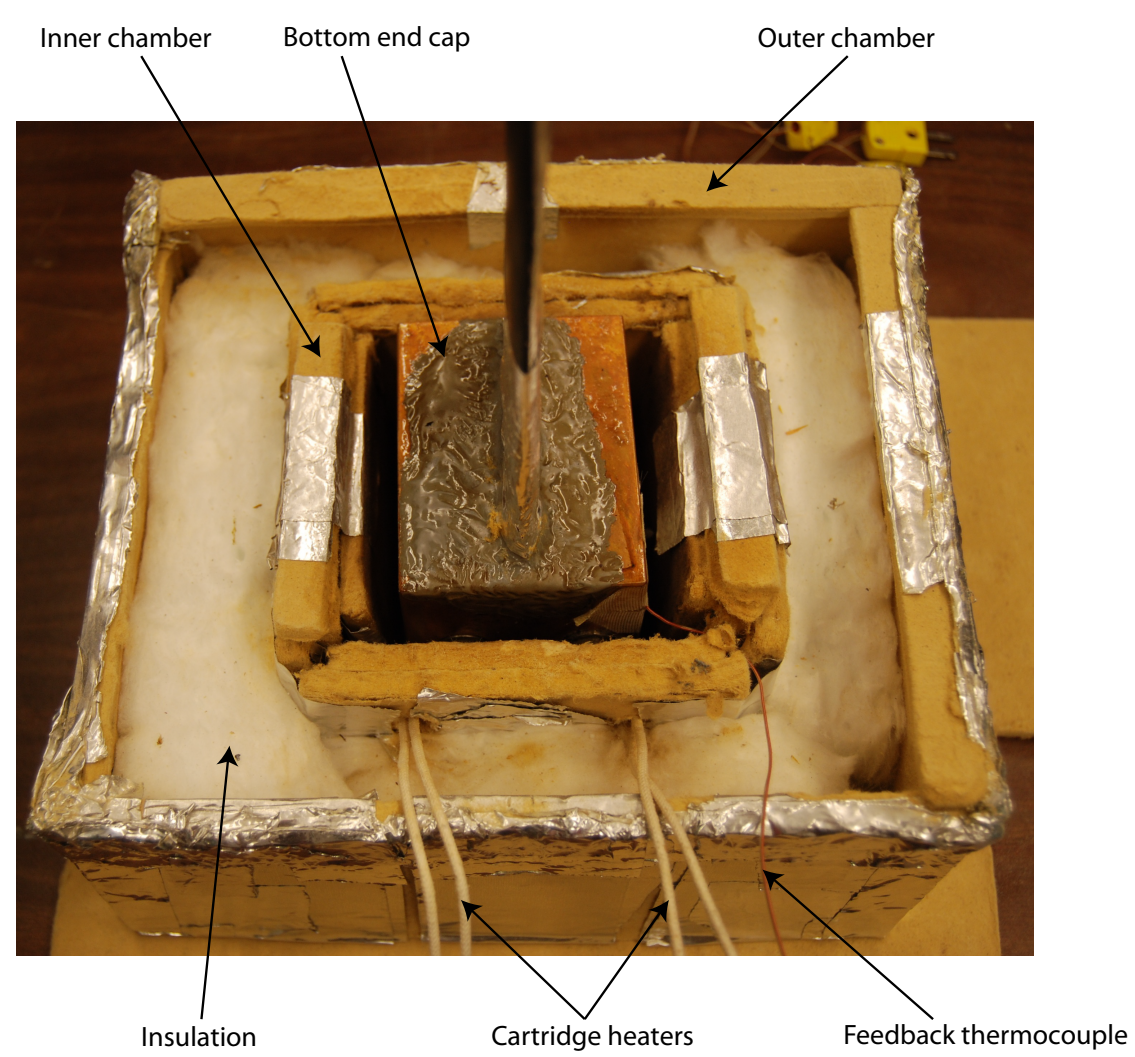

FiguRE 4.6: The slot thermosyphon and heater block are positioned inside the inner chamber. The top pieces are removed to reveal the outer and inner chambers with the insulation sheeting stuffed between them. The cartridge heater wires are fed through the inner chamber walls to the outside, as is the feedback thermocouple.

\subsubsection{Vacuum Pump Setup}

A Pfeiffer TSH064D Turbopump (backed by a roughing pump) was used for evacuating the thermosyphon prior to filling and also to pull the working fluid out of the thermosyphon after testing at a particular fill volume. The tubing is connected to the fill setup at the ball valve mentioned in Section 4.5.1. An image of the vacuum pump is given in Figure 4.7. 


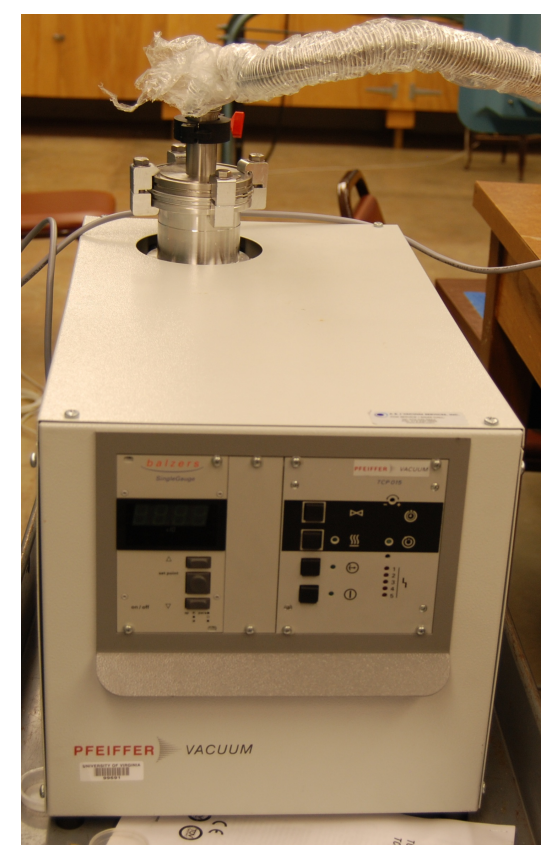

Figure 4.7: The display of the Pfeiffer vacuum pump. The hose coming out of the top connects to the tubing that is attached to the thermosyphon fill setup.

\subsection{Data Acquisition}

\subsubsection{Wind Speed}

A Pitot-static tube was used to measure the speed of the airflow in the test section. A Dwyer Differential Pressure Indicating Transmitter (Series 621), shown in Figure 4.8, was attached to the Pitot-static tube via a series of tubing and digitally displays the differential pressure in inches of water.

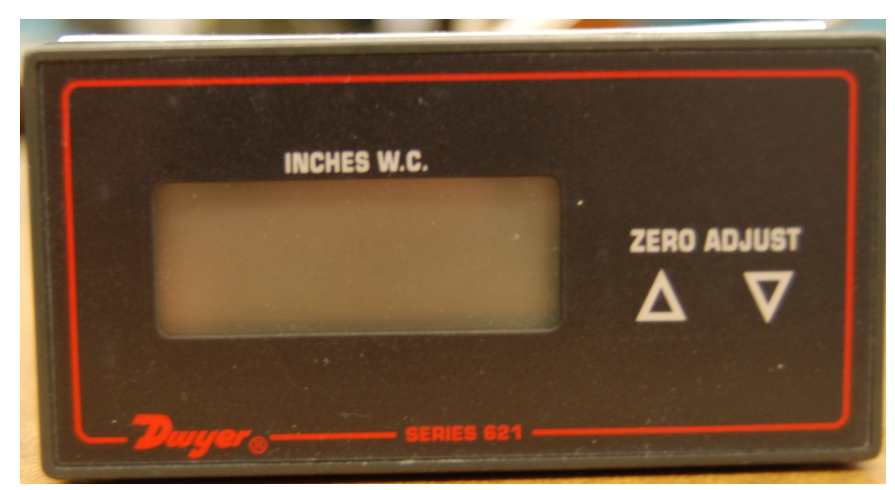

Figure 4.8: The display of the Series 621 Dwyer Differential Pressure Indicating Transmitter. The tubing that attaches to the Pitot-static tube is located in the back of the transmitter (not shown). 
This value is converted to wind speed by using a constant value for the density of air, and using the appropriate conversion factors, to form an expression used to find the speed of the airflow in the test section in mph given the differential pressure in inches of water, which is given by Equation 4.1:

$$
V[m p h]=45.1 \sqrt{\Delta P\left[i n H_{2} O\right]}
$$

The differential pressure indicator was powered by a Hewlett Packard Model 721A power supply, shown in Figure 4.9 .

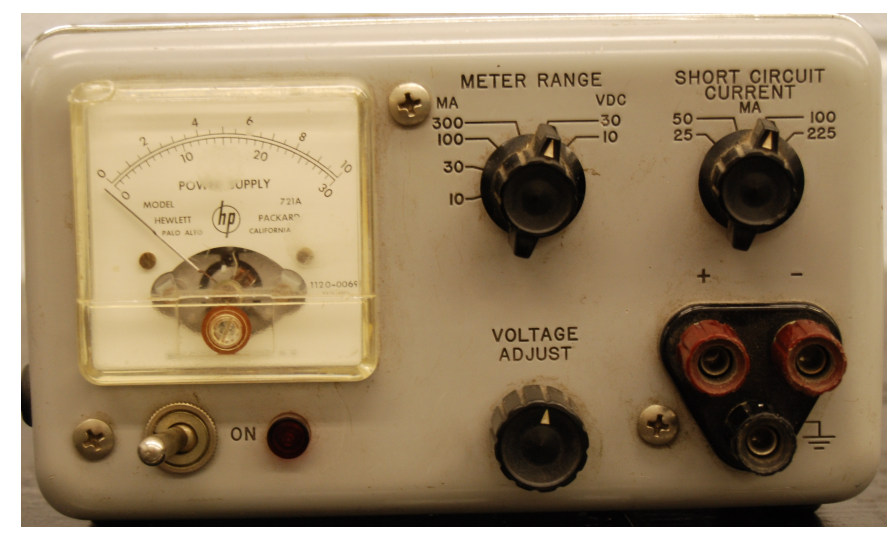

Figure 4.9: The display of the HP Model 721A power supply used to power the differential pressure indicating transmitter and also the pressure transducer used to read the internal pressure of the thermosyphon.

\subsubsection{Thermosyphon Internal Pressure}

Each thermosyphon is fitted with a separate PX176 model pressure transducer, manufactured by OMEGA, which is rated to measure pressures between 0 and 100 psia. The output of the pressure transducer is voltage, which is read by a standard TENMA multimeter. The pressure transducer is powered by the same HP power supply used to power the pressure indicator used to measure wind speed. A wiring diagram illustrating the arrangement of the pressure transducer, multimeter, and power supply is displayed in Figure 4.10. 


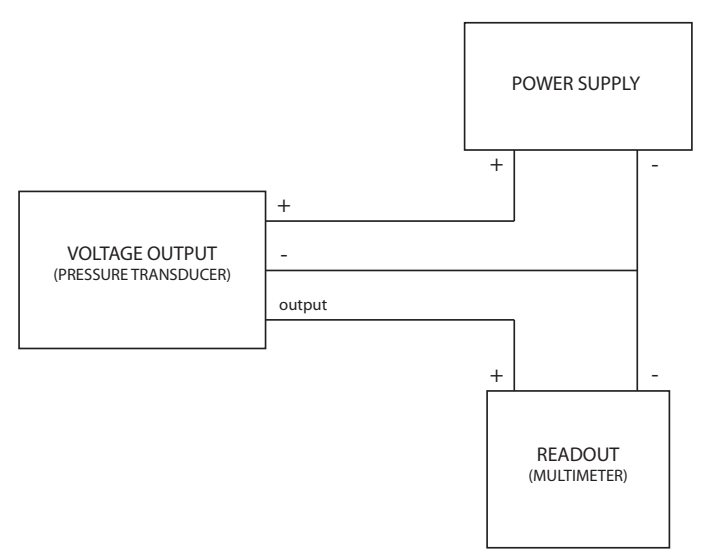

FigURE 4.10: Wiring diagram for pressure transducer, multimeter, and power supply setup.

The relationship between the pressure transducer's output voltage and the actual pressure being measured is linear and is defined by Equation 4.2.

$$
\text { Pressure }[\text { psia }]=20(\text { Voltage }[V])-20
$$

However, most pressure transducers output a voltage that is not exactly unity for a pressure of 0 psia. The method for converting a particular pressure transducer's voltage readout to actual pressure is outlined in Appendix C.1.1.

\subsubsection{Thermosyphon Surface Temperature}

Six OMEGA self-adhesive precision fine wire type-K thermocouples (0.010 in in diameter and 36 in in length) are placed along the surface of each thermosyphon. They are positioned over the area where the cavity is located and are verticallyspaced equal distances from each other. A schematic of the thermocouple placement

for both thermosyphons, including the designated origin from which the $x$ and $y$ positions of the thermocouples are measured, is shown in Figure 4.11. 


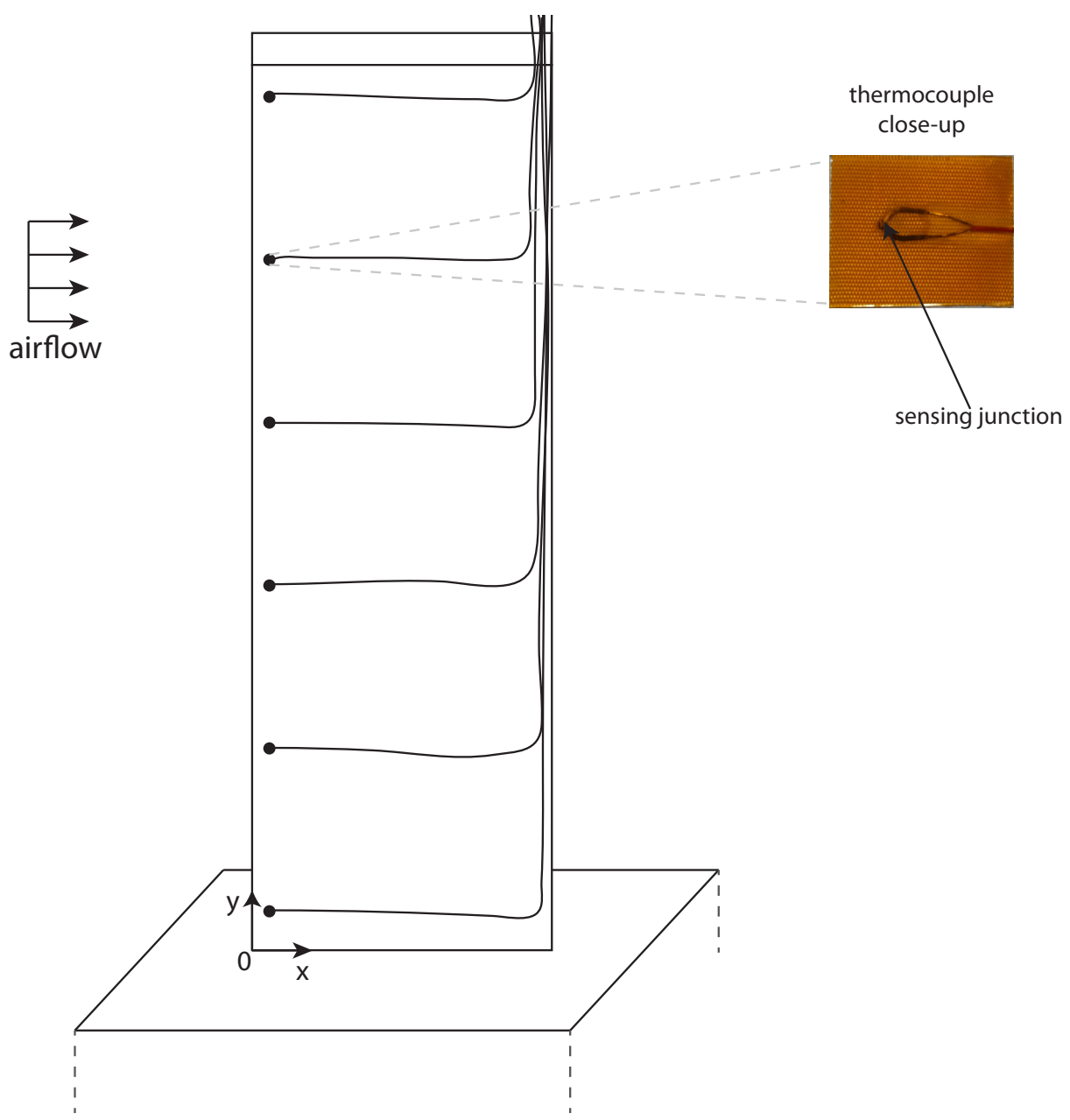

Figure 4.11: The thermosyphon body is shown with the the filled-in circles representing the location of the sensing junction for each thermocouple. On the right side of the figure is a close-up of the sensing junction, two dissimilar wires, and the adhesive backing that allows for the attachment to the thermosyphon.

The vertical and horizontal positions (and corresponding margins of error) of the thermocouples for both thermosyphons are displayed in Table 4.3. 
TABLE 4.3: Location of Thermocouples on Thermosyphon Surface

\begin{tabular}{|c|c|c|}
\hline $\begin{array}{l}\mathrm{TC} \\
{[\#]}\end{array}$ & $\begin{array}{c}\mathrm{x} \\
{[ \pm 1 / 16 \text { in }]}\end{array}$ & $\begin{array}{c}\mathrm{y} \\
{[ \pm 1 / 16 \text { in }]}\end{array}$ \\
\hline 1 & $3 / 16$ & 1 \\
\hline 2 & $3 / 16$ & 3 \\
\hline 3 & $3 / 16$ & 5 \\
\hline 4 & $3 / 16$ & 7 \\
\hline 5 & $3 / 16$ & 9 \\
\hline 6 & $3 / 16$ & $10 \quad 7 / 8$ \\
\hline
\end{tabular}

To ensure that the thermocouples did not get pulled off by the air flow and also to preserve the aerodynamic shape of the thermosyphon, the surface was covered in foil tape. For data acquisition, the thermocouples are connected to an OMEGA TempScan/1100 high speed temperature measurement system with an OMB-TEMPTC32B thermocouple scanning module installed. Data acquisition is performed with the use of the program Chartview, which is installed on a computer used throughout the experiments.

\subsubsection{Thermosyphon Rate of Heat Transfer}

The reasoning behind the necessity of a steady state measurement of the thermosyphon rate of heat transfer is discussed in Section 4.4. The power delivered to the cartridge heaters to maintain a constant evaporator temperature is equivalent to the rate of heat transfer from the surface of the condenser section to the airstream. Since it is very straightforward to measure the power delivered to the cartridge heaters, this is the quantity measured to find the thermosyphons rate of heat transfer. The power delivered to the cartridge heaters is manually controlled using a model 3PN1210B Staco Energy variable autotransformer (commonly referred to as a variac), shown in 
Figure 4.12. The cartridge heaters are wired in parallel and connected to a cable with a plug on one end, which is plugged into the variac.

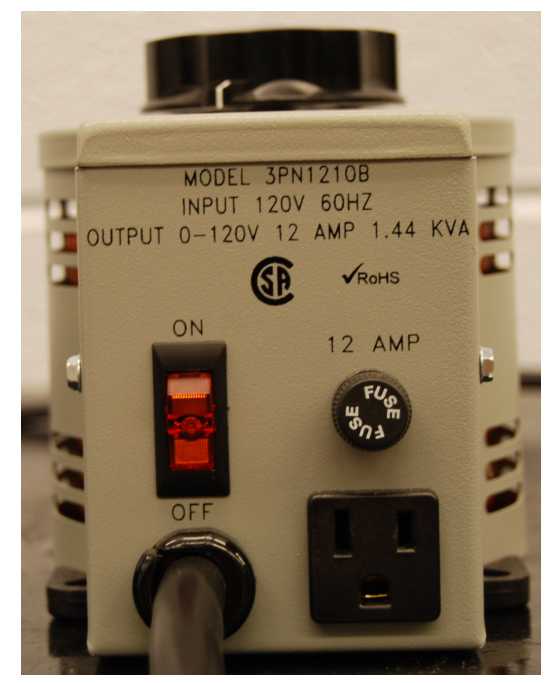

FIGURE 4.12: The variable voltage transformer used to control the power delivered to the cartridge heaters, which was plugged into the Eagle 120 power recorder. The cartridge heaters are plugged into the empty socket shown here.

The amount of power delivered to the cartridge heaters is measured using an Eagle 120 plug-in receptacle recorder manufactured by Power Monitor, Inc. An image of the Eagle 120 recorder is displayed in Figure 4.13. The variac is plugged into the Eagle 120, which is then plugged into a wall outlet. The Eagle 120 is also connected to a computer used for data acquisition via a USB cable. The data acquisition setup was such that the power and the temperatures could be recorded simultaneously.

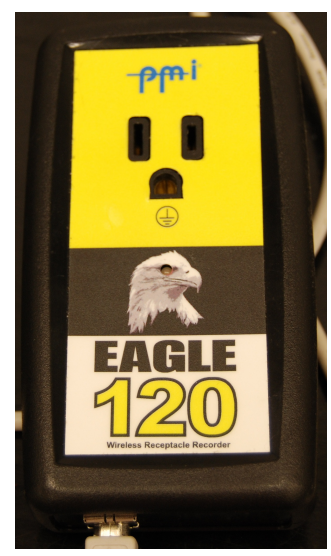

Figure 4.13: The Eagle 120 power recorder recorded the power drawn by the cartridge heaters during the data taking process. 


\subsection{Testing}

\subsubsection{Offsets}

Despite the fact that the heater block is well insulated, there is some unknown amount of heat transfer from the cartridge heaters, through the insulation, to the surroundings. If the power delivered to the cartridge heaters is measured without accounting for this loss, then the reported rate of heat transfer will be greater than the actual rate of heat transfer from the thermosyphon to the airstream. This heat loss through the insulation is accounted for by measuring the power delivered to the cartridge heaters that is required to keep the heater block alone at a particular temperature. These offsets represent the heat transfer from only the heater block so they were measured prior to attaching the bottom end cap (heater block) to the thermosyphon body. The offsets are measured using the slot thermosyphon's bottom end cap; the results are used to calculate the actual rate of heat transfer for both the cylinder and slot thermosyphon. For the offset measurements, the bottom end cap was placed in the insulation box and the top pieces of board were taped into place. The airfoil-shaped hole created by the two pieces, where the thermosyphon emerges from the insulation box, was left open to the air.

The offsets were measured for the following evaporator temperatures: 250, 275, 300, 315, and 325 degrees Fahrenheit. These evaporator temperatures were chosen because they are the temperatures at which the thermosyphon rate of heat transfer are measured for the slot and cylinder thermosyphons. The power delivered to the cartridge heaters is measured using the Eagle 120 and the software that accompanies it. The offsets for these evaporator temperatures are displayed in Table 4.4. The calculation of the errors associated with these offsets is outlined in Appendix C. 
TABLE 4.4: Offset Rate of Heat Transfer Values

\begin{tabular}{cc}
$\begin{array}{r}\text { Evaporator Temp. } \\
{\left[{ }^{\circ} F\right]}\end{array}$ & $\begin{array}{c}\text { Offset } \\
{[W]}\end{array}$ \\
\hline 250 & $26.0 \pm 2.02$ \\
\hline 275 & $27.4 \pm 2.70$ \\
\hline 300 & $28.4 \pm 2.52$ \\
\hline 315 & $30.0 \pm 2.02$ \\
\hline 325 & $31.6 \pm 2.58$ \\
\hline
\end{tabular}

\subsubsection{Experiment Details}

For a given experiment, the thermosyphon rate of heat transfer was measured at five evaporator temperatures: 250, 275, 300, 315, 325 degrees Fahrenheit. The length of the experiment for each fill volume was approximately five hours, which includes the time required to heat the heater block up to the first evaporator temperature and also the cooling time after the experiment was concluded.

At the beginning of the experiment, the wind tunnel frequency was set to a value such that the wind speed in the test section yielded a differential pressure reading equivalent of approximately $100 \mathrm{mph}$. Over time, the wind speed would decrease slightly so the frequency was adjusted accordingly to maintain the desired wind speed during data acquisition. Using the variac to adjust the power supplied to the heaters, the heater block was slowly brought up to the first evaporator temperature to be tested $\left(250^{\circ} \mathrm{F}\right)$. At this point, the power supplied was fine-tuned so that the thermosyphon reached steady state operation, where the power supplied to the heaters was equivalent to the rate of heat transfer from the condenser section to the airstream. After the feedback thermocouple read a steady temperature (not varying by more than one degree Fahrenheit) for several minutes, the power and temperatures (thermosyphon 
surface, air, and feedback) were recorded over a period of ten minutes. The variac was adjusted to bring the heater block up to the next evaporator temperature after the data-taking period was complete.

Due to the high wind speeds and the sensitivity of the Pitot-static probe, the differential pressure readout fluctuated significantly throughout the data-taking period. During the ten-minute data acquisition interval, the minimum and maximum differential pressure values were recorded and averaged to obtain a wind speed estimate. Throughout the entire experiment the internal pressure of the thermosyphon was monitored by visual inspection of the multimeter readout. The pressure was recorded at the beginning and the end of each ten-minute data-taking period. 


\section{Chapter 5}

\section{Results and Discussion}

As mentioned in Chapter 3, two thermosyphon assemblies were fabricated for testing, each with a differently shaped cavity. The rates of heat transfer of the two thermosyphons were tested at different fill volumes and evaporator temperatures. The results from these sets of experiments, as outlined in Chapter 4, are presented and discussed in this chapter. The rate of heat transfer and surface temperature results from the two thermosyphons are presented in separate sections and subsequently compared and contrasted.

\subsection{Cylinder-Shaped Cavity Thermosyphon Results}

\subsubsection{Rate of Heat Transfer}

The effective rate of heat transfer of the cylinder thermosyphon was tested at five different evaporator temperatures for three different fill volumes. The results of these tests, which take into account the offset rate of heat transfer discussed in Section 4.7.1, are displayed in Figure 5.1. The calculation of the error bars displayed in the figure is discussed in Appendix C.2.

All three sets of data for the cylinder thermosyphon indicate a positive and approximately linear relationship between rate of heat transfer and evaporator temperature. 


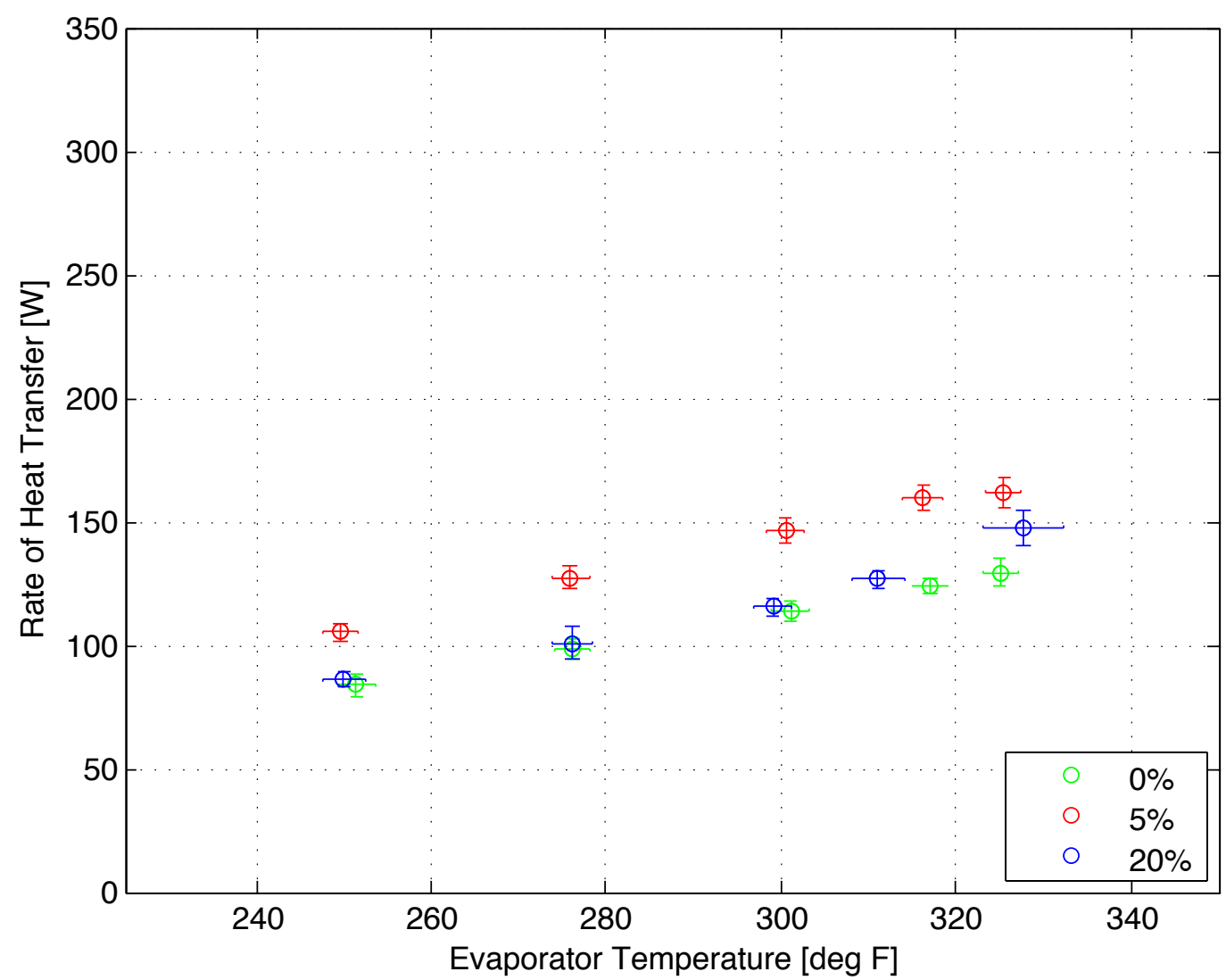

FiguRE 5.1: The rates of heat transfer for the cylinder-shaped cavity thermosyphon at the five evaporator temperatures for the $0 \%, 5 \%$, and $20 \%$ fill volumes.

The $0 \%$ fill volume rate of heat transfer ranges from approximately 85 to $125 \mathrm{~W}$ over the range of evaporator temperatures. At $20 \%$ fill volume the thermosyphon's performance is negligibly better than at $0 \%$ fill volume with a range of approximately 90 to $150 \mathrm{~W}$. The $325^{\circ} \mathrm{F}$ data point seems to be the only one that differs significantly between the $0 \%$ and $20 \%$ fill volumes. The $5 \%$ fill volume rate of heat transfer is consistently higher than that for both the $0 \%$ and $20 \%$ fill volumes and ranged from approximately 100 to $160 \mathrm{~W}$. Despite this, the $5 \%$ fill volume does not dramatically out-perform the $0 \%$ fill volume.

\subsubsection{Surface Temperature}

The surface temperatures measured by the thermocouples placed over the cavity and along the length of the thermosyphon (with the smallest vertical position being 
closest to the evaporator) at the five evaporator temperatures tested are displayed in Figures 5.2, 5.3, 5.4, 5.5, and 5.6. In each figure, the surface temperatures at the three fill volumes are plotted on separate graphs and placed side-by-side for comparison. The calculation of the error bars, which are smaller than the symbol used to plot the temperatures, is outlined in Appendix C.3.
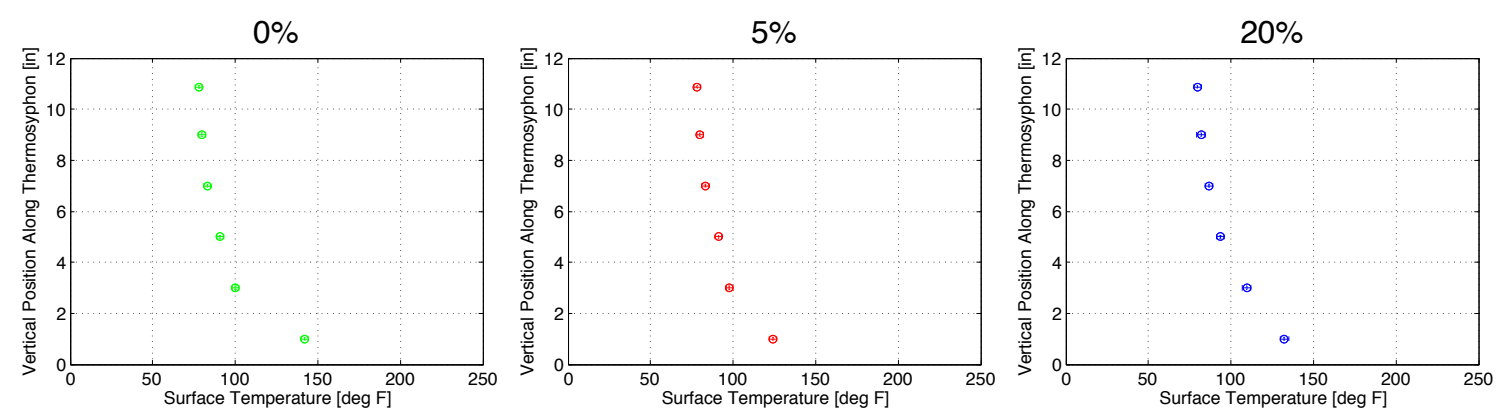

FiguRE 5.2: The surface temperature distributions along the length of the thermosyphon for the $0 \%, 5 \%$, and $20 \%$ fill volumes (left to right) at an evaporator temperature of $250^{\circ} \mathrm{F}$.
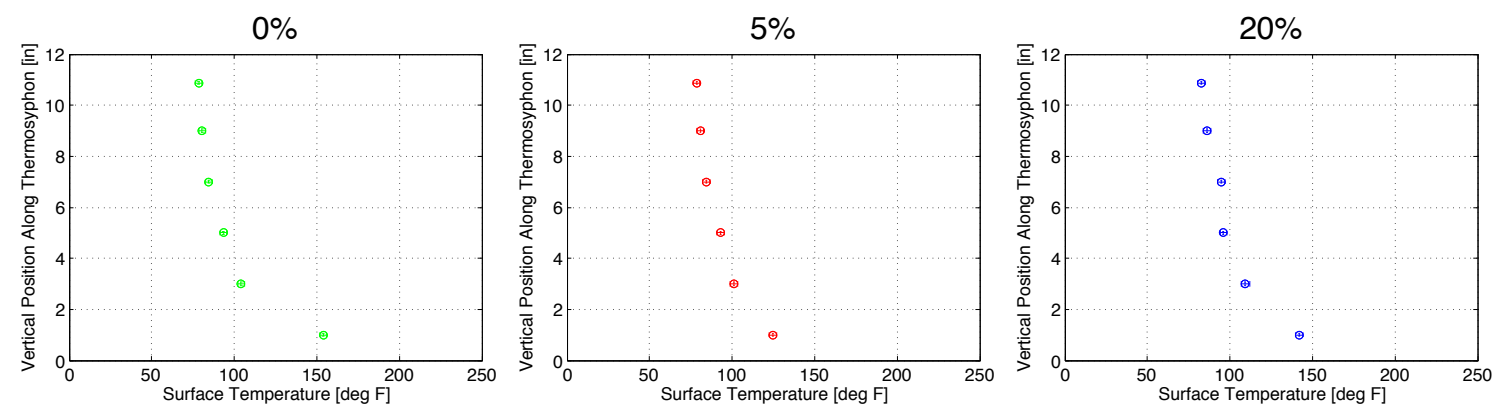

FiguRE 5.3: The surface temperature distributions along the length of the thermosyphon for the $0 \%, 5 \%$, and $20 \%$ fill volumes (left to right) at an evaporator temperature of $275^{\circ} \mathrm{F}$.
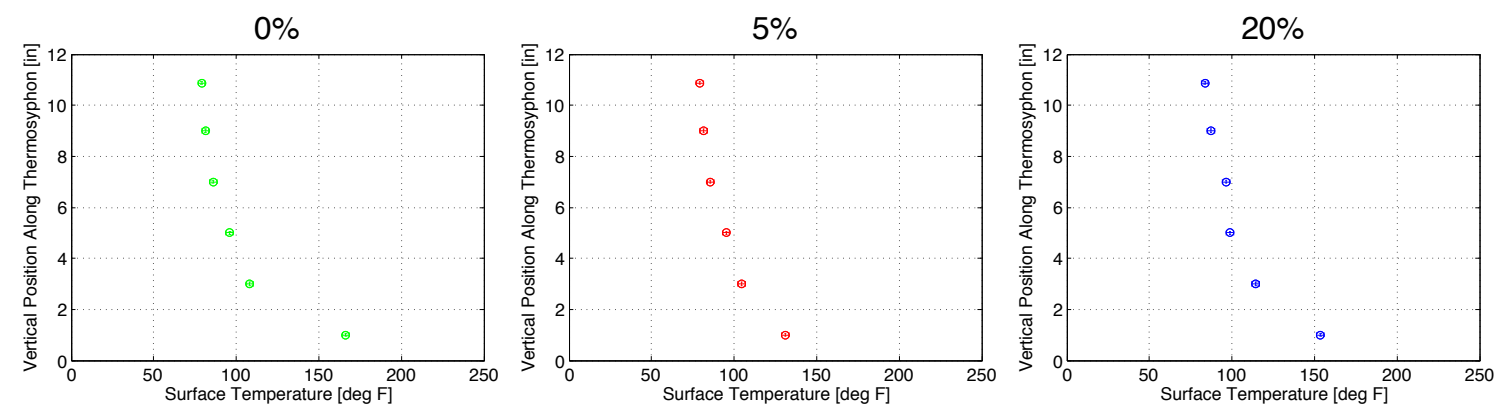

Figure 5.4: The surface temperature distributions along the length of the thermosyphon for the $0 \%, 5 \%$, and $20 \%$ fill volumes (left to right) at an evaporator temperature of $300^{\circ} \mathrm{F}$. 

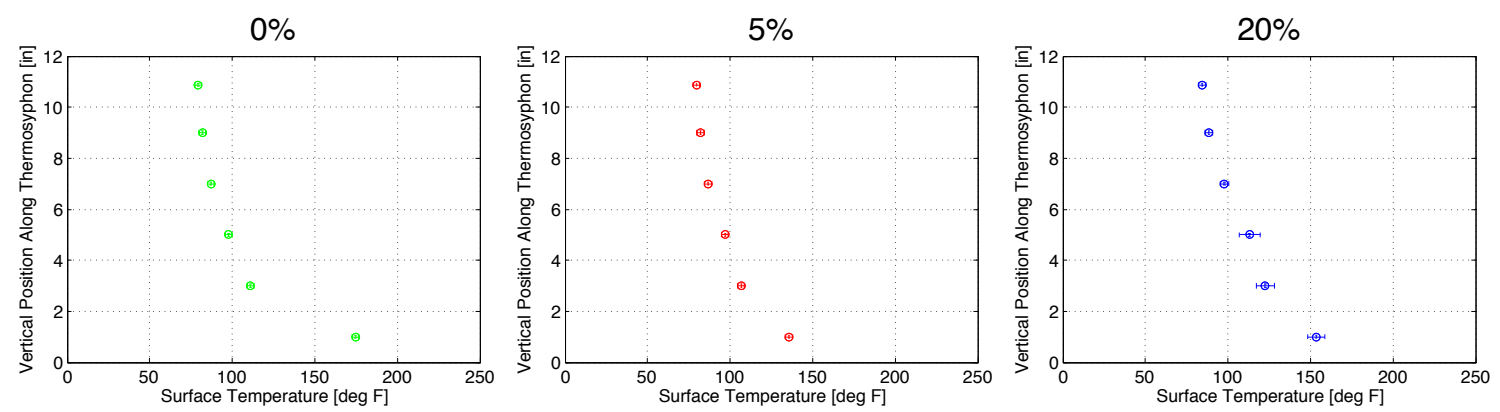

Figure 5.5: The surface temperature distributions along the length of the thermosyphon for the $0 \%, 5 \%$, and $20 \%$ fill volumes (left to right) at an evaporator temperature of $315^{\circ} \mathrm{F}$.
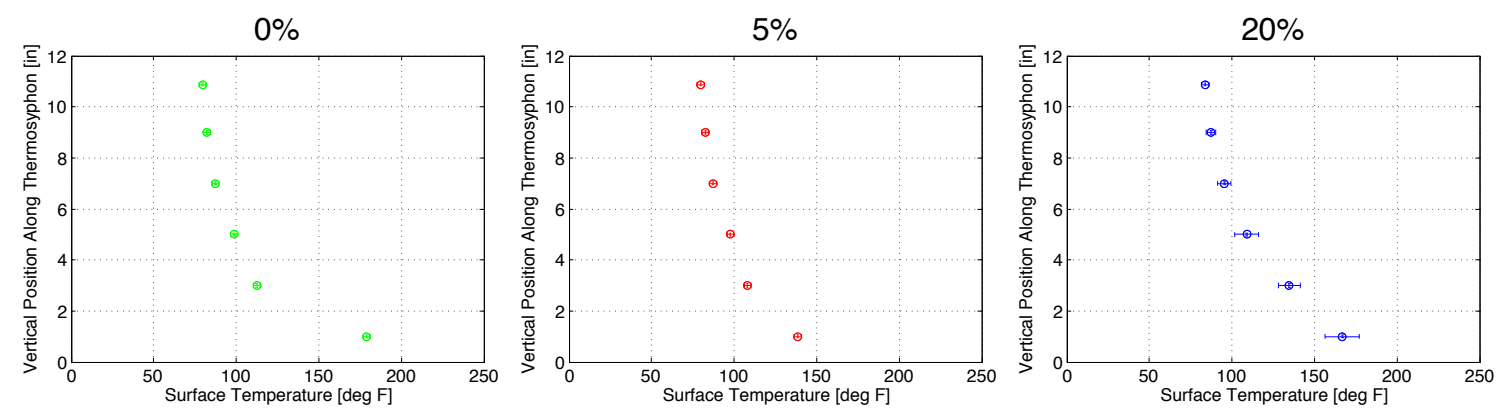

FiguRE 5.6: The surface temperature distributions along the length of the thermosyphon for the $0 \%, 5 \%$, and $20 \%$ fill volumes (left to right) at an evaporator temperature of $325^{\circ} \mathrm{F}$.

Throughout all evaporator temperatures, the surface temperature distribution for the $0 \%$ fill volume retains the same trend: very high temperatures near the evaporator and much cooler temperatures near the top of the thermosyphon, with the surface temperature at the 1-inch location increasing from approximately $140^{\circ} \mathrm{F}$ to $180^{\circ} \mathrm{F}$ as the evaporator temperature increases from $250^{\circ} \mathrm{F}$ to $325^{\circ} \mathrm{F}$. Both the $5 \%$ and $20 \%$ fill volumes exhibit a similar surface temperature profile as the $0 \%$ fill volume data.

The primary difference between the $0 \%$ fill volume and the $5 \%$ and $20 \%$ fill volumes is that the variation between the top and bottom surface temperatures is not as great for the $0 \%$ fill volume. The $20 \%$ fill volume surface temperature distributions maintain the same shape through all evaporator temperatures with the temperature at the 1 -inch location increasing from approximately $130^{\circ} \mathrm{F}$ to $170^{\circ} \mathrm{F}$ as evaporator temperature increases. 


\subsubsection{Internal Pressure}

The internal pressures measured by the pressure transducer attached to the cylinder thermosyphon during each of the experiments conducted are reported in Table 5.1. The pressure reported is an average of the pressure measured at the beginning and end of each ten-minute experiment, and the methodology for the error calculation is outlined in Appendix C.1. The error bars span into negative values at low pressures. This is due to the fact that the error in the pressure measurement is based on a percentage of the full scale value of the pressure transducer (see Appendix C.1). This is also the reason why the error associated with the pressure is large compared to the actual values seen during operation. At $0 \%$ fill volume, the thermosyphon does not experience a significant increase in internal pressure as the evaporator temperature increases whereas at the $5 \%$ and $20 \%$ fill volumes the internal pressure increases steadily with evaporator temperature. Despite this increasing internal pressure, none of these reported values remotely approach the pressures seen by both Randolph and DeCecchis during their experiments (as discussed in Chapter 3).

TABLE 5.1: Cylinder Thermosyphon Internal Pressures (psia)

\begin{tabular}{cccc}
\hline $\begin{array}{c}\text { Evaporator } \\
\text { Temperature }\end{array}$ & $0 \%$ & $5 \%$ & $20 \%$ \\
\hline $250^{\circ} \mathrm{F}$ & $0.85 \pm 1.60$ & $0.65 \pm 1.60$ & $0.69 \pm 1.60$ \\
\hline $275^{\circ} \mathrm{F}$ & $0.84 \pm 1.60$ & $0.68 \pm 1.60$ & $0.84 \pm 1.60$ \\
\hline $300^{\circ} \mathrm{F}$ & $0.85 \pm 1.60$ & $0.91 \pm 1.60$ & $0.95 \pm 1.61$ \\
\hline $315^{\circ} \mathrm{F}$ & $0.86 \pm 1.60$ & $2.01 \pm 1.62$ & $2.78 \pm 1.63$ \\
\hline $325^{\circ} \mathrm{F}$ & $0.90 \pm 1.60$ & $4.92 \pm 1.65$ & $7.68 \pm 1.69$ \\
\hline
\end{tabular}




\subsection{Slot-Shaped Cavity Thermosyphon Results}

\subsubsection{Rate of Heat Transfer}

The effective rate of heat transfer of the slot thermosyphon was tested at five different evaporator temperatures for three different fill volumes, and the results are displayed in Figure 5.7. The method for determining the error is outlined in Appendix C.2. All sets of data for the slot thermosyphon indicate a positive and approximately linear relationship between rate of heat transfer and evaporator temperature.

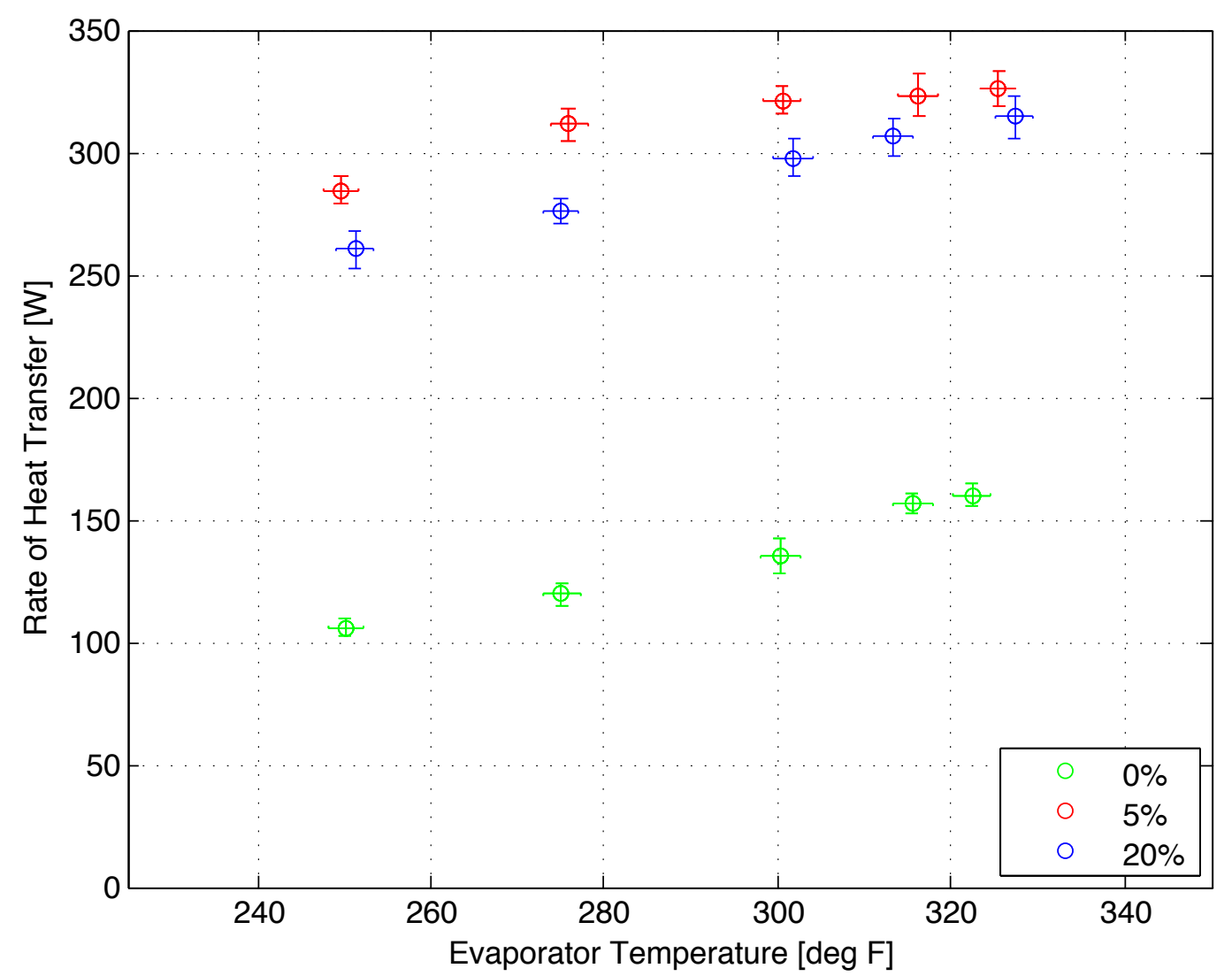

Figure 5.7: The rates of heat transfer for the slot-shaped cavity thermosyphon at the five evaporator temperatures for the $0 \%, 5 \%$, and $20 \%$ fill volumes.

The rate of heat transfer for the $0 \%$ fill volume varies from 100 to $150 \mathrm{~W}$ over the range of evaporator temperatures. The $5 \%$ and $20 \%$ fill volumes have rates of heat transfer that are over twice as large as the rates for when the thermosyphon contains no working fluid. The $5 \%$ fill volume ranges from approximately 275 to $325 \mathrm{~W}$ while 
the $20 \%$ fill volume has a range of 260 to $315 \mathrm{~W}$. The rate of heat transfer for the $20 \%$ fill volume is consistently lower than that for the $5 \%$ fill volume.

\subsubsection{Surface Temperature}

The surface temperatures measured by the thermocouples placed over the cavity and along the length of the thermosyphon (with the smallest vertical position being closest to the evaporator) at the five evaporator temperatures at which the rate of heat transfer was measured are plotted in Figures 5.8, 5.9, 5.10, 5.11, and 5.12. As with the cylinder thermosyphon surface temperature errors, the method for their calculation is provided in Appendix C.3.
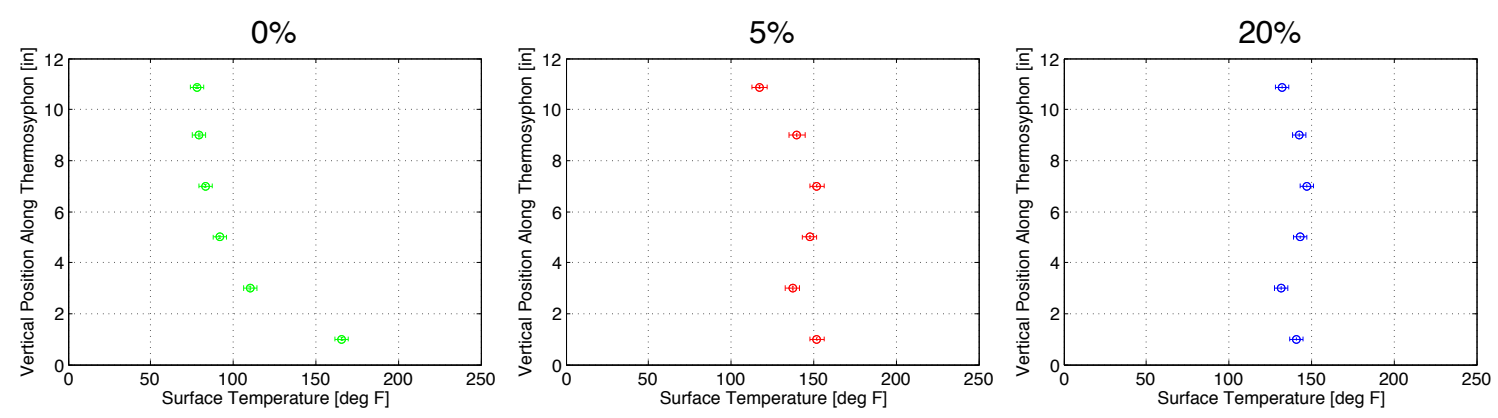

FiguRE 5.8: The surface temperature distributions along the length of the thermosyphon for the $0 \%, 5 \%$, and $20 \%$ fill volumes (left to right) at an evaporator temperature of $250^{\circ} \mathrm{F}$.
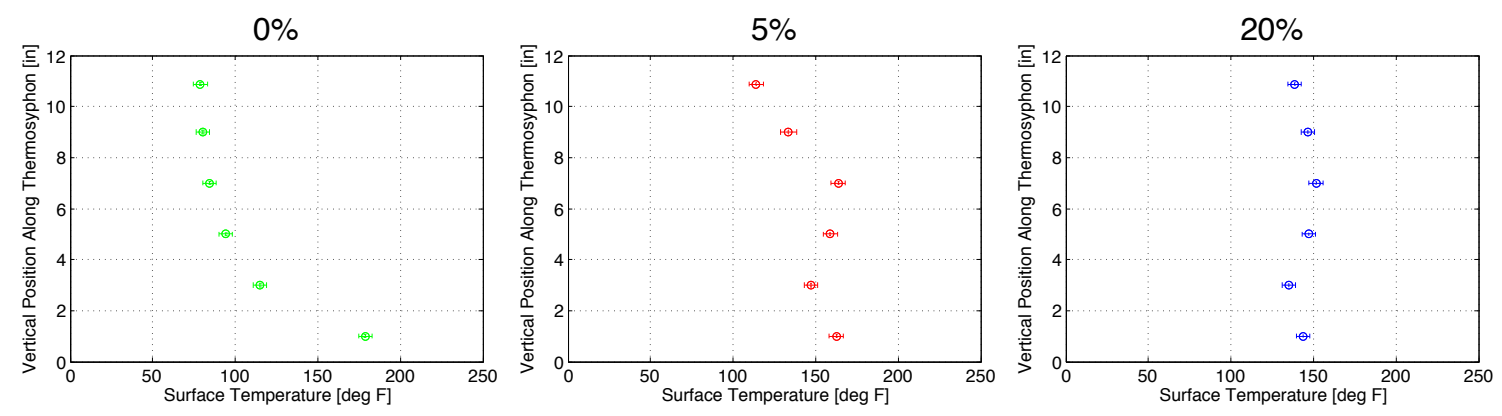

Figure 5.9: The surface temperature distributions along the length of the thermosyphon for the $0 \%, 5 \%$, and $20 \%$ fill volumes (left to right) at an evaporator temperature of $275^{\circ} \mathrm{F}$.

At the largest evaporator temperature, the $0 \%$ fill volume exhibits the highest temperature of approximately $210^{\circ} \mathrm{F}$ nearest the evaporator section and also exhibits the lowest temperature of approximately $80^{\circ} \mathrm{F}$ at the top of the condenser section. 

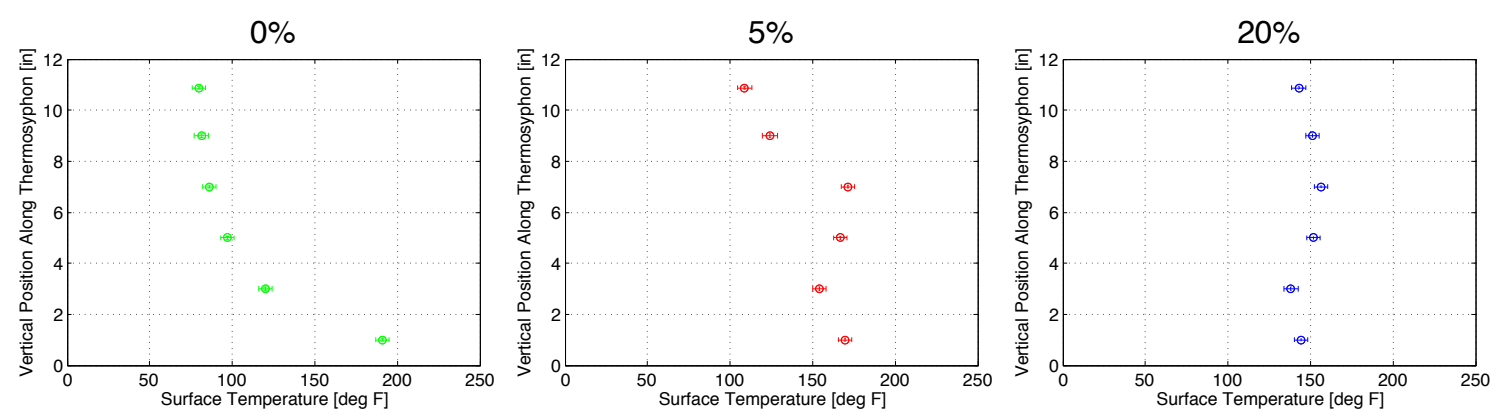

Figure 5.10: The surface temperature distributions along the length of the thermosyphon for the $0 \%, 5 \%$, and $20 \%$ fill volumes (left to right) at an evaporator temperature of $300^{\circ} \mathrm{F}$.
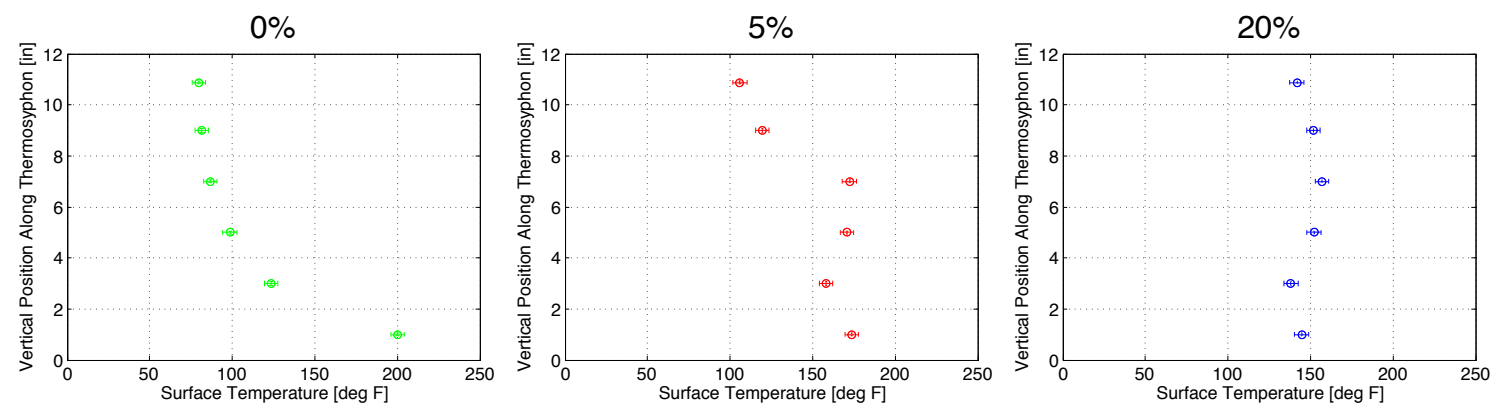

FiguRE 5.11: The surface temperature distributions along the length of the thermosyphon for the $0 \%, 5 \%$, and $20 \%$ fill volumes (left to right) at an evaporator temperature of $315^{\circ} \mathrm{F}$.
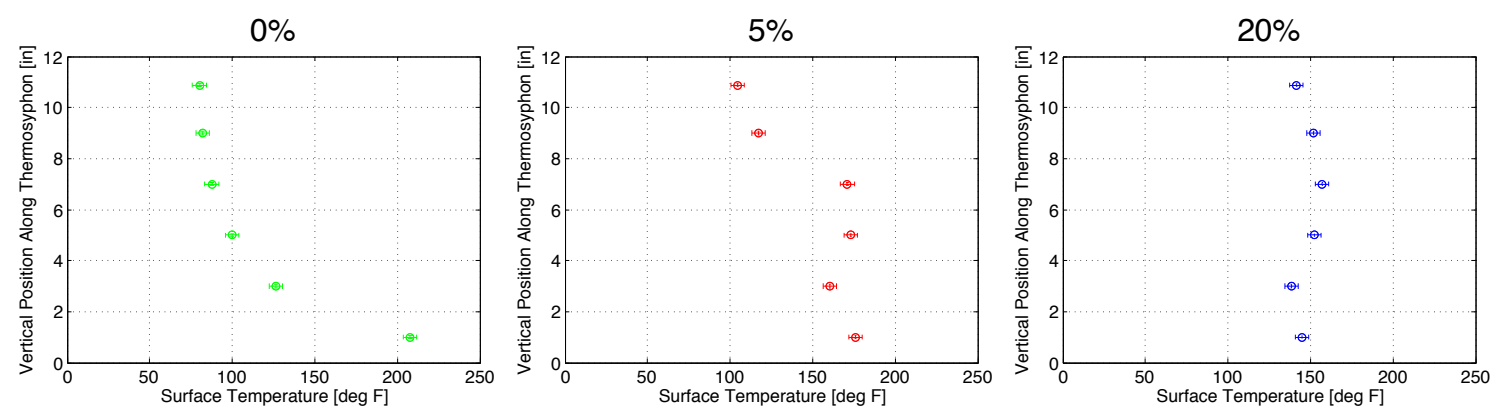

Figure 5.12: The surface temperature distributions along the length of the thermosyphon for the $0 \%, 5 \%$, and $20 \%$ fill volumes (left to right) at an evaporator temperature of $325^{\circ} \mathrm{F}$.

This disparity of surface temperatures over the length of the slot thermosyphon at $0 \%$ fill volume is apparent for all evaporator temperatures, and the surface temperature at the 1-inch location increases as evaporator temperature increases. At 5\% and $20 \%$ fill volumes, the temperature distributions are more isothermal than the $0 \%$ fill volume by a considerable amount. This difference illustrates the effect that the addition of a small amount of working fluid has on heat transfer rate. When a thermosyphon is functioning as a true thermosyphon, the surface temperature distri- 
bution is isothermal. It is evident from the figures that the $5 \%$ fill volume does not indicate that the surface is truly isothermal. At the 9-inch position, the surface temperature drops and does not recover as the vertical position increases. This feature becomes magnified as the evaporator temperature increases. When the evaporator temperature is $325^{\circ} \mathrm{F}$, the temperature drop at the 9-inch location is approximately $50^{\circ} \mathrm{F}$. In contrast to the $5 \%$ fill volume, at $20 \%$ fill volume the surface temperature data remains approximately isothermal for every evaporator temperature tested, and the temperatures do not increase with evaporator temperature, remaining close to $150^{\circ} \mathrm{F}$.

\subsubsection{Internal Pressure}

Table 5.2 displays the internal pressures experienced by the slot thermosyphon during each experiment. The reported pressures and their respective errors are calculated in the same way as those for the cylinder thermosyphon, discussed in Section 5.1.3. Similar to the cylinder results, at $0 \%$ fill volume the internal pressure remains low throughout the experiment. However, at the $325^{\circ} \mathrm{F}$ evaporator temperature the epoxy cracked and the vacuum broke. Because there was no fluid in the thermosyphon, the vacuum pump was turned on for the experiment and remained on throughout the data taking, which explains the lower pressure. The internal pressure increases with evaporator temperature for both the $5 \%$ and $20 \%$ fill volumes for

the slot thermosyphon (which is also the case for the cylinder thermosyphon). It is important to note that, as with the cylinder thermosyphon, the slot thermosyphon never experienced pressures approaching those seen by DeCecchis and Randolph. 
TABLE 5.2: Slot Thermosyphon Internal Pressures (psia)

\begin{tabular}{cccc}
\hline $\begin{array}{c}\text { Evaporator } \\
\text { Temperature }\end{array}$ & $0 \%$ & $5 \%$ & $20 \%$ \\
\hline $250^{\circ} \mathrm{F}$ & $0.53 \pm 1.60$ & $6.55 \pm 1.67$ & $5.23 \pm 1.65$ \\
\hline $275^{\circ} \mathrm{F}$ & $0.59 \pm 1.60$ & $9.22 \pm 1.71$ & $6.10 \pm 1.67$ \\
\hline $300^{\circ} \mathrm{F}$ & $0.63 \pm 1.60$ & $11.54 \pm 1.74$ & $7.06 \pm 1.68$ \\
\hline $315^{\circ} \mathrm{F}$ & $0.70 \pm 1.60$ & $12.93 \pm 1.76$ & $7.22 \pm 1.68$ \\
\hline $325^{\circ} \mathrm{F}$ & $0.38 \pm 1.60^{*}$ & $13.82 \pm 1.78$ & $7.33 \pm 1.68$ \\
\hline
\end{tabular}

*Vacuum pump was turned on during operation due to leaking

\subsection{Discussion of Results}

In Section 5.3.1, the heat transfer rate and surface temperature results are discussed for the $0 \%$ fill volume for both the cylinder and slot thermosyphons. Similarly, the results for the $5 \%$ and $20 \%$ fill volumes are discussed in Sections 5.3.2 and 5.3.3, respectively. The results for the fill volumes are also compared to each other. The pressure data for all fill volumes and both thermosyphons is discussed in Section 5.3.4, and lastly several recommendations for future work are also outlined.

\subsubsection{0\% Fill Volume}

With no working fluid, the heat transfer rate of both the cylinder and slot thermosyphons is the lowest of all fill volumes tested and is considered the base level of performance. In other words, this is the poorest performance that may be expected from either thermosyphon. The slot thermosyphon, however, did exhibit slightly higher heat transfer rate by approximately $25 \mathrm{~W}$ at every evaporator temperature with no working fluid. 
The surface temperature distribution for the $0 \%$ fill volume is distinctly nonisothermal for the cylinder thermosyphon, and this is due to the fact that the heat transfer is attributable to conduction up the walls from the evaporator section as opposed to heat transfer via the phase change of the working fluid when it is present. This temperature distribution is characterized by very high temperatures near the evaporator and very low temperatures near the top of the condenser section. The rapid decrease of temperature along the length of the thermosyphon results in lower rates of heat transfer. This phenomenon was also exhibited for the slot thermosyphon's surface temperature distribution at $0 \%$ fill volume.

\subsubsection{5\% Fill Volume}

The $5 \%$ fill volume exhibited the best performance in terms of rate of heat transfer (and without regard to whether or not thermosyphon action is taking place) for all evaporator temperatures for both the cylinder and slot thermosyphons. The slot thermosyphon exhibited a significant increase in rate of heat transfer at all evaporator temperatures at this fill volume as compared to the results at the $0 \%$ fill volume. This behavior, however, did not occur for the cylinder thermosyphon heat transfer rate at the $5 \%$ fill volume. There is a particular characteristic of the slot thermosyphon that may explain the dramatically higher rate of heat transfer at $5 \%$ fill volume as compared to that of the cylinder thermosyphon; this is the larger surface area that is associated with the slot cavity geometry. The total cavity surface area for the cylinder thermosyphon is $4.71 \mathrm{in}^{2}$ whereas the total cavity surface area for the slot thermosyphon is $23.0 \mathrm{in}^{2}$. The slot cavity provides much more surface area for the vaporized working fluid to condense on, which leads to a larger surface having a higher temperature and consequently more heat transfer. In addition, the slot thermosyphon has a larger surface area through which heat transfer from the heater block to the pool of liquid in the evaporator may take place. This increased surface area, in conjunction with thinner shell walls, may account for the disparity in rates of heat 
transfer between the slot and cylinder thermosyphons at 5\% fill volume. The smaller internal surface area associated with the cylindrical cavity thermosyphon may also explain why the $5 \%$ fill volume rate of heat transfer barely outpaced the $0 \%$ rate of heat transfer.

The surface temperature distribution for the slot thermosyphon at $5 \%$ fill volume is much more isothermal than that for the cylinder thermosyphon. The exhibition of approximately isothermal surface temperatures for the slot thermosyphon implies that typical thermosyphon behavior is occurring. There is a significant drop in temperature near the top of the condenser, which may be attributed to all the vaporized working fluid condensing prematurely, i.e. prior to reaching the top of the condenser section, on the thermosyphon walls. One can only infer the reason for this behavior, as the instrumentation used in these experiments does not offer any insight into the internal behavior of the thermosyphon. In contrast to this, the cylinder thermosyphon's surface temperature distribution at 5\% fill volume has the same shape as the $0 \%$ fill volume, and this similarity is indicative of the fact that the cylinder thermosyphon is not truly exhibiting thermosyphon action at $5 \%$ fill volume.

\subsubsection{0\% Fill Volume}

As discussed in Section 4.5.1, the evaporator section for both the cylinder and slot thermosyphons is equivalent to $8 \%$ of the total cavity volume. Therefore, the thermosyphons' evaporator sections are overfilled at $20 \%$ of the total thermosyphon volume, which may explain the decreased performance when compared to the $5 \%$ fill volume. When the evaporator section is overfilled the working fluid is heated mostly from the bottom, as a pot of water is heated on a stove. When the fill volume is smaller than the evaporator volume, the entire quantity of working fluid is in direct contact with the walls of the evaporator section, which is a more effective way of heating the fluid than having a fraction of the working fluid that is not in direct contact with the evaporator walls. The heat transfer rate at $20 \%$ fill volume is slightly 
lower than that for the $5 \%$ fill volume (for all evaporator temperatures) for both thermosyphons. For the cylinder thermosyphon, the $20 \%$ data is more comparable to the $0 \%$ data, indicating that the primary heat transfer method is via conduction up through the thermosyphon walls instead of through thermosyphon action. For the slot thermosyphon, the $20 \%$ fill volume heat transfer rate data is lower than that for the $5 \%$ data, which may be explained by the overfilled evaporator section, but the difference is small.

As is the case for the $0 \%$ fill volume, the surface temperature distribution for the $20 \%$ fill volume is clearly non-isothermal for the cylinder thermosyphon. This temperature distribution results in a much lower average surface temperature and consequently results in lower rates of heat transfer. In contrast to this, the surface temperature distribution at $20 \%$ fill volume for the slot thermosyphon is approximately constant along the length of the thermosyphon. This exhibition of approximately isothermal surface temperatures implies typical thermosyphon behavior is taking place to some extent. The average temperature is lower for the $20 \%$ fill volume than it is for the $5 \%$ fill volume, which is illustrated by the lower rate of heat transfer.

\subsubsection{Pressures}

The cylinder thermosyphon exhibits fairly low internal pressures for all fill volumes tested. The internal pressure remained approximately constant through all evaporator temperatures for the $0 \%$ fill volume. For the $5 \%$ and $20 \%$ fill volumes, the pressure increased with increasing evaporator temperature but never reached atmospheric pressure. The increasing pressure with increasing evaporator temperature is expected because of the increased activity of the vapor molecules associated with the increase in temperature. The increasing pressure with fill volume may be attributed to the decrease in volume available for the vapor to occupy. The increasing pressure, however, is also influenced by the leaking due to the ineffective sealant, as discussed 
in Appendix B. Because of this, it is difficult to isolate the specific causes for the increases in internal pressure.

The saturated vapor pressure in the cylinder thermosyphon cavity is calculated based on the average of the surface temperature values along the length of the condenser section (the locations of the thermocouples are given in Table 4.3). The outer surface temperatures are the closest approximation of the cavity temperature available for these experiments. The average surface temperature and calculated vapor pressure is provided in Table 5.3 for the $5 \%$ fill volume. The measured pressures are also provided for comparison. Similarly, these values that correspond to the $20 \%$ fill volume are provided in Table 5.4. The calculated saturated vapor pressures begin to deviate significantly from the measured values at higher evaporator temperatures. This may be due to the thermosyphon's cavity conditions approaching dry out where assuming saturated conditions is no longer appropriate. The most likely explanation for this deviation is that the temperature used to calculate the vapor pressure is the outer surface temperature, which is lower (possibly considerably lower) than the actual cavity temperature. The temperature difference between the cavity and the outer surface is due to the presence of both the copper and especially the thin layer of condensed working fluid located on the cavity walls. The thermal conductivity of water is much lower than copper, which means that the liquid presents a significant resistance to heat transfer from the cavity to the outer surface. 
TABle 5.3: Cylinder Thermosyphon Calculated Vapor Pressure for 5\% Fill Volume

\begin{tabular}{cccc}
\hline $\begin{array}{c}\text { Evaporator } \\
\text { Temperature }\left[{ }^{\circ} \mathrm{F}\right]\end{array}$ & $\begin{array}{c}\text { Average Surface } \\
\text { Temperature }\left[{ }^{\circ} \mathrm{F}\right]\end{array}$ & $\begin{array}{c}\text { Calculated Vapor } \\
\text { Pressure }[\mathrm{psia}]\end{array}$ & $\begin{array}{c}\text { Measured } \\
\text { Pressure [psia] }\end{array}$ \\
\hline 250 & 92.39 & 0.752 & 0.65 \\
\hline 275 & 93.70 & 0.784 & 0.68 \\
\hline 300 & 96.16 & 0.845 & 0.91 \\
\hline 315 & 97.85 & 0.890 & 2.01 \\
\hline 325 & 98.98 & 0.921 & 4.92
\end{tabular}

TABLE 5.4: Cylinder Thermosyphon Calculated Vapor Pressure for 20\% Fill Volume

\begin{tabular}{cccc}
\hline $\begin{array}{c}\text { Evaporator } \\
\text { Temperature }\left[{ }^{\circ} \mathrm{F}\right]\end{array}$ & $\begin{array}{c}\text { Average Surface } \\
\text { Temperature }\left[{ }^{\circ} \mathrm{F}\right]\end{array}$ & $\begin{array}{c}\text { Calculated Vapor } \\
\text { Pressure [psia] }\end{array}$ & $\begin{array}{c}\text { Measured } \\
\text { Pressure [psia] }\end{array}$ \\
\hline 250 & 97.20 & 0.872 & 0.69 \\
\hline 275 & 101.88 & 1.004 & 0.84 \\
\hline 300 & 105.78 & 1.127 & 0.95 \\
\hline 315 & 109.98 & 1.274 & 2.78 \\
\hline 325 & 112.87 & 1.385 & 7.68
\end{tabular}

The internal pressure for the slot thermosyphon remained relatively low for the $0 \%$ fill volume, but a very large leak occurred at the $325^{\circ} \mathrm{F}$ evaporator temperature. Given that the thermosyphon had no working fluid in the cavity, the vacuum pump was turned on at that point and remained on throughout the $325^{\circ} \mathrm{F}$ data set. This explains the drop in internal pressure at that temperature. The highest pressures for the slot thermosyphon were seen at the $5 \%$ fill volume, unlike the cylinder thermosyphon, though the internal pressure never reached atmospheric pressure. As with the cylinder thermosyphon, effectively sealing the thermosyphons was an ongoing 
and unresolved issue so it is not possible to completely isolate the influences on the thermosyphon internal pressure.

As with the cylinder thermosyphon, the saturated vapor pressure was calculated for the $5 \%$ and $20 \%$ fill volumes, provided in Tables 5.5 and 5.6, respectively. The difference between the calculated saturated vapor pressures and the measured values increases with evaporator temperature. The possible explanations for this phenomenon include the difference between the surface temperature and the cavity temperature and the lack of saturated conditions.

TABLE 5.5: Slot Thermosyphon Calculated Vapor Pressure for 5\% Fill Volume

\begin{tabular}{cccc}
\hline $\begin{array}{c}\text { Evaporator } \\
\text { Temperature }\left[{ }^{\circ} \mathrm{F}\right]\end{array}$ & $\begin{array}{c}\text { Average Surface } \\
\text { Temperature }\left[{ }^{\circ} \mathrm{F}\right]\end{array}$ & $\begin{array}{c}\text { Calculated Vapor } \\
\text { Pressure [psia] }\end{array}$ & $\begin{array}{c}\text { Measured } \\
\text { Pressure [psia] }\end{array}$ \\
\hline 250 & 141 & 2.964 & 6.55 \\
\hline 275 & 146.67 & 3.421 & 9.22 \\
\hline 300 & 149.21 & 3.645 & 11.54 \\
\hline 315 & 150.04 & 3.721 & 12.93 \\
\hline 325 & 150.42 & 3.756 & 13.82
\end{tabular}

Table 5.6: Slot Thermosyphon Calculated Vapor Pressure for 20\% Fill Volume

\begin{tabular}{cccc}
\hline $\begin{array}{c}\text { Evaporator } \\
\text { Temperature }\left[{ }^{\circ} \mathrm{F}\right]\end{array}$ & $\begin{array}{c}\text { Average Surface } \\
\text { Temperature }\left[{ }^{\circ} \mathrm{F}\right]\end{array}$ & $\begin{array}{c}\text { Calculated Vapor } \\
\text { Pressure [psia] }\end{array}$ & $\begin{array}{c}\text { Measured } \\
\text { Pressure [psia] }\end{array}$ \\
\hline 250 & 139.58 & 2.857 & 5.23 \\
\hline 275 & 143.84 & 3.186 & 6.1 \\
\hline 300 & 147.47 & 3.491 & 7.06 \\
\hline 315 & 147.58 & 3.500 & 7.22 \\
\hline 325 & 147.72 & 3.513 & 7.33
\end{tabular}




\subsection{Future Work}

The performance of the slot and cylinder thermosyphons indicates important information that may be used to improve future thermosyphon designs. First, as a result of prior testing by Randolph and DeCecchis it was reasonable to fear that the thermosyphon would fail when pressurized if the shell walls were too thin. Precautions were taken and the shell walls were made thicker than the finite element analysis indicated would be necessary. After these experiments were conducted it was evident that thermosyphons of this size and shape do not pressurize during operation. Therefore, the shell walls may be made thinner, which will aid in increasing the rate of heat transfer. In addition to thinner walls, the slot cavity cross-section may be expanded to create an airfoil-shaped cross-section. The cylinder thermosyphon was considered to be very conservative as far as structural integrity and cavity shape are concerned and was made to ensure that at least one of the thermosyphons would be able to withstand the potential high pressures encountered during experiments. The results from the thermosyphon testing indicate that both cavity shape designs were overly conservative, i.e. the cavity size was too small. In light of all this, it may be safely assumed that fabricating and testing a thermosyphon with a larger cavity with thinner walls is feasible and would have a higher rate of heat transfer.

A new method of attaching, and consequently sealing, the end caps to the thermosyphon body will be crucial for the future design and testing of these airfoil-shaped thermosyphons. It was clear during experiments that using a metal-filled repair epoxy to attach the end caps is not a sustainable option. Attempting to, and never altogether successfully, reseal the thermosyphon between experiments is not a long term solution. Therefore, research into other attachment methods that are appropriate for the application and materials involved should be a high priority.

Given the decreased performance at the $20 \%$ fill volume for both the cylinder and slot thermosyphons, any further investigation of fill volume should be limited to volumes smaller than that of the evaporator section. Also, an exploration of the 
application of further heat transfer enhancing methods should be conducted, and feasible options should be applied to this technology.

Finally, in order to more accurately gauge the internal pressure of the thermosyphon at low pressures, a pressure transducer with a more limited range that is appropriate for the experimental environment should be used. The error associated with the pressure transducer, as mentioned earlier, is calculated as a percentage of the full scale value, so a pressure transducer with a smaller full scale value will lead to more accurate readings. It would be more beneficial to have two pressure transducers inserted into the system: one to measure larger pressures (in case of dangerous pressurization) and another to measure lower pressures. This would be a more ideal approach to accurately measuring the internal pressure of the thermosyphons through a large range of possible pressures. 


\section{Chapter 6}

\section{Conclusion}

Both heat pipe and cooling fin technology have been implemented in a wide variety of heat transfer applications. In applications involving a favorable orientation in the gravitational field, a thermosyphon, a wickless heat pipe, is beneficial as a wick is not necessary. Combining these two technologies into a cooling fin thermosyphon has the potential to yield a vastly improved rate of heat transfer. In particular, the development of a cooling fin thermosyphon will be very useful in applications requiring the accommodation of high heat fluxes. An airfoil-shaped cooling fin thermosyphon is especially appropriate for the case where a cooling fin is immersed in an airflow.

Two airfoil-shaped thermosyphons were fabricated, one with a cylindrical-shaped cavity and the other with a slot-shaped cavity. Each thermosyphon was successfully hydrostatic pressure tested at pressures up to 100 psig, thus demonstrating their ability to withstand high internal pressures. After completing the task of fabricating structurally sound thermosyphons, the effect of fill volume and evaporator temperature on thermosyphon output rate of heat transfer was investigated experimentally. Testing was conducted with the condenser section of the thermosyphon positioned in the test section of a wind tunnel at the University of Virginia. The evaporator and adiabatic sections were positioned just outside of the test section and insulated heavily. During steady state operation, the heat transfer rate into the evaporator 
section is equivalent to the heat transfer rate out of the condenser section to the air stream. Therefore, measuring the power drawn by the cartridge heaters used to heat the evaporator section is equivalent to measuring the output rate of heat transfer. The surface temperature along the length of the thermosyphon was measured using thermocouples. The rate of heat transfer for each thermosyphon was measured for three fill volumes $(0 \%, 5 \%$, and $20 \%$ of the total thermosyphon volume) and five evaporator temperatures $\left(250^{\circ} \mathrm{F}, 275^{\circ} \mathrm{F}, 300^{\circ} \mathrm{F}, 315^{\circ} \mathrm{F}\right.$, and $\left.325^{\circ} \mathrm{F}\right)$.

With no working fluid, the heat transfer rate of both the cylinder and slot thermosyphons is the lowest of all fill volumes tested and is considered the base level of performance. In other words, this is the poorest performance that may be expected from either thermosyphon. The slot thermosyphon, however, did exhibit slightly higher heat transfer rate by approximately $20 \%$ at every evaporator temperature at this fill volume.

The rate of heat transfer for the slot and cylinder thermosyphons was lowest when no working fluid was present ( $0 \%$ fill volume) and represents the performance of a simple cooling fin. The heat transfer rate was highest for both the slot and cylinder thermosyphon at 5\% fill volume, which is expressed as a percentage of the total cavity volume. For the slot thermosyphon, the rate of heat transfer increased significantly after the addition of working fluid. This was not the case for the cylinder thermosyphon. The difference in heat transfer rate between the $0 \%$ and $5 \%$ for the slot is approximately $200 \mathrm{~W}$, while for the cylinder the difference is approximately 25 $W$. At $20 \%$ fill volume, the heat transfer rate for both thermosyphons was lower than that at $5 \%$ fill volume. For the cylinder thermosyphon, the results at $20 \%$ fill volume were comparable to those at $0 \%$ fill volume. For the slot thermosyphon, however, the results at $20 \%$ fill volume were more comparable to those at $5 \%$ fill volume. For both thermosyphons, the rate of heat transfer increased approximately linearly with evaporator temperature. Therefore, the highest heat transfer rates were achieved at an evaporator temperature of $325^{\circ} \mathrm{F}$ for all fill volumes for both the slot and cylinder 
thermosyphons. Similarly, the lowest heat transfer rates occurred at $250^{\circ} \mathrm{F}$ for all data sets.

Given the low internal pressures that both thermosyphons experienced during operation, it is clear that they were over-designed for structural stability. It is probable that thinner walls and a larger cavity, e.g. an airfoil-shaped cavity, would not experience significant pressurization during operation but would pass a hydrostatic pressure test up to 100 psig nonetheless. The significant increase in heat transfer rate that occurs when the thermosyphon cavity is expanded from a cylinder to a slot implies that further expansion, e.g. from a slot to an airfoil, should further increase the thermosyphon's output rate of heat transfer.

In summary, forming thin airfoil-shaped thermosyphons has been demonstrated as a viable means for cooling fin design and thermal management. It was found that the geometry of the thermosyphon cavity does influence rate of heat transfer, i.e. performance, by a significant amount. The larger cavity surface area associated with the slot thermosyphon corresponds to increased rate of heat transfer as the slotshaped cavity has more surface area upon which the vaporized working fluid may condense. Also, fill volume plays an important role in rate of heat transfer, especially in relation to evaporator volume. The rate of heat transfer is larger when the fill volume is less than the evaporator volume than when the fill volume is greater than the evaporator volume. When there is no fluid in the thermosyphon the rate of heat transfer is quite low and is comparable for the slot and cylinder thermosyphons. The successful development of this cooling fin thermosyphon design could eventually be utilized in a broad range of air-cooled cooling fin applications. 


\section{Bibliography}

[1] Incropera, F., And De Witt, D. Fundamentals of Heat and Mass Transfer, 3rd ed. 1990.

[2] FAGHRI, A. Heat pipe science and technology. Taylor \& Francis, Washington, DC, 1995.

[3] Pioro, L., And Piono, I. Industrial Two-phase Thermosyphons. begell house, inc., 1997.

[4] Negishi, K., And Sawada, T. Heat transfer performance of an inclined twophase closed thermosyphon. International Journal of Heat and Mass Transfer 26 (Aug. 1983), 1207-1213.

[5] Noie, S. H., Emami, M. R. S., and Khoshnoodi, M. Effect of inclination angle and filling ratio on thermal performance of a Two-Phase closed thermosyphon under normal operating conditions. Heat Transfer Engineering 28 (Apr. 2007), 365-371.

[6] Wang, J. C., AND MA, Y. Condensation heat transfer inside vertical and inclined thermosyphons. Journal of Heat Transfer (Transactions of the ASME (American Society of Mechanical Engineers) 113:3 (1991), 777-780.

[7] Park, Y. J., Kang, H. K., And Kim, C. J. Heat transfer characteristics of a two-phase closed thermosyphon to the fill charge ratio. International Journal of Heat and Mass Transfer 45, 23 (2002), 4655-4661.

[8] Jouhara, H., Martinet, O., and Robinson, A. Experimental study of small diameter thermosyphons charged with water, FC-84, FC-77 \& FC-3283.

[9] NoIE, S. Heat transfer characteristics of a two-phase closed thermosyphon. Applied Thermal Engineering 25, 4 (Mar. 2005), 495-506.

[10] Lee, Y., And Mital, U. A Two-Phase closed thermosyphon. International Journal of Heat and Mass Transfer 15, 9 (1972), 1695-1707.

[11] Randolph, T. L. Thermosyphon Technology for Heat Management in HighBypass Jet Engines Aboard Next Generation Boeing 737 Aircraft. M.S. thesis, University of Virginia, 2008. 
[12] De Cecchis, P. M. Investigation of the effect of fill volume on heat transfer from air-cooled low aspect ratio thermosyphons. $\mathrm{PhD}$ thesis, University of Virginia, 2010.

[13] Prasad, B., Tawfek, A., And RaO, V. Heat transfer from aerofoils in Cross-Flow. Int. Comm. Heat Mass Transfer 19 (1992), 879-890. 


\section{Appendix A}

\section{Thermosyphon Drawings}

\section{A.1 Cylinder Thermosyphon}

Figure A.1 displays the drawing for the top end cap of the cylinder thermosyphon. The body of the cylinder thermosyphon is displayed in Figure A.2. Finally, the bottom end cap for the cylinder thermosyphon is shown in Figure A.3.

\section{A.2 Slot Thermosyphon}

The drawing for the slot thermosyphon's top end cap is displayed in Figure A.4. The drawing of the body of the cylinder thermosyphon is displayed in Figure A.5, and the bottom end cap for the cylinder thermosyphon is shown in Figure A.6. 


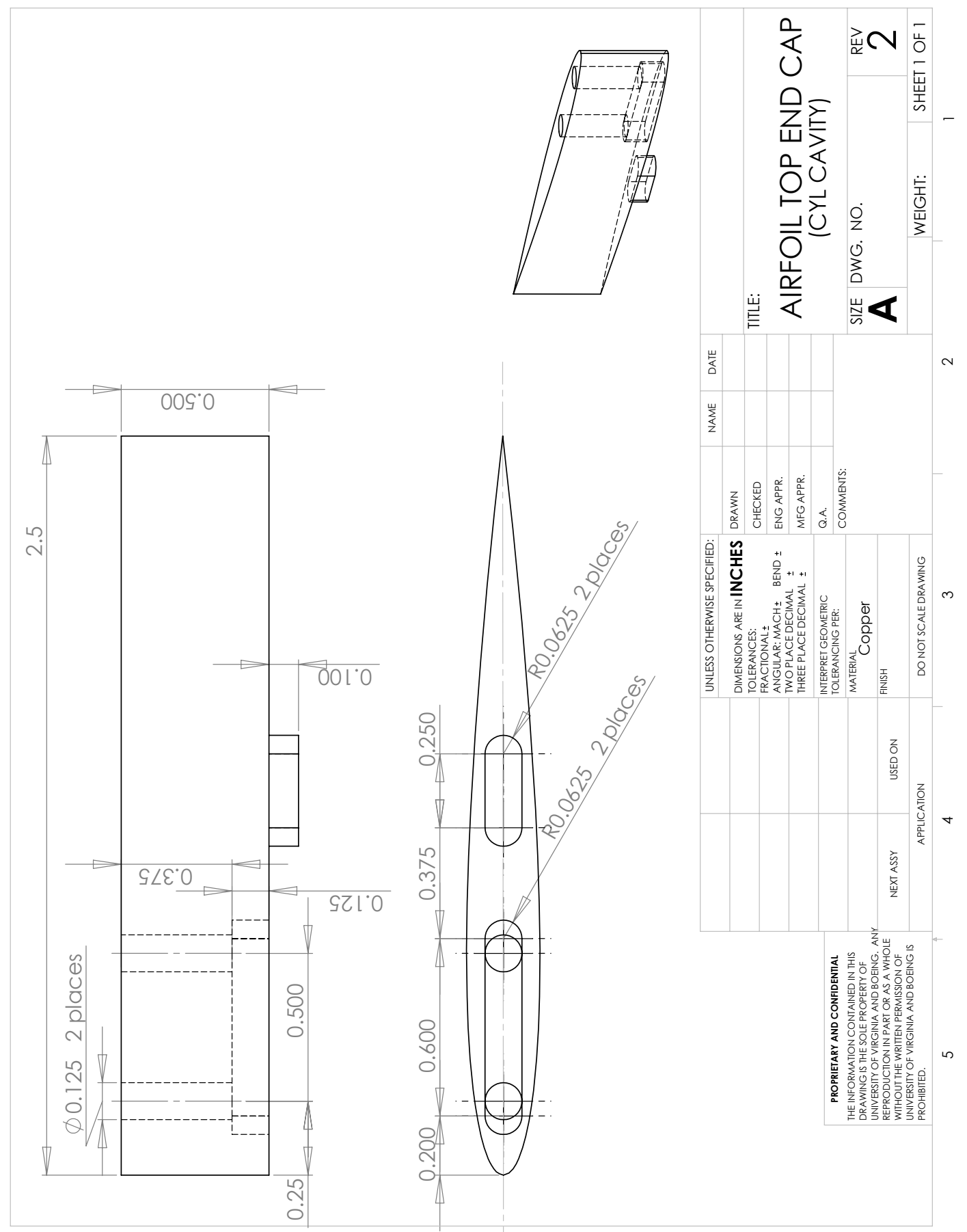

Figure A.1: Several views and dimensions of the top end cap of the cylinder thermosyphon. 


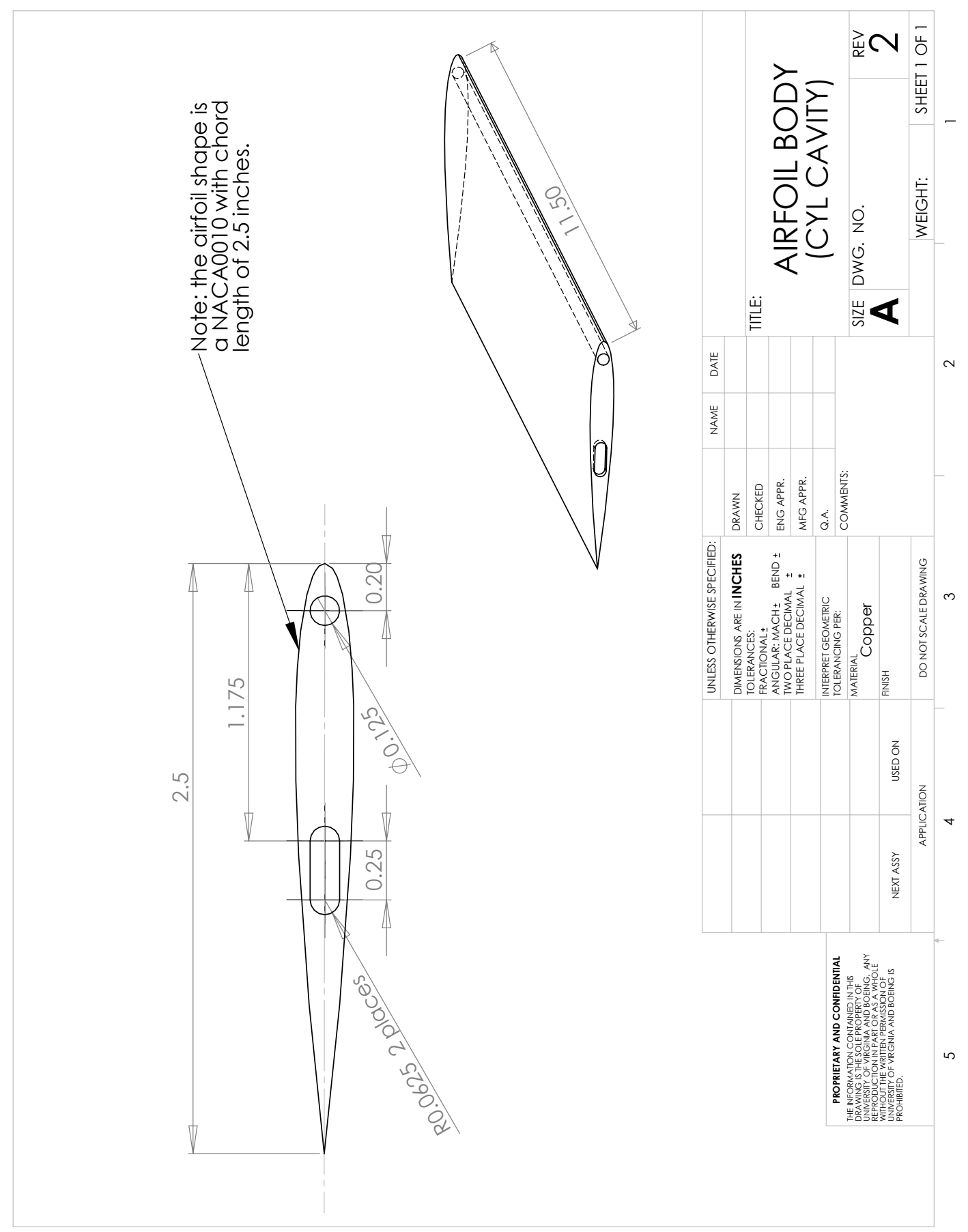

Figure A.2: Several views and dimensions of the body of the cylinder thermosyphon. 


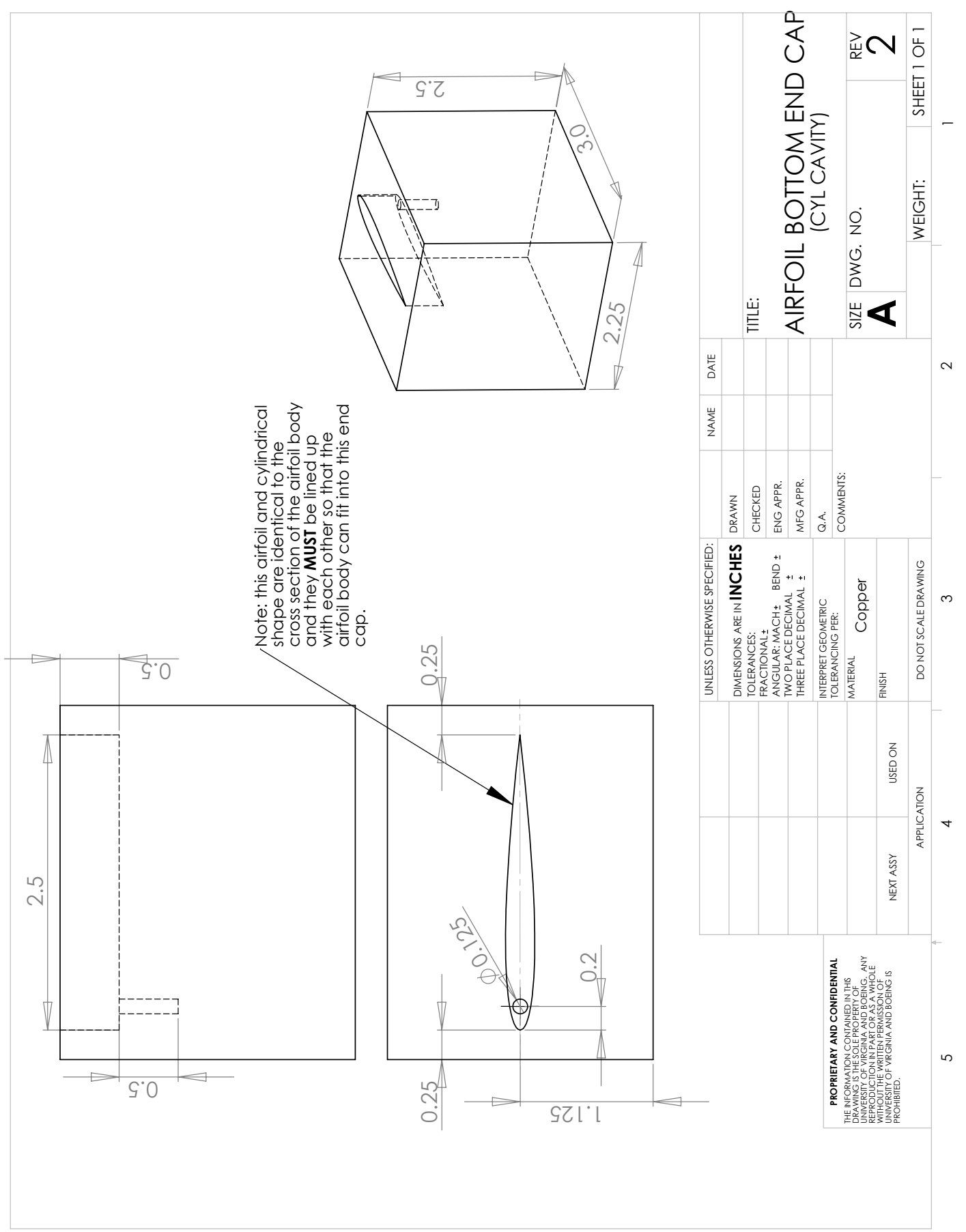

FiguRE A.3: Several views and dimensions of the bottom end cap of the cylinder thermosyphon. 


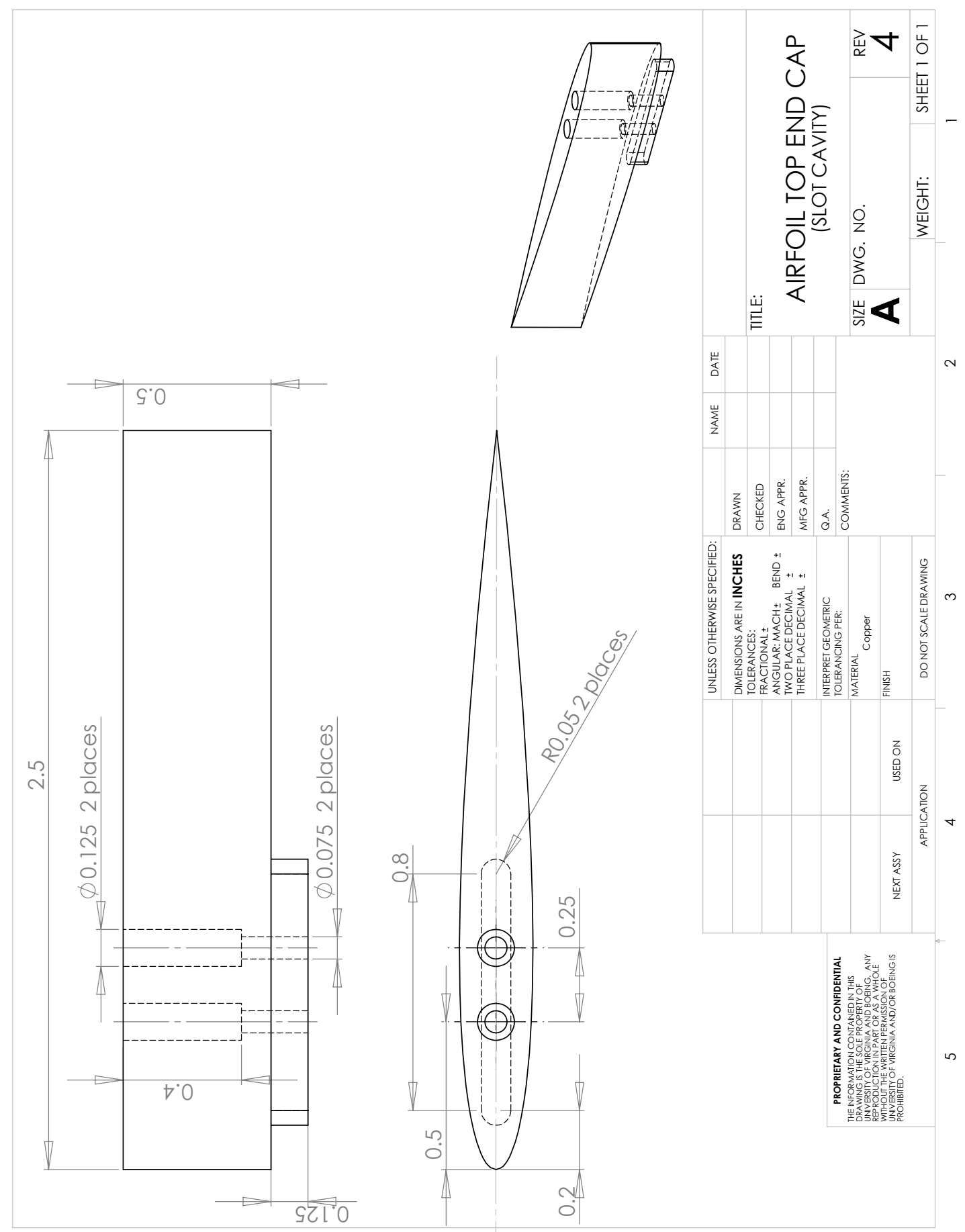

FiguRE A.4: Several views and dimensions of the top end cap of the slot thermosyphon. 


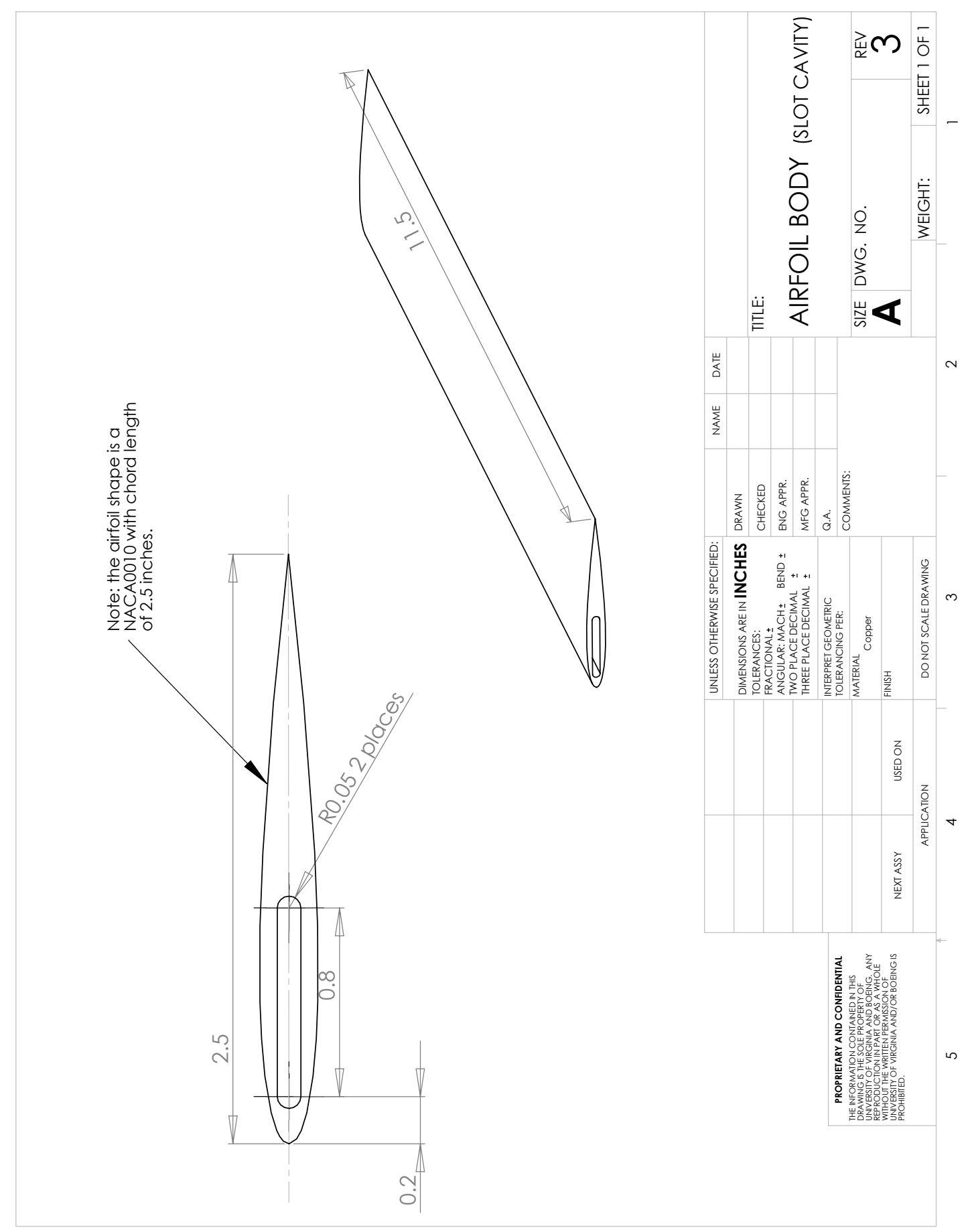

Figure A.5: Several views and dimensions of the body of the slot thermosyphon. 


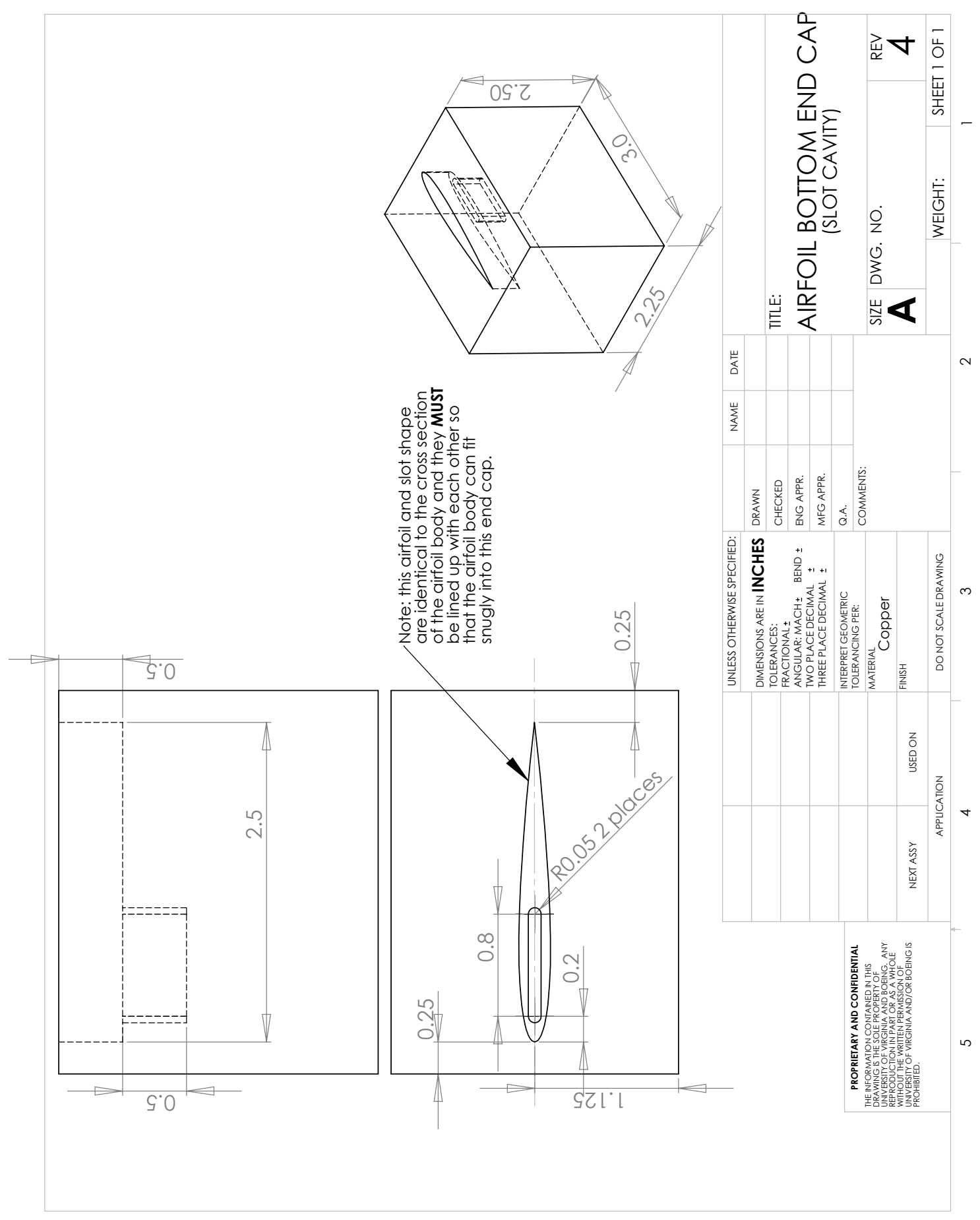

Figure A.6: Several views and dimensions of the bottom end cap of the slot thermosyphon. 


\section{Appendix B}

\section{Leaking}

\section{B.1 End Cap Attachment Options}

Randolph [11] utilized electron beam welding as the method for end cap attachment. With their radial symmetry, cylindrical thermosyphons were particularly suited to this method of attachment. Due to the unusual shape of the airfoil thermosyphons, the cost associated with electron beam welding would be significantly higher. This increased cost was the primary reason for not using electron beam welding for the current project.

The possibility of brazing the end caps was also investigated. A test piece of copper tubing was placed in a furnace at a typical brazing temperature for several minutes. The copper became annealed and was very soft and ductile. The resulting change to the copper was a concern with regards to the structural integrity of the thermosyphon during operation should high internal pressures occur. As a result, the method of brazing for attaching the end caps onto the thermosyphon body was ruled out.

Attaching the end caps using an epoxy was also researched. The experimental conditions narrowed the options for appropriate epoxies, including operating temper- 
ature and compatibility with copper. The type of epoxy that was primarily researched was a metal-filled repair epoxy purchased from McMaster-Carr. The characteristics of several variants of this type of epoxy are provided in Table B.1. Only one withstood temperatures that were higher than the operating temperatures experienced by the thermosyphons. The details of the particular epoxy used are provided in Appendix D.

Table B.1: Metal-Filled Epoxy Details

\begin{tabular}{cccc}
\hline $\begin{array}{c}\text { Withstands Temp } \\
\text { up to }\left[{ }^{\circ} \mathrm{F}\right]\end{array}$ & Bonds Copper? & $\begin{array}{c}\text { Cure time } \\
{[\mathrm{hr}]}\end{array}$ & Strength \\
\hline 500 & Yes & $12-24$ & Machinable \\
250 & Yes & 16 & Machinable \\
225 & Yes & 6 & Machinable \\
180 & Yes & 168 & Machinable \\
250 & Yes & 24 & Drillable \\
\hline
\end{tabular}

Several copper samples were tested by first drilling a hole through them and then coating and inserting stainless steel tubing into the holes. The samples themselves were then attached to a larger piece of copper using the same epoxy. An example of this test piece setup is displayed in Figure B.1. After allowing ample time for curing, the samples were evacuated using the vacuum pump to test the ability of the epoxy to maintain a vacuum. After successfully using these samples to develop a method of applying the epoxy effectively and evenly and determining that the epoxy was capable of holding a vacuum, the metal-filled repair epoxy was used to attach the end caps to the thermosyphon bodies.

\section{B.2 Leaking and Solutions}

After heating and subsequently cooling the cylinder thermosyphon for the first time, it was clear that the application of heat affected the bond between epoxy and 


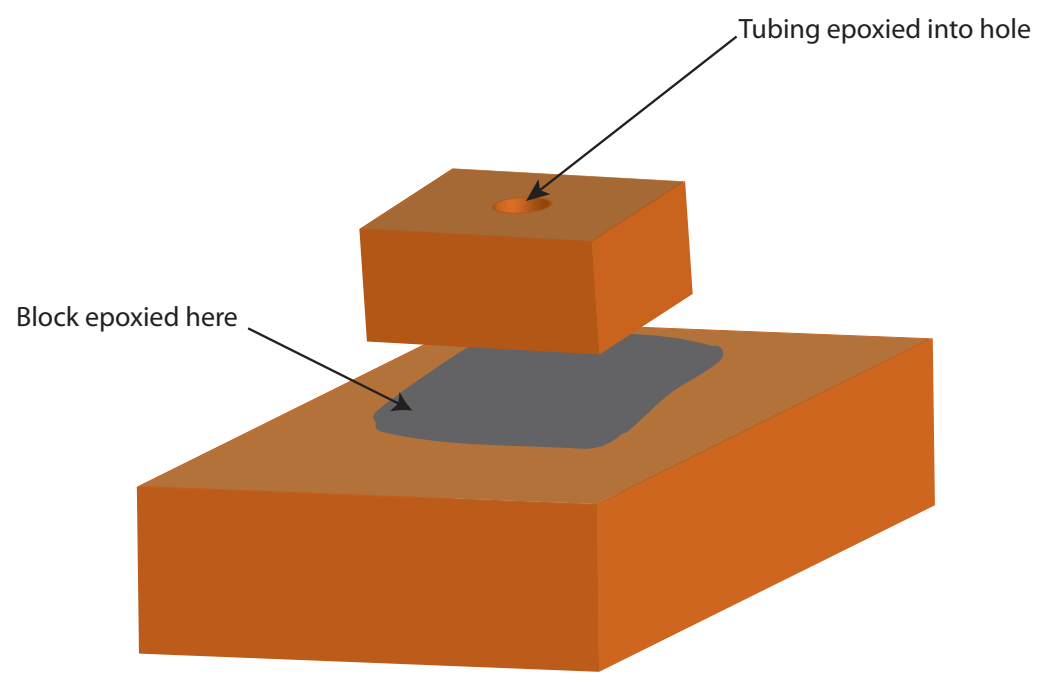

Figure B.1: The tubing is epoxied into the hole in the top piece and this top piece is epoxied to a larger copper block.

copper such that the maintenance of a vacuum in the cavity was not possible. Since the epoxy was already applied to both thermosyphons, several options to use in addition to the existing epoxy were investigated. Among these solutions were the use of 5 Minute Epoxy made by Devcon and 5 Minute Epoxy made by Loctite, among others. The use of a high vacuum leak sealant in spray-form made by Vacseal was also tested. After many rounds of testing, it was determined that the most effective, though not perfect, solution for maintaining a vacuum for several hours was to apply a thick layer of 5 Minute Epoxy made by Devcon over top of the metal-filled repair epoxy. After the Devcon epoxy was completely cured, the epoxy was sprayed thoroughly several times with the Vacseal high vacuum sealant spray.

This solution was very effective for the epoxy-attached top end cap but was not as effective for the bottom end cap. This was hypothesized to be due to the higher temperatures experienced at the bottom end cap. Despite the lack of success for the bottom end cap seal, it was possible to take data because the epoxy was capable of maintaining some semblance of a vacuum in the thermosyphon cavity for the length of the experiment. No long term satisfactory solution was found prior to the conclusion 
of experiments. As a result of these experiences, it was concluded in no uncertain terms that epoxy should not be used for attaching the end caps to the thermosyphon. 


\section{Appendix $\mathrm{C}$}

\section{Error Analysis}

Each measurement of the physical quantities taken in the experiments outlined in Chapter 4 has an error associated with it. The error for each measured quantity, like temperature and rate of heat transfer, has multiple contributions, and each contribution can be categorized as a bias error or a random error. A bias error is associated with instrument-derived error, and the random error is associated with uncontrollable variations in a measurement itself. Each of these contributions must be accounted for when calculating a particular error and must be combined in an appropriate way. This appendix outlines the methodology for calculating the error in the following measurements: internal pressure, rate of heat transfer, and surface and evaporator temperature.

\section{C.1 Pressure Error}

\section{C.1.1 Voltage to Pressure Conversion}

The equation describing the linear relationship between pressure and voltage is calculated using the pressure and associated voltage output from the pressure transducer for two known points. In this case, the two known pressures are at vacuum and 
at atmospheric pressure. These two points are assigned as $\left(P_{1}, V_{1}\right)$ for the vacuum point and $\left(P_{2}, V_{2}\right)$ for the atmospheric pressure point. The equation relating pressure and voltage can be described in terms of these two points and is displayed in Equation C.1 with the units of the quantities indicated in the brackets.

$$
P[\text { psia }]=f_{m} V[V]+f_{b}
$$

where

$$
\begin{gathered}
f_{m}=\frac{P_{2}-P_{1}}{V_{2}-V_{1}} \\
f_{b}=\frac{P_{1} V_{2}-P_{2} V_{1}}{V_{2}-V_{1}}
\end{gathered}
$$

The errors associated with $f_{m}$ and $f_{b}, u_{m}$ and $u_{b}$ respectively, are calculated using the propagation of error equation displayed in Equation C.4 and Equation C.5, respectively.

$$
\begin{gathered}
u_{m}^{2}=\left|\frac{\partial f_{m}}{\partial P_{2}}\right|^{2} u_{P_{2}}^{2}+\left|\frac{\partial f_{m}}{\partial V_{2}}\right|^{2} u_{V_{2}}^{2}+\left|\frac{\partial f_{m}}{\partial P_{1}}\right|^{2} u_{P_{1}}^{2}+\left|\frac{\partial f_{m}}{\partial V_{1}}\right|^{2} u_{V_{1}}^{2} \\
u_{b}^{2}=\left|\frac{\partial f_{b}}{\partial P_{2}}\right|^{2} u_{P_{2}}^{2}+\left|\frac{\partial f_{b}}{\partial V_{2}}\right|^{2} u_{V_{2}}^{2}+\left|\frac{\partial f_{b}}{\partial P_{1}}\right|^{2} u_{P_{1}}^{2}+\left|\frac{\partial f_{b}}{\partial V_{1}}\right|^{2} u_{V_{1}}^{2}
\end{gathered}
$$

The error associated with the pressure values themselves, assumed to be equivalent for both points as shown in Equation C.6, is approximated using the uncertainty in pressure between 0 and 500 feet above sea level, and in this range is the location of the lab in which the data was taken.

$$
u_{P_{1}}=u_{P_{2}} \cong 0.3 p \text { sia }
$$


The error associated with the voltage values, also assumed to be equivalent for both points as shown in Equation C.7, is approximated by the sensitivity of the voltmeter used to measure the output voltage from the pressure transducer.

$$
u_{V_{1}}=u_{V_{2}} \cong 0.001 \mathrm{~V}
$$

\section{C.1.2 Pressure Error}

The errors in the reported pressure values have three contributions and are derived from the propagation of error in the expression relating pressure to voltage, Equation C.1. With the errors associated with each quantity included, Equation C.1 becomes Equation C.8.

$$
P \pm u_{P}=\left(f_{m} \pm u_{m}\right)\left(V \pm u_{V}\right)+\left(f_{b} \pm u_{b}\right)
$$

The error associated with $f_{m}$ is calculated in Equation C.4 and the error associated with $f_{b}$ is calculated in Equation C.5. The error associated with the voltage reading has two sources, outlined in Table C.1, where the error from the pressure transducer is given by $1 \%$ of the full scale (as indicated in the literature) and the error in the multimeter is given by the resolution of the instrument itself.

TABLE C.1: Voltage Measurement Error Contributions

\begin{tabular}{ccc}
\hline Error in $V$ & Details & Value $[V]$ \\
\hline$u_{1}$ & Error from Transducer & 0.06 \\
\hline$u_{2}$ & Error in Multimeter & 0.001 \\
\hline
\end{tabular}

The total error for each measured voltage value is calculated using the two individual sources of error from Table C.1 and is displayed in Equation C.9.

$$
u_{V}^{2}=u_{1}^{2}+u_{2}^{2}
$$


The total error in the pressure, $u_{P}$, is calculated using standard propagation of error though the calculations in Equation C.8.

\section{C.2 Rate of Heat Transfer Error}

There are three sources of error in the measurement of the thermosyphon rate

of heat transfer $\dot{Q}$, which are summarized in Table C.2. The standard deviation is calculated from the set of rate of heat transfer data collected by the Eagle 120 over the course of ten minutes of data taking, as outlined in Section 4.7.2. The error associated with the Eagle 120 is reported in its product manual. The error in the variac (variable autotransformer) was estimated based on smallest possible change in power drawn by the cartridge heaters using the dial on the variac.

TABle C.2: Rate of Heat Transfer Error Contributions

\begin{tabular}{ccc}
\hline Error in $\dot{Q}$ & Details & Value $[W]$ \\
\hline$u_{1}$ & Random error & Varies \\
\hline$u_{2}$ & Error in Variac & \pm 2 \\
\hline$u_{3}$ & Error in Eagle 120 power recorder & $1 \%$ of reading \\
\hline
\end{tabular}

The total error for each measured rate of heat transfer value is calculated using the three individual sources of error from Table C.2 and is displayed in Equation C.10.

$$
u_{\dot{Q}}^{2}=u_{1}^{2}+u_{2}^{2}+u_{3}^{2}
$$

\section{C.3 Temperature Error}

There are three sources of error in the temperature values, as measured by the thermocouples (including the surface temperatures along the length of the thermosyphon, 
the evaporator temperature, and the air temperature). These sources are given in Table C.3. As with the error in pressure, the standard deviation is calculated from the set of data taken by the TempScan 1100 over the ten minutes of data acquisition. The error associated with the type $\mathrm{K}$ thermocouples themselves is reported in the literature. The limit of accuracy of the TempScan 1100 is also given in its product manual.

TABle C.3: Rate of Heat Transfer Error Contributions

\begin{tabular}{ccc}
\hline Error in $T$ & Details & Value $\left[{ }^{\circ} F\right]$ \\
\hline$u_{1}$ & Random error & Varies \\
\hline$u_{2}$ & Error in thermocouple & \pm 1.98 \\
\hline$u_{3}$ & Error in TempScan & \pm 0.18 \\
\hline
\end{tabular}

The total error for each measured temperature value is calculated using the three individual sources of error from Table C.3 and is displayed in Equation C.11.

$$
u_{T}^{2}=u_{1}^{2}+u_{2}^{2}+u_{3}^{2}
$$




\title{
Appendix D
}

\section{Supplier Contact and Product Information}

\section{D.1 Suppliers}

\author{
Company Precision Tool and Die Inc. \\ Description Fabrication of copper airfoil body and end caps \\ Location 2805 Decatur Street, Richmond, VA 23224 \\ Contact Charles Oldham \\ Phone 804-233-8810 \\ Fax 804-233-4672 \\ Website http://www.precisiontoolanddie.com/
}

\section{D.2 Products}

$\begin{array}{ll}\text { Product } & \text { Metal-filled repair epoxy } \\ \text { Company } & \text { McMaster-Carr } \\ \text { Product Number } & 75325 \mathrm{~A} 1 \\ \text { Website } & \text { www.mcmaster.com }\end{array}$




$\begin{array}{ll}\text { Product } & 5 \text { minute epoxy } \\ \text { Company } & \text { Devcon } \\ \text { Product Number } & \text { DA051 } \\ \text { Website } & \text { www.devcon.com }\end{array}$

$\begin{array}{ll}\text { Product } & \text { High vacuum leak sealant } \\ \text { Company } & \text { Vacseal } \\ \text { Product Number } & \text { 05051-AB } \\ \text { Website } & \text { http://www.2spi.com/catalog/vac/vacleak.shtml }\end{array}$ 